\title{
Design and simulation of high-performance hybrid electric vehicle powertrains
}

Samuel P. Taylor

West Virginia University

Follow this and additional works at: https://researchrepository.wvu.edu/etd

\section{Recommended Citation}

Taylor, Samuel P., "Design and simulation of high-performance hybrid electric vehicle powertrains" (2001). Graduate Theses, Dissertations, and Problem Reports. 1136.

https://researchrepository.wvu.edu/etd/1136

This Thesis is protected by copyright and/or related rights. It has been brought to you by the The Research Repository @ WVU with permission from the rights-holder(s). You are free to use this Thesis in any way that is permitted by the copyright and related rights legislation that applies to your use. For other uses you must obtain permission from the rights-holder(s) directly, unless additional rights are indicated by a Creative Commons license in the record and/ or on the work itself. This Thesis has been accepted for inclusion in WVU Graduate Theses, Dissertations, and Problem Reports collection by an authorized administrator of The Research Repository @ WVU. For more information, please contact researchrepository@mail.wvu.edu. 


\title{
Design and Simulation of High Performance Hybrid Electric Vehicle Powertrains
}

\author{
Samuel P. Taylor \\ Thesis submitted to the \\ College of Engineering and Mineral Resources \\ at West Virginia University \\ in partial fulfillment of the requirements \\ for the degree of \\ Master of Science \\ In \\ Mechanical Engineering \\ Chris M. Atkinson, Sc.D., Chair \\ Nigel N. Clark, Ph.D. \\ Parviz Famouri, Ph.D. \\ Department of Mechanical and Aerospace Engineering \\ Morgantown, West Virginia \\ 2001
}

Keywords: Hybrid Electric Vehicles, Powertrain, Simulation, Design 


\title{
Abstract \\ Design and Simulation of High Performance Hybrid Electric Vehicle Powertrains
}

\author{
Samuel P. Taylor
}

The intent of this study was the design, modeling, and simulation of several highperformance light-duty hybrid electric vehicle powertrains. The design requirements of each proposed configuration are to meet or exceed a set of performance baselines based on a composite set of particular high-performance conventional vehicles presently available, while demonstrating increased fuel efficiency over regulated government cycles.

Several hybrid powertrain configurations were studied; however, the most promising and feasible for production designs were selected for further modeling. All of the proposed designs are post-transmission parallel hybrids for primarily performance reasons, with the auxiliary motive power coming after the transmission, utilizing a modeled spark-ignited, Variable Valve Timing (VVT) equipped internal combustion engine. A control strategy has been developed for the operation of these powertrains for virtually any driving condition - the strategy was not optimized for any particular government regulated cycle. Computer simulations were performed to simulate both the performance and the fuel economy of the proposed vehicle designs.

The simulation results show that the fuel economy of the modeled hybrid vehicles exceeds that of the comparable conventional vehicles, as well as meeting or exceeding the performance requirements of the baseline vehicles by $12-23 \%$. In addition the exhaust gas emissions may be reduced, compared to a conventional vehicle due to hybridization. All modeled components were selected from available off-the-shelf applications, and the selected designs were chosen to be readily mass-produced. 


\section{Table of Contents}

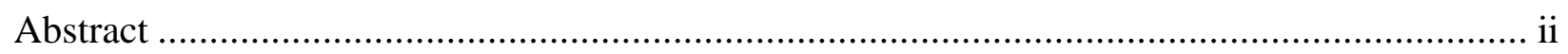

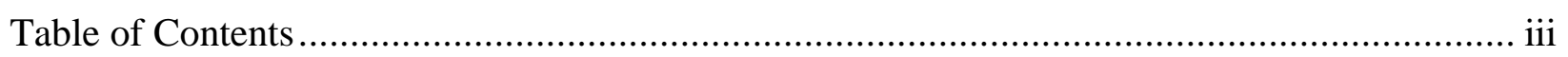

Table of Figures .................................................................................................... vii

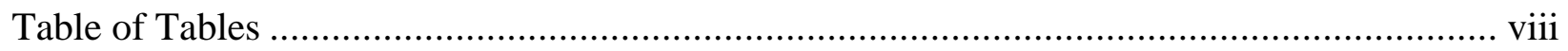

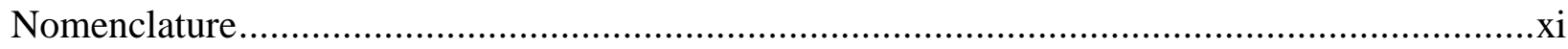

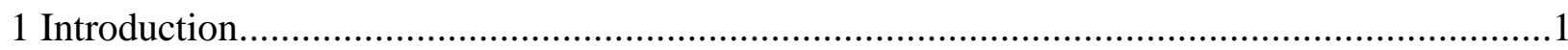

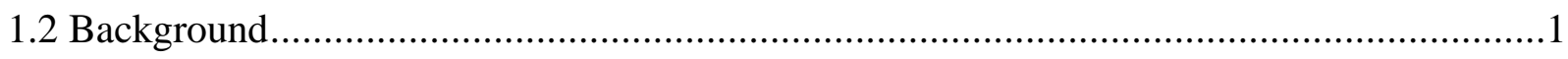

1.2.1 The Advantages and Disadvantages of Series Hybrid Vehicles................................2

1.2.2 The Advantages and Disadvantages of Parallel Hybrid Vehicles .............................3

1.2.3 The Advantages and Disadvantages of Combination Hybrid Vehicles ........................4

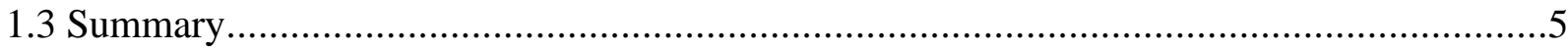

2 Literature Review...............................................................................................

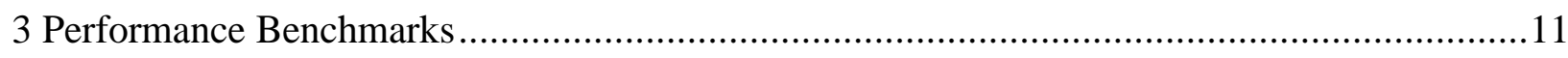

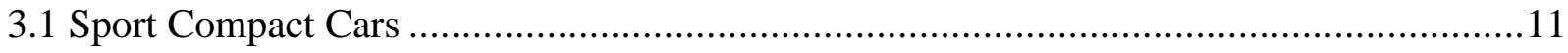

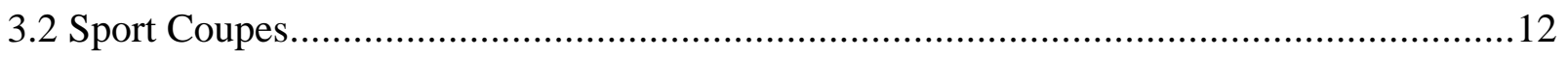

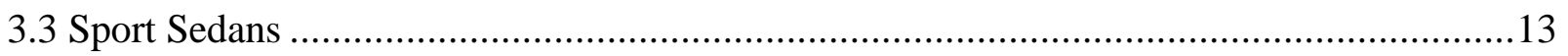

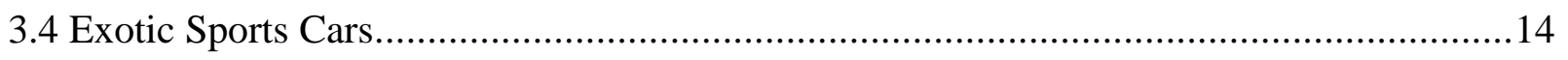

4 Component Sizing Using Modeling ..................................................................... 16 


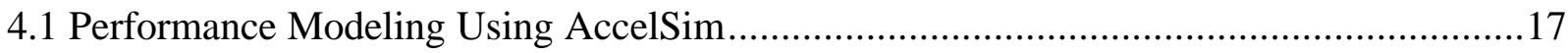

4.1.1 Development and Validation of the AccelSim Model ..............................................17

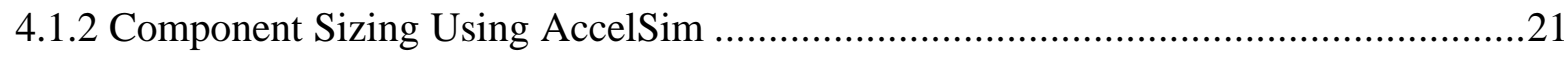

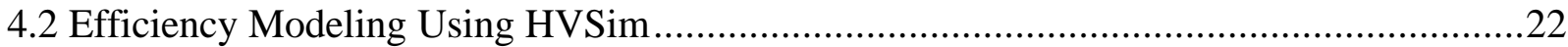

4.2.1 Development and Validation of the HVSim Model..................................................22

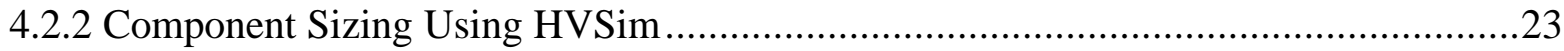

5 Performance and Efficiency Gains Through Vehicle Optimization ..........................................27

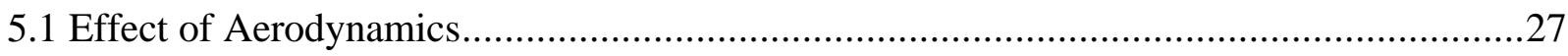

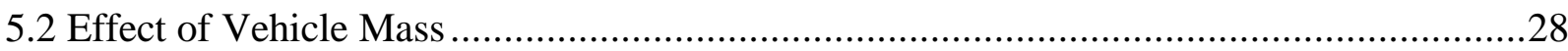

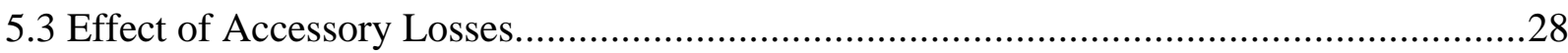

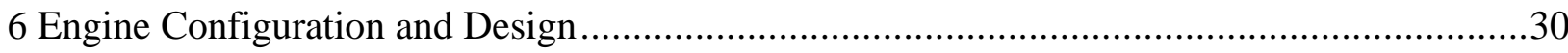

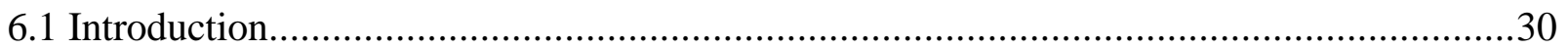

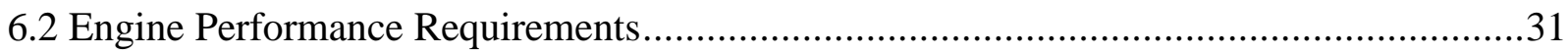

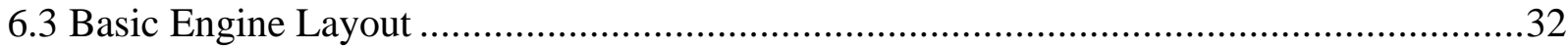

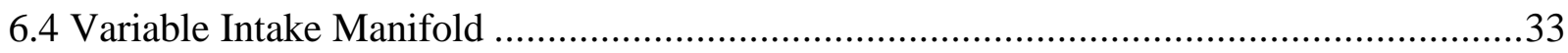

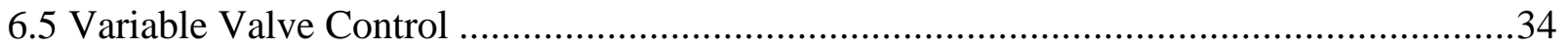

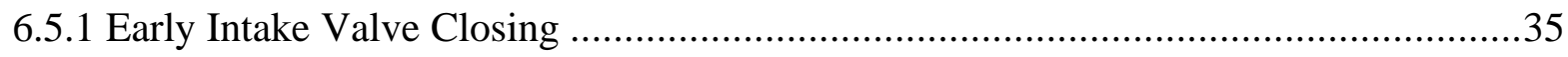

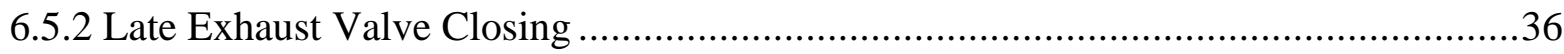

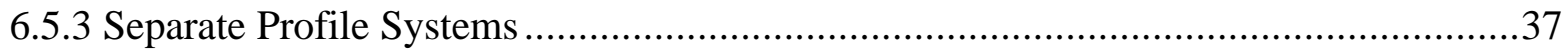

6.5.4 Full Authority Systems, Camless Valve Systems........................................................

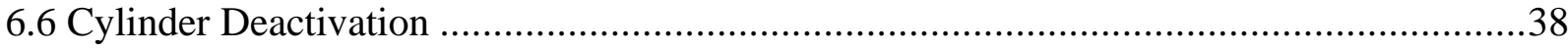

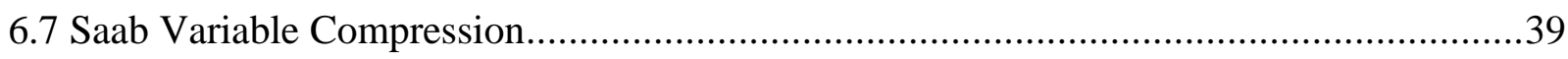

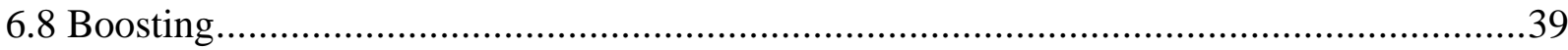




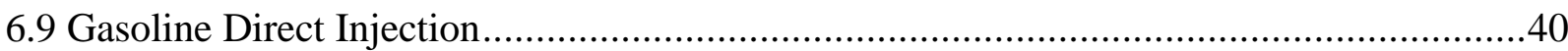

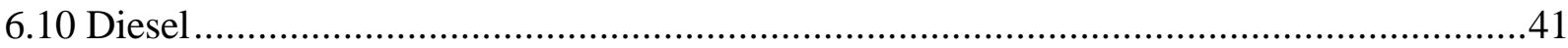

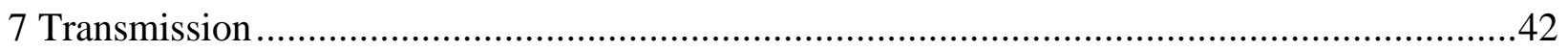

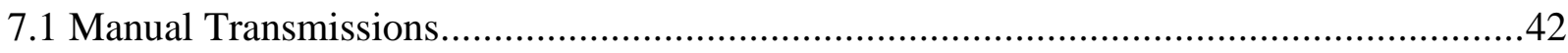

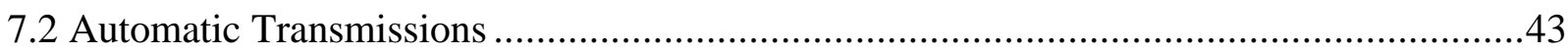

7.3 Continuously Variable Transmissions ...........................................................................

7.4 Automatically Shifted Manual Transmissions.................................................................45

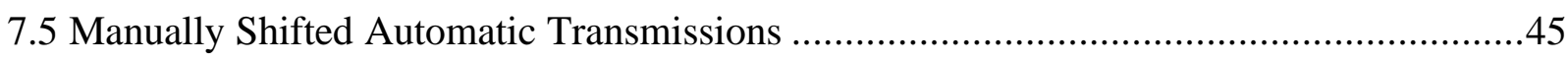

7.6 Planetary Transmissions ...............................................................................................

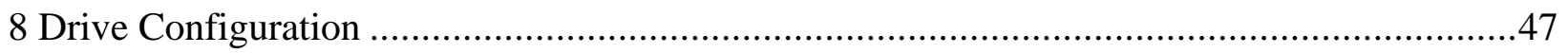

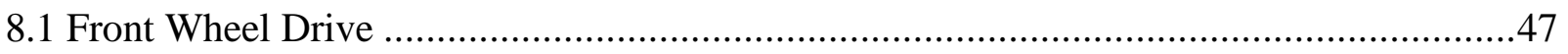

8.2 Rear Wheel Drive

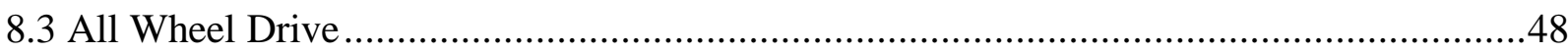

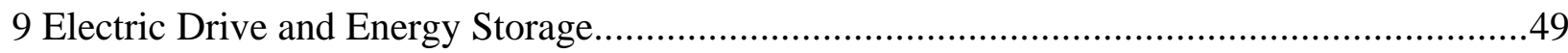

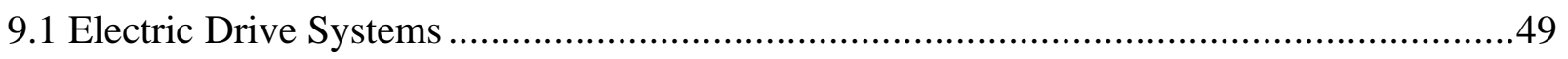

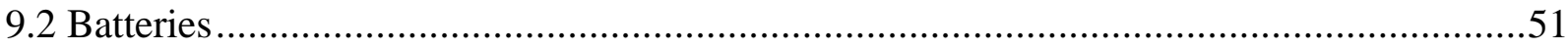

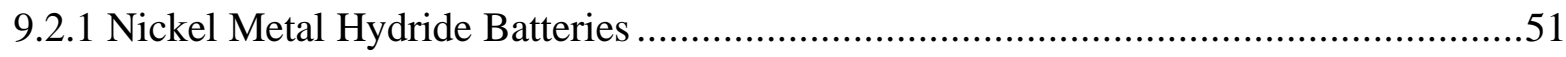

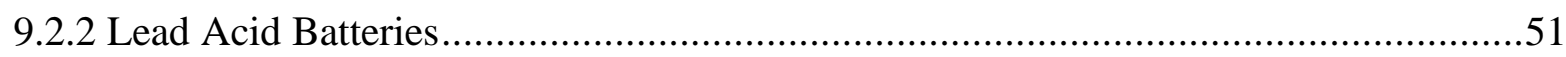

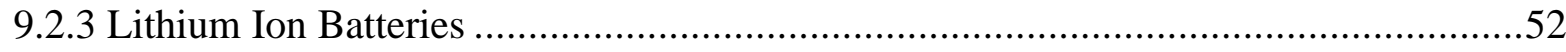

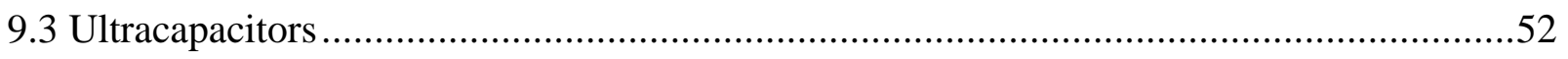

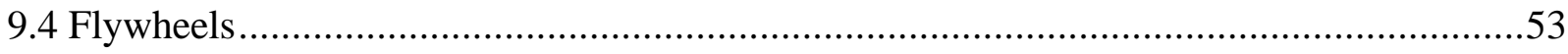

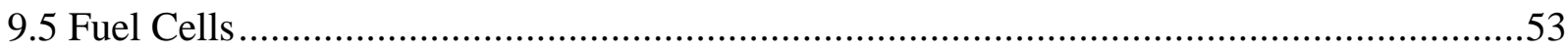

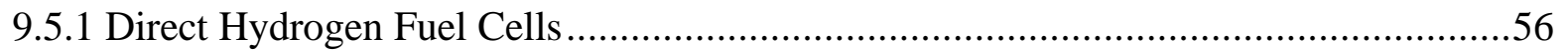




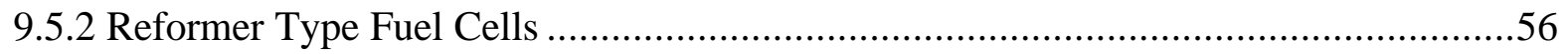

9.6 Combination Energy Storage Systems: Batteries and Ultracapacitors ...............................57

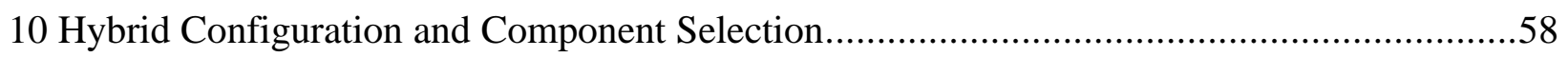

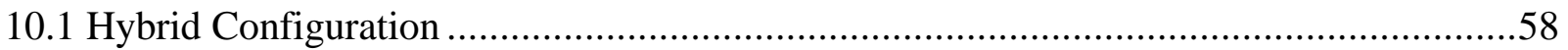

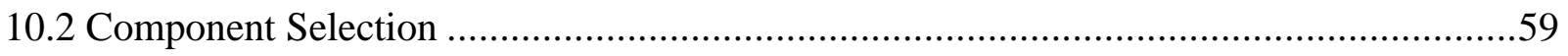

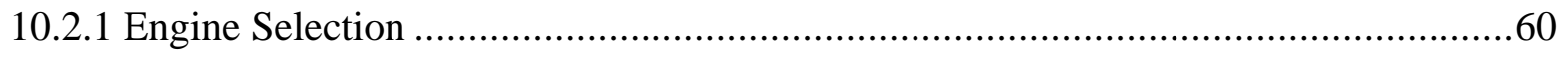

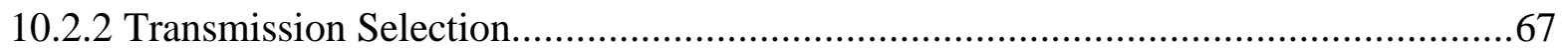

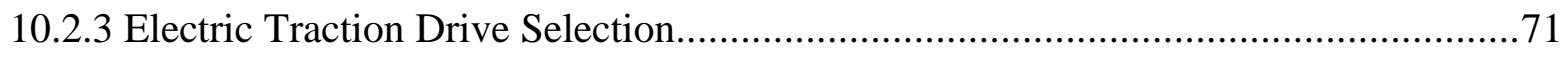

10.2.4 Electric Energy Storage Selection ......................................................................72

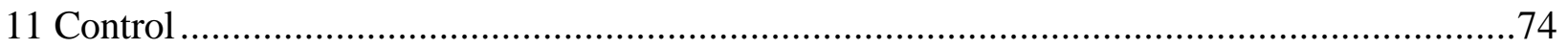

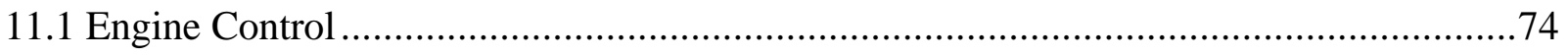

11.2 Electrical Drive Control and Combination Energy Storage Pack Control .........................75

11.3 Brake System/Traction Control System .....................................................................

11.4 Total System Control ……………..........................................................................

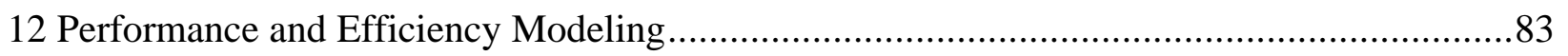

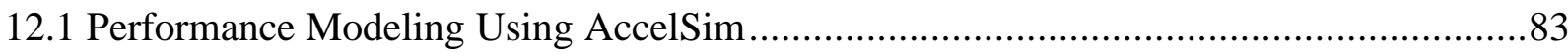

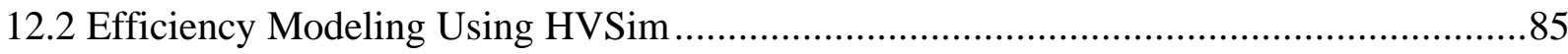

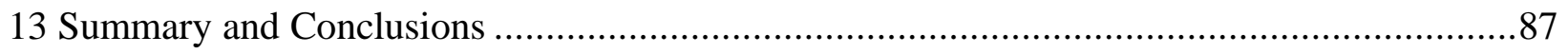

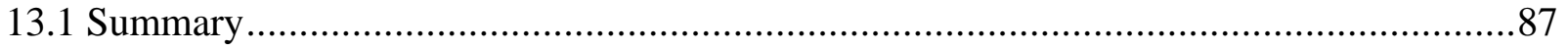

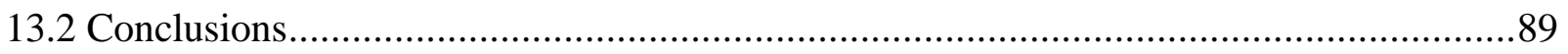

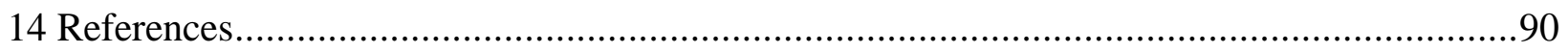




\section{Table of Figures}

Figure 4.1. Interrelation between Concepts for Hybrid Component Sizing ............................16

Figure 4.2. Engine Output Curves, 162kW 4-cylinder Engine........................................20

Figure 4.3. Speed-Time Plot, Track Trace, with Section of FTP for Comparison....................23

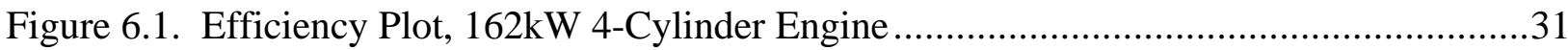

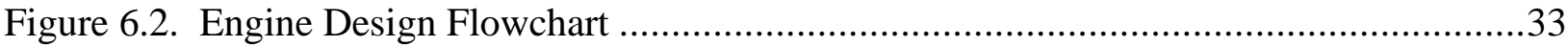

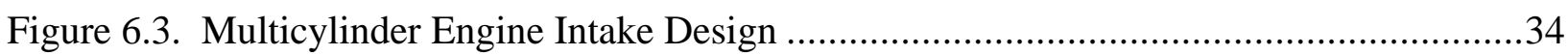

Figure 10.1. Post Transmission Parallel Layout Diagram..............................................58

Figure 10.2. Maximum Piston Speed vs. Specific Power ..............................................62

Figure 10.3. Bore/Stroke Ratio vs. Specific Power ........................................................63

Figure 10.4. BMEP vs. Specific Power................................................................................64

Figure 10.5. Compression Ratio vs. Specific Power.....................................................65

Figure 10.6. Surface Area-Volume Ratio vs. Specific Power ...........................................66

Figure 10.7. Sport Compact Car Engine Speed vs. Vehicle Speed .......................................69

Figure 10.8. Sport Coupe Engine Speed vs. Vehicle Speed ..............................................69

Figure 10.9. Sport Sedan Engine Speed vs. Vehicle Speed ............................................70

Figure 10.10. Exotic Sports Car Engine Speed vs. Vehicle Speed ....................................70

Figure 10.11. Unique Mobility 53kW Motor Output Curves..........................................71

Figure 11.1. Regeneration Control Flow Diagram .................................................... 76

Figure 11.2. Motoring Control Flow Diagram ....................................................... 77

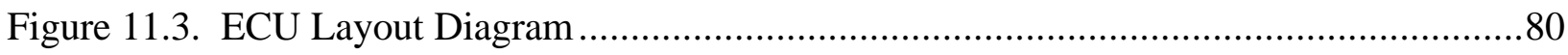

Figure 11.4. APS vs. Torque - Charge Depleting Map …..........................................82

Figure 12.1. Effect of Weight to Power Ratio on Acceleration Performance ..........................84

Figure 12.2. Fuel Economy Improvement vs. Degree of Hybridization...............................86 


\section{Table of Tables}

Table 1.1. Comparisons of Hybrid and Conventional Vehicles ............................................5

Table 3.1. Sport Compact Car Baselines................................................................... 11

Table 3.2. Performance Baselines............................................................................... 12

Table 3.3. Sport Coupe Baselines ........................................................................ 13

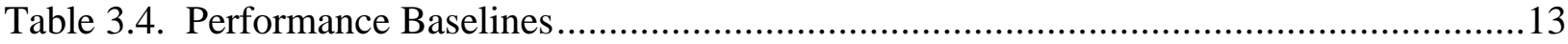

Table 3.5. Sport Sedan Baselines............................................................................. 14

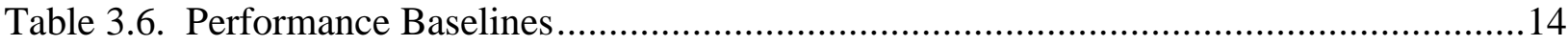

Table 3.7. Exotic Sports Car Baselines .................................................................. 15

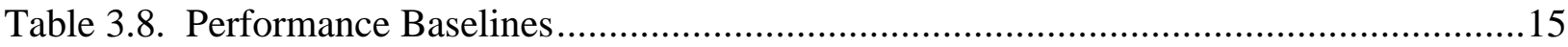

Table 4.1. Vehicle mass estimation.............................................................................21

Table 4.2. Continuous Power Requirements .........................................................22

Table 4.3. Modeled Vehicle Characteristics...............................................................24

Table 4.4. Sport Compact Car Power Requirements. ........................................................24

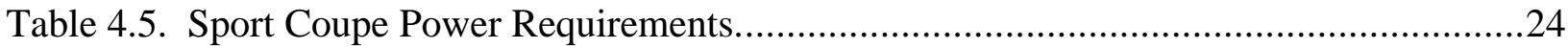

Table 4.6. Sport Sedan Power Requirements. ...........................................................25

Table 4.7. Exotic Sports Car Power Requirements..........................................................25

Table 4.8. Sports Compact Car Peak and Average Regeneration Values..............................26

Table 4.9. Sport Coupe Peak and Average Regeneration Values.......................................26

Table 4.10. Sport Sedan Peak and Average Regeneration Values. .....................................26

Table 4.11. Exotic Sports Car Peak and Average Regeneration Values...............................26

Table 9.1. Various Energy Storage Type Comparison......................................................49

Table 10.1. Sport Compact Component Summary ….........................................................59

Table 10.2. Sport Coupe Component Summary …...................................................59 
Table 10.3. Sport Sedan Component Summary ……………………………………….........60

Table 10.4. Exotic Sports Car Component Summary ..............................................................6

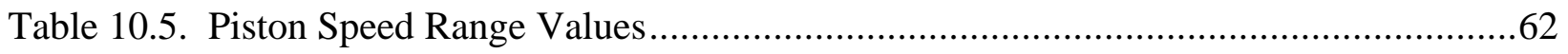

Table 10.6. Bore/Stroke Ratio Range Values ............................................................................63

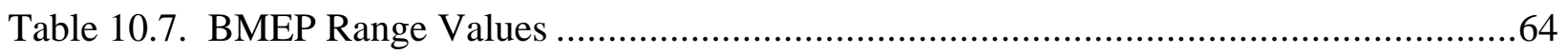

Table 10.8. Compression Ratio Range Values ....................................................................65

Table 10.9. Proposed Engine Specifications .......................................................................6

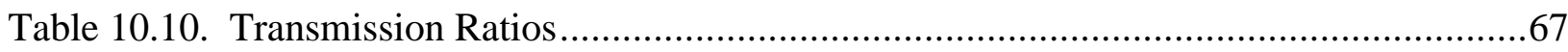

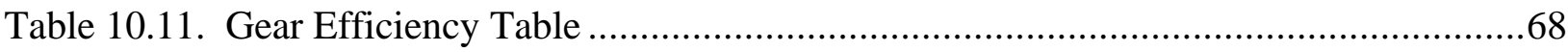

Table 10.12. Motor Drive Specifications …………….......................................................

Table 10.13. Maxwell Technologies 2.7V Ultracapacitor Specifications...................................72

Table 10.14. Hawker Energy 12V Lead Acid Battery Specifications .......................................72

Table 10.15. Ultracapacitor Stack Properties ..........................................................................73

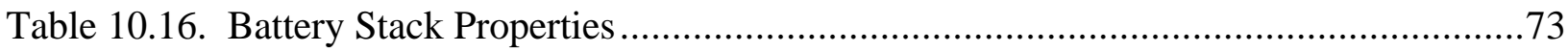

Table 10.17. Total Energy Storage Stack Properties ………………………….....................73

Table 10.18. Electrical Storage Volume Requirements .............................................................73

Table 12.1. Sport Compact Car Final Performance Estimates ....................................................83

Table 12.2. Sport Coupe Final Performance Estimates ............................................................

Table 12.3. Sport Sedan Final Performance Estimates ...............................................................83

Table 12.4. Exotic Sports Car Final Performance Estimates ..................................................84

Table 12.5. Sport Compact Car Final Fuel Efficiency Estimates (mpg).....................................85

Table 12.6. Sport Coupe Final Fuel Efficiency Estimates (mpg) ..............................................85

Table 12.7. Sport Sedan Final Fuel Efficiency Estimates (mpg)...............................................85

Table 12.8. Exotic Sports Car Final Fuel Efficiency Estimates (mpg) .......................................86 
Table 13.1. Final Vehicle Specifications and Performance.. 


\section{Nomenclature}

\begin{tabular}{|c|c|}
\hline A & -Frontal area \\
\hline $\mathrm{a}$ & -Acceleration \\
\hline ABS & -Anti-lock Braking System \\
\hline APS & -Accelerator Position Sensor \\
\hline AWD & -All Wheel Drive \\
\hline BMEP & -Brake Mean Effective Pressure \\
\hline CAFE & -Corporate Average Fuel Economy \\
\hline $\mathrm{C}_{\mathrm{d}}$ & -Drag Coefficient \\
\hline CI & -Compression Ignition \\
\hline $\mathrm{CO}$ & -Carbon monoxide \\
\hline $\mathrm{CO}_{2}$ & -Carbon dioxide \\
\hline $\mathrm{CR}$ & -Compression Ratio \\
\hline CVT & -Continuously Variable Transmission \\
\hline ECU & -Electronic Control Unit \\
\hline EGR & -Exhaust Gas Recirculation \\
\hline EIVC & -Early Intake Valve Closing \\
\hline EPA & -Environmental Protection Agency \\
\hline $\mathrm{ES}$ & -Engine Speed \\
\hline ET & -Elapsed Time \\
\hline $\mathrm{F}$ & -Force \\
\hline FTP & -Federal Test Procedure \\
\hline FWD & -Front Wheel Drive \\
\hline
\end{tabular}




\begin{tabular}{|c|c|}
\hline $\mathrm{g}$ & -Gravitational Acceleration \\
\hline GDI & -Gasoline Direct Injection \\
\hline $\mathrm{HC}$ & -Hydrocarbons \\
\hline HEV & -Hybrid Electric Vehicle \\
\hline HWFET & -High Way Fuel Economy Test \\
\hline ICE & -Internal Combustion Engine \\
\hline $\mathrm{m}$ & -Mass \\
\hline mpg & -Miles Per Gallon \\
\hline $\mathrm{mph}$ & -Miles Per Hour \\
\hline$\mu$ & -Coefficient of rolling resistance \\
\hline LEV & -Low Emission Vehicle \\
\hline $\mathrm{Li}+$ & -Lithium Ion \\
\hline LEVC & -Late Exhaust Valve Closing \\
\hline LIVC & -Late Intake Valve Closing \\
\hline $\mathrm{m}$ & -Mass \\
\hline$\eta$ & -Efficiency \\
\hline $\mathrm{NiMH}$ & -Nickel Metal Hydride \\
\hline NOx & -Oxides of Nitrogen \\
\hline $\mathrm{PbA}$ & -Lead Acid \\
\hline PM & -Particulate Matter \\
\hline$\rho$ & -Density of air \\
\hline RWD & -Rear Wheel Drive \\
\hline SA & -Surface Area \\
\hline SI & -Spark Ignition \\
\hline
\end{tabular}




\begin{tabular}{|c|c|}
\hline SoC & -State Of Charge \\
\hline SVC & -Saab Variable Compression \\
\hline TA & -Torque Available for Acceleration \\
\hline $\mathrm{TE}$ & -Torque Available from Powertrain \\
\hline TGR & -Total Gearing Ratio \\
\hline To & -Torque Output \\
\hline TS & -Trap Speed \\
\hline $\mathrm{TT}$ & -Track Trace \\
\hline TTR & -Through The Road \\
\hline $\mathrm{V}$ & -Velocity \\
\hline V & -Voltage \\
\hline Vol & -Volume \\
\hline VTEC & -Variable Timing Electronically Controlled \\
\hline VVT & -Variable Valve Timing \\
\hline VVTL-i & -Variable Valve Timing and Lift - Intelligent \\
\hline UDDS & -Urban Dynamometer Driving Schedule \\
\hline US06 & -United States \#6 Driving Cycle \\
\hline
\end{tabular}




\section{Introduction}

In the minds of the consumer vehicles are judged on many characteristics. Some of the areas that consumers are concerned with are safety, style, utility, fuel efficiency and performance. Of these things fuel efficiency, emissions and safety are regulated in some form. Present day hybrids are aimed at increasing fuel efficiency and reducing emissions while attempting to meet minimum requirements for the other characteristics outlined above. A further concern is the desire to reduce greenhouse gas emissions, primarily $\mathrm{CO}_{2}$, one of the natural products of combustion, with an accompanying increase in fuel efficiency. However, at this time fuel efficiency is not a top priority for most consumers; in 1980 consumers rated fuel efficiency as the second most important factor in a vehicle buying decision, in 1998 it was ranked fourteenth, behind such features as performance and styling. In 2001, with ever increasing fuel prices, this issue is of presumably higher importance to consumers. With this in mind a hybrid powertrain design that seeks to meet a consumer's demand for good performance, while still providing the efficiency benefits of hybridization becomes attractive.

\subsection{Background}

Hybrid electric vehicles are vehicles that make use of more than one supply of energy. There are many different possible hybrid powertrain configurations possible, using many different possible propulsion devices. Propulsion devices that have been used to date in hybrids include spark ignition (SI) engines, compression ignition (CI) engines, fuel cells, gas turbines, and high output electric traction drives. Electrical energy storage devices that are currently being researched and used include batteries, ultracapacitors, and flywheels. A hybrid electric drivetrain can be utilized to increase greatly vehicle fuel economy while lowering exhaust emissions, through engine downsizing and the capturing of braking energy through 
regeneration. Hybrid designs also offer the extended range and rapid refueling that consumers expect from a vehicle. In order for these type of vehicles to gain widespread acceptance, the operation of the hybrid system must be transparent to the user, maintain all required safety features, be available at a cost comparable to that of conventional vehicles, and the vehicle should have at least adequate dynamic performance. It can be argued that the first two HEVs available in the US today (2001) fulfill all of these requirements, although most criticisms tend to be over the latter issue of performance.

The combination of multiple power sources allows for overall vehicle efficiency to be improved by giving the ability for the most efficient power source to be used at any given operating condition. This is of importance in that currently available electrochemical batteries,

the most commonly used energy storage device in hybrids, cannot provide all the required energy for a reasonable vehicle range as measured over a typical driving cycle; as a result almost all energy consumed in meeting typical range requirements is taken from the on-board fuel. The use of advanced control strategies, along with advances in energy storage, may make more highly efficient and adaptive hybrids possible in the future. These efficiency gains will be evident in higher fuel economy and lower greenhouse gas emissions as well as in reduced regulated exhaust gas emissions.

There are several types of hybrids, including series, parallel and combination hybrids. In the following sections each type will be discussed and advantages and disadvantages of each type will be examined.

\subsubsection{The Advantages and Disadvantages of Series Hybrid Vehicles}

A series hybrid vehicle typically consists of an internal combustion engine (ICE), either SI (spark ignited) or CI (compression ignited), directly connected to an electric generator or alternator. The vehicle motive power is provided entirely by an electric traction drive that is 
supplied with energy by the battery pack or a combination of the battery pack and the generator. The benefit of this layout is that engine operation is not directly dependent on the instantaneous vehicle load and the engine only runs when the battery state of charge (SoC) has dropped below some low predetermined level. This type of engine operation allows for optimization of engine fueling and ignition timing, as well as exhaust gas recirculation and three-way catalyst exhaust aftertreatment optimization in a spark-ignited engine. In a compression ignition engine fueling and injection timing, as well as boost and exhaust gas recirculation can be optimized for the specific range of operation. The engine is operated in the most efficient speed and torque range without experiencing the transient load of the vehicle. The result of this style of operation is excellent fuel efficiency and low exhaust gas emissions. A further benefit of this configuration is the relative ease with which the drive system can be controlled, as the engine operates at one set point. Series HEV operation is best suited to highly transient vehicle operation with somewhat low average power requirements, such as city-type driving. One disadvantage of series operation is the relatively large energy conversion losses from mechanical to electrical and then from electrical to mechanical energy. Further losses are incurred when energy is stored in the batteries, as battery internal resistance penalizes energy transfer both into and out of the battery at higher currents. The largest limitations to widespread series vehicle adoption is that dynamic performance is limited due to the electric traction drive being the only motive power source and the vehicle weight due to the battery storage required.

\subsubsection{The Advantages and Disadvantages of Parallel Hybrid Vehicles}

Parallel hybrid drivetrains also utilize two power sources, typically an internal combustion engine and an electric traction motor with both coupled mechanically to the wheels. The motor may be coupled to the wheels either through the transmission, or directly to 
the wheels after the transmission. In this configuration the engines sees substantial transient load, but the motor can be used as a load-leveling device to permit the engine to operate in a more efficient manner. When the vehicle is operating in a low power regime the engine can be disconnected from the drivetrain and turned off, or the motor can be used to regenerate electrical energy in a charge-while-driving mode, putting a larger power demand on the engine and storing the resultant excess energy in the battery pack. The disadvantage of parallel hybrids is that the direct connection of the engine to the wheels necessitates transient engine operation with respect to vehicle speed. This transient operation typically increases fuel consumption and increases exhaust emissions. Optimization of combustion timing and fueling can only be accomplished in a limited manner. Control of parallel drivetrains is also more difficult than that of series drivetrains, owing to the transient operation of both the motor and the engine. The primary advantage of parallel hybrids is that the dynamic capabilities of a vehicle using such a powertrain layout are much higher than those of a series-type configuration using the same components. More motive power is available as both the engine and motor can provide power to the wheels simultaneously. These traits allow parallel HEVs to perform well in high load, high average power conditions.

\subsubsection{The Advantages and Disadvantages of Combination Hybrid Vehicles}

A combination hybrid vehicle has the advantages of both a series and a parallel hybrid vehicle. At low load or in highly transient operation the vehicle may be operated as a series hybrid while under higher loads, such as high speeds, heavy accelerations, or while carrying or towing heavy loads, the vehicle may be operated as a parallel hybrid. The accompanying efficiency gains of both configurations may be achieved with this layout, as well as acceptable dynamic performance. The primary drawback to such a system is the much greater complexity, both in the actual mechanical design and in the added control structure. The 
Toyota Prius is a currently available combination hybrid that utilizes a highly complex planetary hybrid system and control (Anderson, 2000).

\subsection{Summary}

Hybrids have been produced that have very good fuel efficiency compared to conventional vehicles, and accompanying low emissions, but vehicle driveability suffers, especially with regard to dynamic performance. It should be noted that all of the current production or near-production passenger car hybrids are either of parallel or combination configurations; no are series. This is due to the series configuration's inherently poor dynamic performance. Table 1.1. shows performance comparisons of the hybrid Toyota Prius vs. the conventional Toyota Echo and the hybrid Honda Insight vs. the conventional Honda Civic, comparable vehicles in size, cost, and utility (Car and Driver).

Table 1.1. Comparisons of Hybrid and Conventional Vehicles

\begin{tabular}{|c|c|c|c|c|}
\hline & Hybrid & Conventional & Hybrid & Conventional \\
\hline & Honda Insight & Honda Civic & Toyota Prius & Toyota Echo \\
\hline 0-60mph (sec) & 12.1 & 7.1 & 12.7 & 8.5 \\
\hline 1/4mi ET (sec.) & 18.7 & 15.7 & 18.9 & 16.7 \\
\hline 1/4mi ts (mph) & 73.3 & 88 & 75.3 & 82 \\
\hline Top Speed (mph) & 103 & 127 & 94 & 112 \\
\hline EPA City (mpg) & 61 & 26 & 52 & 34 \\
\hline EPA Highway (mpg) & 70 & 31 & 45 & 41 \\
\hline Combined (mpg) & 64.7 & 28.0 & 48.6 & 36.9 \\
\hline Efficiency Improvement \% & 131 & - & 31.7 & - \\
\hline Cost (US \$) & 20,700 & 17,000 & 18,400 & 14,270 \\
\hline
\end{tabular}

The gains in fuel efficiency from hybridization can be seen to be sizeable for these vehicles, however the dynamic performance is severely lacking. The hybrid designs proposed for this study will not show fuel efficiency gains as dramatic as the ones illustrated above, but 
should show fuel efficiency and dynamic performance improvements when compared to the conventional vehicles.

This work seeks to determine potential hybrid electric vehicle configurations that will offer both good fuel efficiency and good performance to make HEVs more attractive to the driving public; if people do not purchase more efficient vehicles then the greenhouse gas reductions promised by these vehicles will be inconsequential. 


\section{Literature Review}

Hybrid electric vehicles are a relatively youthful technology, and literature on these concepts is somewhat limited in scope. Work on the performance aspects of hybrids has been even more limited, and as such even less existing work is available for scrutiny. This section is intended to provide a brief review of work being performed on high performance hybrids, both on whole vehicle concepts, and in component design.

\section{Hybrid Options for Light-Duty Vehicles}

Recent work by Argonne National Laboratories (An et al., 1999) analyzes how, why, and by how much vehicle hybridization can reduce energy consumption and improve fuel economy. The focus of this paper is entirely on the effect of hybridization and not on other measures such as weight, drag, or rolling-resistance reduction, as these measures would also benefit conventional vehicles. The emphasis of this paper is that the potential for fuel economy gains from hybridization can be estimated in three areas:

- The reduction of engine idling operation

- $\quad$ The recoverability of braking energy losses (regeneration)

- Improvement of engine load profiles

The conclusions of this paper are that energy benefits from hybridization vary with test cycles and with performance requirements. The hybrid benefits for high-performance vehicles are greater than for low-performance vehicles. An increasing acceleration requirement would result in larger fuel economy benefits from hybridization.

\section{The Prospects for Hybrid Electric Vehicles, 2005-2020: Results of a Delphi Study}

In another paper by the advanced powertrain group at Argonne National Laboratories (Ng et al., 1999), desirable and likely attributes of future HEVs were defined. The trends 
found throughout the industry indicate a belief that ICEs have life at least until 2020, when fuel cells are expected to become viable, and that even then gasoline is expected to split the fuel market with hydrogen. This is merely a hypothetical work, with industry leaders sharing their vision for HEVs in the future. One aspect of future HEVs that is not expected to change is the price penalty for hybridization, estimated to be $33 \%$ more than a comparable $\$ 20,000$ conventional vehicle in 2020.

\section{High Performance Electric Vehicles}

This paper on Indiana University-Purdue University at Indianapolis' (IUPUI) Formula Lightning race vehicle was of interest because of the discussion of electric propulsion system performance at or above the continuous rating, and the behavior of lead-acid batteries operating in high-current discharge environments. The main conclusion from this work is that even at high current discharge levels, battery performance is relatively predictable (Rennels et al., 1999).

\section{How Size and Performance of Hybrid Electric Vehicle Components are influenced}

\section{by Acceleration Patterns}

This paper, although focusing on the behavior of series hybrids, has valuable insight into the sizing of electrical drivetrains and the performance of these systems. The general premise of this paper is that the desired performance characteristics of a car are determined by our experience with today's vehicles. Furthermore, a slight change in the acceleration profile while maintaining overall performance would greatly influence the size of components and would lead to a reduction of fuel consumption. This concept shows promise, and can be applied to parallel hybrid design as well (Lamperth and Pullen, 1999). 


\section{Development of the High Speed 2ZZ-GE Engine}

The Toyota 2ZZ-GE engine is a mass-produced high-speed high specific output 4cylinder SI engine employing VVT technologies. This engine was chosen as an example of the type of engine that would be ideal for higher performance hybrid use, with small displacement, low weight, and high output. The VVTL-I system used in this engine also is indicative of the types of mechanisms that can be used in mass-production engines (Shikada et al., 2000).

\section{Development of the High Power, Low Emission Engine for the "Honda S2000"}

This engine, coded the F20C, is the one of the most advanced small displacement, high output engines in production today. Its specific output of $120 \mathrm{hp} / \mathrm{l}$ is the highest output of any mass production naturally aspirated engine ever. This engine is also an excellent example of an engine that would be well suited for high output hybrid use, in that it is small displacement and high power, with low exhaust emissions. The VTEC variable valve timing system utilized on this engine is also indicative of the potential for production VVT systems (Otobe et al., 2000).

Performance Scaling of SI Engines, Correlation and Historical Analysis of Production Engine Data

This study examined the scaling between engine performance, engine configuration, and engine size and geometry for modern spark-ignited engines. The primary focus of this paper is on design features that impact engine breathing, namely boosting, multi-valve head configurations, and variable valve timing. This paper analyzed historical trends to show how technology has improved engine performance. Finally different geometric properties such as displacement, piston area, number of cylinders, number of valves per cylinder, bore to stroke ratio, and compression ratio are examined for boosted and naturally aspirated engines. The techniques used in this study show great promise for engine design, and potential for insight 
into future engine technology assessments. Finally, the effects of scaling are readily apparent for torque vs. displacement, and between maximum piston speed and maximum power (Heywood and Chon, 2000).

\section{A Manufacturer's Perspective on IC Engine Technology at Century's End}

This paper presents a broad summary of automotive engine technology. Regulatory requirements, including emissions, $\mathrm{CAFE}$, and safety as well as customer requirements are considered, while highlighting some of the challenges facing the automotive industry in satisfying these two often conflicting desires. Popular and less popular IC engine research areas like cylinder deactivation, VVT, and boosting are examined and observations are made regarding their acceptance into the manufacturing mainstream (Asmus, 2000).

Modularity in Spark Ignition Engines: A Review of Its Benefits, Implementation, and Limitations

This paper presents various concepts in "modularity", defined in the paper as design, operation, and sensing on an individual cylinder basis. Several modular approaches with respect to breathing, fueling, power generation, and sensing are presented. The effects of intake design, variable valve timing, and cylinder deactivation are studied, as well as combinations of these concepts with boosting (Atkinson and Yacoub, 1998). 


\section{Performance Benchmarks}

There is a range of sporty cars, varying in performance and cost. In order to be able to compare the dynamic performance of hybrids versus conventional vehicles, four sets of vehicle dynamic performance parameters were established for use in this design. A compilation of vehicle performance data was constructed and averages were found for each of the four groups. The four groups of vehicles are divided into sport compact cars, sport coupes, sport sedans, and exotic sports cars. The following parameters are used as requirements for the hybrid vehicles' performance. All of the individual vehicle information used in constructing these values is attached as Appendix A. Original performance data was taken from available public sources. Note that in some cases top speed is gearing and not power limited, or top speed may be electronically limited.

\subsection{Sport Compact Cars}

The first set of parameters was based on a less expensive commonly available sport compact car. The current trends for such a vehicle are shown in Table 3.1.

\section{Table 3.1. Sport Compact Car Baselines}

\begin{tabular}{|c|c|}
\hline Number Sampled & 6 \\
\hline Average Cost (\$) & 28,000 \\
\hline Engine Layout & L-4 (6/6) \\
\hline Average Displacement (1) & 1.9 \\
\hline Aspiration & NA (4/6), Turbocharged w/ Intercooling $(2 / 6)$ \\
\hline Weight (kg) & 1241 \\
\hline Driveline & FWD (4/6), AWD (2/6) \\
\hline Average Power (kW) & 140 \\
\hline Valve Train & DOHC (6/6), Variable Valve Timing (4/6) \\
\hline Power to Weight $(\mathrm{kg} / \mathrm{kW})$ & 8.9 \\
\hline
\end{tabular}


It can be seen from Table 3.1. that the trend in this type of vehicle is to utilize a high output, low displacement four-cylinder engine, with either variable valve timing or boosting. Also, low weight and relatively high fuel economy are hallmarks of this vehicle. Two thirds of the sampled vehicles were front wheel drive, with the remaining one-third all-wheel drive.

Average performance baselines for this type of vehicle are shown in Table 3.2.

Table 3.2. Performance Baselines

\begin{tabular}{|c|c|}
\hline 0-60 mph $(\mathrm{sec})$ & 6.2 \\
\hline 1/4mi ET $(\mathrm{sec})$ & 14.8 \\
\hline 1/4mi $(\mathrm{mph})$ & 95.1 \\
\hline Top Speed (mph) & 138 \\
\hline EPA City $(\mathrm{mpg})$ & 25 \\
\hline EPA Highway (mpg) & 33 \\
\hline Combined (mpg) & 28.1 \\
\hline
\end{tabular}

\subsection{Sport Coupes}

The sport coupe segment is intended to represent a more purpose built performance vehicle, encompassing both the traditional "musclecar" type vehicle and the somewhat more expensive sports coupes on the market. These vehicles were combined in the same group based on their relative performance. The trends for these sampled vehicles are shown in Table 3.3 . 
Table 3.3. Sport Coupe Baselines

\begin{tabular}{|c|c|}
\hline Number Sampled & 6 \\
\hline Average Cost (\$) & 37,570 \\
\hline Engine Layout & V-8 (2/6), V-6 (1/6), H-6 (1/6), L-4 (2/6) \\
\hline Average Displacement (1) & 3.4 \\
\hline Aspiration & NA (4/6), Turbocharged w/ Intercooling (2/6) \\
\hline Weight $(\mathrm{kg})$ & 1414 \\
\hline Driveline & RWD (4/6), FWD (1/6), AWD (1/6) \\
\hline Average Power (kW) & 191 \\
\hline Valve Train & DOHC (5/6), OHV (1/6), Variable Valve Timing (1/6) \\
\hline Power to Weight $(\mathrm{kg} / \mathrm{kW})$ & 7.4 \\
\hline
\end{tabular}

In this class of vehicle trends are less obvious. Three types of engines are used, and boosting is only employed on the smaller four-cylinder engines. Double overhead cam valve trains are most commonly employed, but the use of variable valve timing is minimal. Two more apparent trends are the higher cost of these vehicles and the higher power output. The higher performance demands of these vehicles is shown in Table 3.4, as is the lower fuel efficiency.

Table 3.4. Performance Baselines

\begin{tabular}{|c|c|}
\hline $0-60 \mathrm{mph}(\mathrm{sec})$ & 5.8 \\
\hline $1 / 4 \mathrm{mi} \mathrm{ET} \mathrm{(sec)}$ & 14.3 \\
\hline 1/4mi (mph) & 98.9 \\
\hline Top Speed (mph) & 149 \\
\hline EPA City (mpg) & 19 \\
\hline EPA Highway (mpg) & 27 \\
\hline Combined mpg & 21.9 \\
\hline
\end{tabular}

\subsection{Sport Sedans}

Sport sedans are vehicles with dynamic performance meeting and sometimes exceeding that of a sport coupe, with more luxury features and a normally heavier and larger package. As a result these vehicles have a higher purchase price penalty, and lower fuel economy. Trends for the sampled vehicles are shown in Table 3.5. 
Table 3.5. Sport Sedan Baselines

\begin{tabular}{|c|c|}
\hline Number Sampled & 4 \\
\hline Average Cost $(\$)$ & 64,935 \\
\hline Engine Layout & V-8 (3/4), V-6 (1/4) \\
\hline Average Displacement (1) & 4.3 \\
\hline Aspiration & NA (2/4), Turbocharged w/ Intercooling (1/4), Supercharged w/Intercooling (1/4) \\
\hline Weight (kg) & 1743 \\
\hline Driveline & RWD (3/4), AWD (1/4) \\
\hline Average Power $(\mathrm{kW})$ & 259 \\
\hline Valve Train & DOHC (3/4), SOHC (1/4), Variable Valve Timing (1/4) \\
\hline Power to Weight $(\mathrm{kg} / \mathrm{kW})$ & 6.7 \\
\hline
\end{tabular}

In this class of vehicle the output and displacement of the engines has risen dramatically. Overhead cam valve trains are used exclusively, but variable valve timing is used only on one vehicle. Boosting is used in some cases, however it should be noted that one of the boosted engines is the smaller V-6. Vehicle weight and cost have increased substantially too. Vehicle performance has also risen despite the increase in mass. Vehicle performance averages are shown in Table 3.6.

Table 3.6. Performance Baselines

\begin{tabular}{|c|c|}
\hline $0-60 \mathrm{mph}(\mathrm{sec})$ & 5.3 \\
\hline $1 / 4 \mathrm{mi} \mathrm{ET}(\mathrm{sec})$ & 13.8 \\
\hline $1 / 4 \mathrm{mi}(\mathrm{mph})$ & 103 \\
\hline Top Speed $(\mathrm{mph})$ & 156 \\
\hline EPA City $(\mathrm{mpg})$ & 15 \\
\hline EPA Highway $(\mathrm{mpg})$ & 22 \\
\hline Combined mpg & 17.5 \\
\hline
\end{tabular}

\subsection{Exotic Sports Cars}

Exotic sports cars value dynamic performance at all costs. The average price of these vehicles is high, but the performance is equally increased. A summary of exotic sports car characteristics is shown in Table 3.7. 
Table 3.7. Exotic Sports Car Baselines

\begin{tabular}{|c|c|}
\hline Number Sampled & 9 \\
\hline Average Cost $(\$)$ & 117,252 \\
\hline Engine Layout & V-12 (2/9), V-10 (1/9), V-8 (3/9), V-6 (1/9), H-6 (1/9), L-6 (1/9) \\
\hline Average Displacement (1) & 4.7 \\
\hline Aspiration & NA (6/9), Turbocharged w/ Intercooling (2/9), Supercharged w/Intercooling (1/9) \\
\hline Weight $(\mathrm{kg})$ & 1580 \\
\hline Driveline & RWD (6/9), AWD (3/9) \\
\hline Average Power $(\mathrm{kW})$ & 296 \\
\hline Valve Train & DOHC (7/9), OHV (2/9), Variable Valve Timing (4/9) \\
\hline Power to Weight $(\mathrm{kg} / \mathrm{kW})$ & 5.3 \\
\hline
\end{tabular}

Compared to the high performance sports sedans and to the other vehicles sampled these vehicle have the highest average power-to-weight ratio and the largest average displacement. The EPA fuel efficiency numbers are the lowest for this group because of many factors, primarily due to the surplus of engine output and displacement needed for average driving, thus leading to much higher pumping losses over a cycle. Performance baselines required for this class of vehicles are shown in Table 3.8.

Table 3.8. Performance Baselines

\begin{tabular}{|c|c|}
\hline $0-60 \mathrm{mph}$ & 4.6 \\
\hline 1/4mi ET $(\mathrm{sec})$ & 13.0 \\
\hline 1/4mi mph & 111 \\
\hline Top Speed mph & 180 \\
\hline EPA City & 14 \\
\hline EPA Highway & 20 \\
\hline Combined mpg & 16.2 \\
\hline
\end{tabular}




\section{Component Sizing Using Modeling}

In order to accurately size components (engines, motors, and batteries) for use in any high performance application, modeling of both vehicle dynamic performance and vehicle cycle fuel efficiency and power requirements was performed. The basic premise for the sizing and selection of components for use in this simulation is outlined in Figure 4.1.

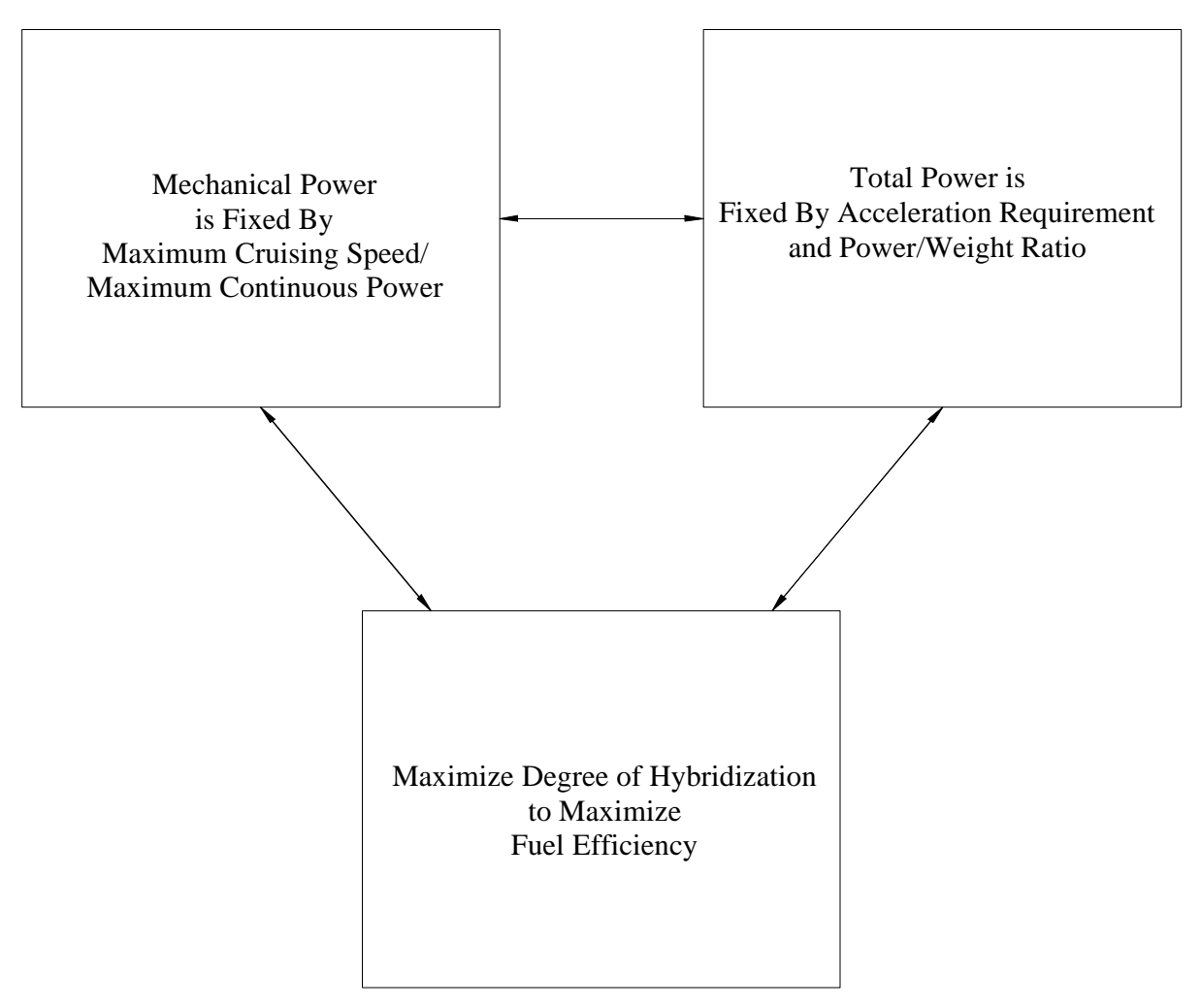

Figure 4.1. Interrelation between Concepts for Hybrid Component Sizing

In order to maximize fuel efficiency it is desirable to maximize the degree of hybridization, or

$$
\text { maximum (hybrid electric power / total power) }
$$

\section{Equation 4.1 Maximum Degree of Hybridization}

where 
Degree of Hybridization = (hybrid electric power/total power $)$

\section{Equation 4.2 Degree of Hybridization}

and

$$
\text { Total Power }=(\text { hybrid electric power }+ \text { mechanical power })
$$

\section{Equation 4.3 Total Power}

with mechanical power in this case equal to the peak engine power.

\subsection{Performance Modeling Using AccelSim}

AccelSim is a forward looking vehicle simulation program written by the author for this work. Using a maximum engine output torque curve, conventional vehicle performance is modeled in an incremental iterative type method, calculating vehicle velocities and accelerations at a user defined frequency. Hybrid vehicles are modeled in a similar manner. Parallel and combination series-parallel type HEVs are considered in this exercise, as they have the greatest performance potential, and two types of parallel configuration have been studied, one with the motor driving through the transmission (pre-transmission), and one with the motor driving after the transmission (post-transmission). Both manual and automatic transmissions are modeled. AccelSim is written to be a modular program, and the basic operation is outlined below.

\subsubsection{Development and Validation of the AccelSim Model}

A vehicle and its physical characteristics are defined first, including mass, drag coefficient, frontal area, and final drive ratio. A transmission is then selected with specific gear ratios, and a specific vehicle layout, either parallel, series-parallel, or conventional. When an engine choice is made the maximum engine speed is specified, and the maximum engine power and torque profiles are modeled by a continuous function of engine speed. An attempt 
has been made to account for differing drivetrain and engine rotational inertias, and transmission efficiencies have been fixed.

There are several types of acceleration events that may be simulated. These events are 0-30mph, 0-60mph, 30-70mph, 50-80mph, 1/8mi top speed and elapsed time, 1/4 mi top speed and elapsed time, and terminal velocity measurements. With the knowledge of what vehicle type and event to simulate, the actual simulation routine is started. Variable time steps may be used, with a coarser step adding error to the simulation, and a smaller step resulting in increased computing time. For the purposes of this exercise, a time step of $0.01 \mathrm{sec}$ was chosen. The driving equations for AccelSim are outlined below.

The power lost in each step is calculated on an instantaneous basis using the road load equation. (Eq. 4.1.)

$$
\mathrm{P}_{\mathrm{L}}=.5 \rho \mathrm{CdAv}^{3}+\mu \mathrm{mgv}
$$

\section{Equation 4.4 Road Load Equation}

$$
\begin{aligned}
& P_{L}=\text { Power lost, in watts } \\
& \rho=\text { Density of air } \\
& \mathrm{Cd}=\text { Drag coefficient } \\
& \mathrm{A}=\text { Vehicle frontal area, in } \mathrm{m}^{2} \\
& \mu=\text { Tire rolling resistance } \\
& \mathrm{m}=\text { Vehicle mass, in kg } \\
& \mathrm{g}=\text { Acceleration of gravity } \\
& \mathrm{v}=\text { Instantaneous vehicle velocity, in } \mathrm{m} / \mathrm{sec}
\end{aligned}
$$


An initial engine speed is selected, which is utilized to determine a drivetrain torque output. Using this drivetrain torque output, and subtracting drivetrain losses and power required from the road load equation, a torque available for acceleration is acquired.

The main equation used in this step is shown below.

$$
\mathrm{TA}=(\mathrm{TE} \times \mathrm{TGR})-\left(\left(.5 \rho \mathrm{CdAv}^{3}+\mu \mathrm{mgv}\right) /(\mathrm{ES} \times(2 \pi / 60))\right)
$$

\section{Equation 4.5 Torque Available for Acceleration}

$\mathrm{TA}=$ Torque Available for Acceleration

$\mathrm{TE}=$ Torque Available from the powertrain

TGR $=$ Total Gear Ratio $=$ Gear Ratio $*$ Final Drive Ratio

ES = Engine Speed, Revolutions Per Minute

This torque is used to evaluate a force available to propel the vehicle, and the resulting vehicle acceleration is calculated from the fundamental equation

$$
\mathrm{F}=\mathrm{ma}
$$

\section{Equation 4.6 Newton's Second Law}

$$
\begin{aligned}
& \mathrm{F}=\text { Calculated force } \\
& \mathrm{m}=\text { the vehicle mass } \\
& \mathrm{a}=\text { the resulting acceleration }
\end{aligned}
$$

At a later date this will also reflect the effect of wheelspin, but at this time these effects are neglected. Using this acceleration value, a distance and a resulting velocity are derived at each time step. The acceleration results in a new vehicle speed, which is then used to derive a 
resultant engine speed for calculation of the next step torque and power values. These equations are used in both the conventional and the pre-transmission hybrid configurations, with the motor torque available added to the engine torque in the hybrid case. In the posttransmission hybrid case, the motor is assumed to continue driving the vehicle through the transmission gear changes. It also effects the torque available as the total gearing ratio for the motor will differ from that of the engine. To demonstrate the method by which engine torque is calculated, a plot of an engine maximum power curve and its modeling function are shown below, in Figure 4.2. An engine speed (ES) in RPM is used in the polynomial, and a resulting engine power $(\mathrm{Po})$ in $\mathrm{kW}$ is calculated for use.

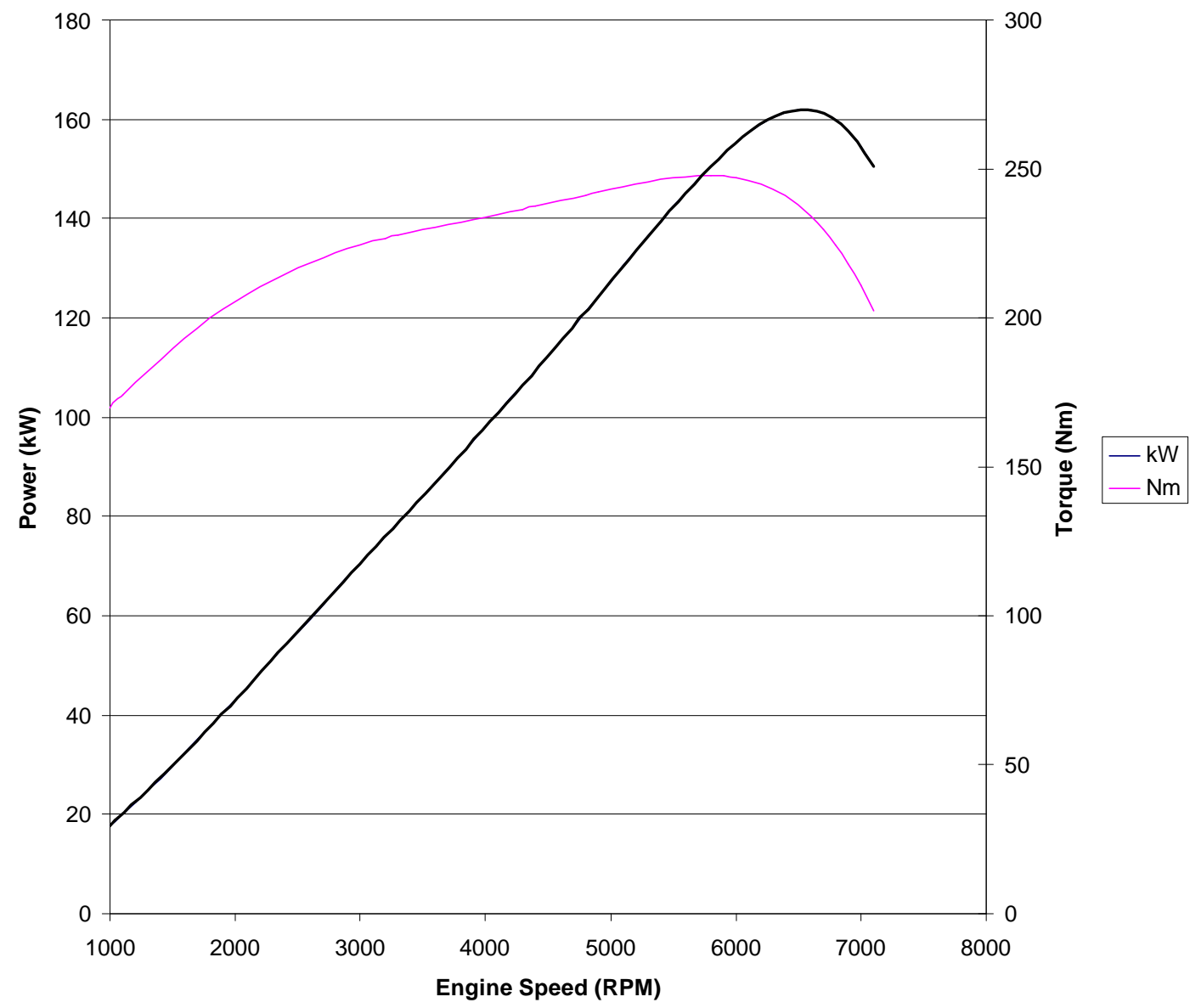

Figure 4.2. Engine Output Curves, 162kW 4-cylinder Engine. Curves are Synthesized from Existing Engine Output Profiles. 


\subsubsection{Component Sizing Using AccelSim}

AccelSim is used to size vehicle components to match the modeled vehicle's specific dynamic performance requirements. Gearing, final drive ratio, motor output, and engine output can be changed, and the results viewed in a process of optimization and selection. Based on AccelSim results minimum theoretical engine outputs are found, for a given vehicle mass, drag etc. Vehicle specifics are shown below, with minimum continuous power requirements. Vehicle mass was calculated from the original baseline value, a lightweighting consideration based on available practices and technology, and then the addition of the hybrid system. The current trend is toward weight reduction, even for conventional vehicles, to gain the accompanying fuel efficiency benefits. Each vehicle is assumed to be capable of a $15 \%$ weight reduction over stock as the lightweighting step to show the difference between today's conventional vehicle and tomorrows hybrids, and other masses are taken from industry sources and practical knowledge. Table 4.1. shows the steps used to estimate vehicle mass.

Table 4.1. Vehicle mass estimation.

\begin{tabular}{|c|c|c|c|c|}
\hline & Exotic & Sport Sedan & Sport Coupe & Sport Compact Car \\
\hline Weight (lb.) & 3483 & 3843 & 3118 & 2737 \\
\hline Mass (kg) & 1580 & 1743 & 1415 & 1242 \\
\hline -15\% Mass (kg) & 1358 & 1499 & 1216 & 1067 \\
\hline Energy Storage Mass (kg) & 300 & 300 & 300 & 300 \\
\hline Motor Mass $(\mathrm{kg})$ & 54 & 54 & 54 & 54 \\
\hline Misc. Mass $(\mathrm{kg})$ & 35 & 35 & 35 & 35 \\
\hline Total Mass $(\mathrm{kg})$ & 1747 & 1887 & 1605 & 1456 \\
\hline
\end{tabular}

Other vehicle parameters, such as drag coefficient and frontal area, are based on averages for each vehicle type, and a maximum continuous power output is found to meet the maximum speed requirement. Using this value the engine output is dictated. 
Table 4.2. Continuous Power Requirements

\begin{tabular}{|c|c|c|c|c|c|}
\hline & Mass $(\mathrm{kg})$ & $\mathrm{Cd}$ & $\mathrm{A}\left(\mathrm{m}^{2}\right)$ & $\mu$ & Power Req. $(\mathrm{kW})$ \\
\hline Sport Compact Car & 1456 & 0.27 & 2.36 & 0.008 & 98.67 \\
\hline Sport Coupe & 1605 & 0.34 & 2.50 & 0.008 & 162.05 \\
\hline Sport Sedan & 1887 & 0.36 & 2.52 & 0.008 & 190.44 \\
\hline Exotic & 1747 & 0.33 & 2.55 & 0.008 & 272.62 \\
\hline
\end{tabular}

\subsection{Efficiency Modeling Using HVSim}

West Virginia University has developed its own in-house vehicle simulation program,

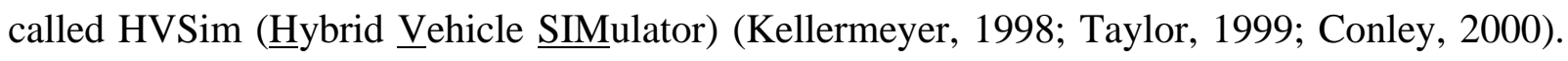
HVSim has been developed and used extensively in hybrid vehicle research at WVU, and has been used to select components and model the hybrid vehicles that WVU has produced for the FutureCar and FutureTruck competitions over the past several years. HVSim is a Matlabbased simulation that uses a backward directed approach to vehicle modeling. HVSim calculates the fuel efficiency of a vehicle over a driving cycle by utilizing the instantaneous power requirement at the wheels, efficiencies of the user-defined drivetrain components in the vehicle, and vehicle constants such as mass, frontal area, rolling resistance and drag. This can be integrated to give true cycle-averaged fuel consumption results for the pre-specified vehicle. HVSim can also be used to evaluate various control strategies for a hybrid or conventional vehicle. For the purposes of this exercise a new routine to model ultracapacitors as the energy storage device was written, and energy efficiency and consumption results shown in later sections are derived from this program.

\subsubsection{Development and Validation of the HVSim Model}

HVSim simulates a vehicle over any given driving cycle. The program is capable of simulating conventional, series hybrid, parallel hybrid, combination hybrid and electric vehicles. The modular program can also facilitate the addition of various systems including 
engine efficiency and emissions maps, transmission efficiency maps, electric motors, driving cycles, as well as control systems and strategies. The power requirements for the baseline vehicles were calculated for the EPA City (FTP), EPA Highway (HWFET), US06 and a custom high power demand track trace (TT). The custom track trace was taken from Toyota test data at the release of the current Celica model (Toyota, 1998). A speed-time plot of the track trace with a section of the FTP for comparison is shown in Figure 4.3.

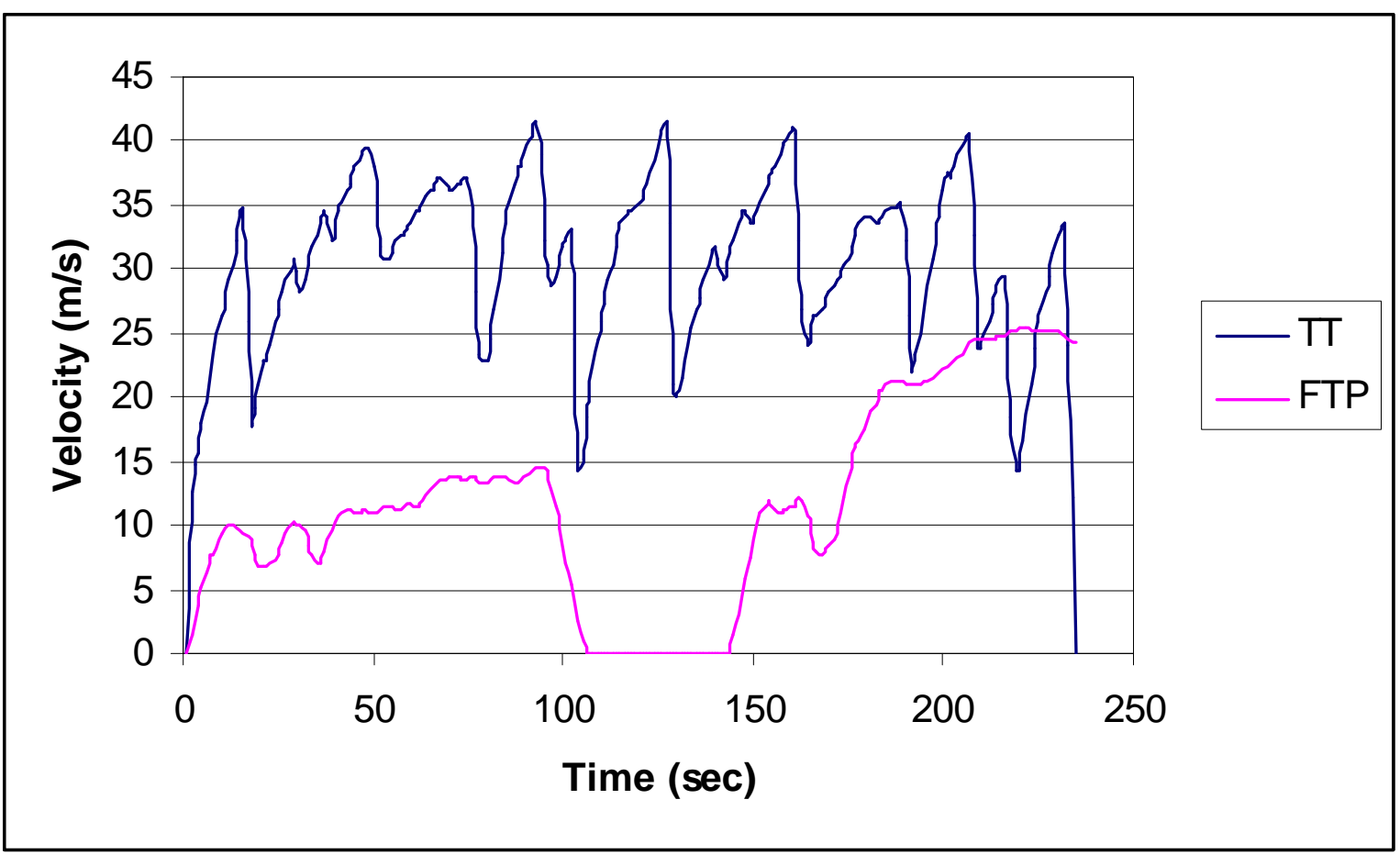

Figure 4.3. Speed-Time Plot, Track Trace, with Section of FTP for Comparison.

\subsubsection{Component Sizing Using HVSim}

After the physical properties of each class of vehicle have been established, elementary cycle modeling to determine the average and peak power requirements of each vehicle was performed. The vehicle physical characteristics are redisplayed in Table 4.3. 
Table 4.3. Modeled Vehicle Characteristics.

\begin{tabular}{|c|c|c|c|c|}
\hline & Mass $(\mathrm{kg})$ & $\mathrm{Cd}$ & $\mathrm{A}\left(\mathrm{m}^{2}\right)$ & $\mu$ \\
\hline Sport Compact Car & 1456 & 0.27 & 2.36 & 0.008 \\
\hline Sport Coupe & 1605 & 0.34 & 2.50 & 0.008 \\
\hline Sport Sedan & 1887 & 0.36 & 2.52 & 0.008 \\
\hline Exotic & 1747 & 0.33 & 2.55 & 0.008 \\
\hline
\end{tabular}

Peak and average power requirements, as well as engine peak power output from the continuous power requirement and a power difference are shown in the following tables for each vehicle. A positive difference in power indicates that the rated continuous engine output is sufficient to meet the trace alone, negative indicates the amount above maximum rated engine power that is required from the hybrid system. The average values shown are average positive power requirements for the cycle, and the maximum values are peak power requirements over the cycle. Continuous power is the maximum available continuously from the internal combustion engine alone.

Table 4.4. Sport Compact Car Power Requirements.

\begin{tabular}{|c|c|c|c|c|}
\cline { 2 - 5 } \multicolumn{1}{c|}{} & $\begin{array}{c}\text { Average } \\
\text { Power }(\mathrm{kW})\end{array}$ & $\begin{array}{c}\text { Maximum } \\
\text { Power }(\mathrm{kW})\end{array}$ & $\begin{array}{c}\text { Continuous } \\
\text { Power }(\mathrm{kW})\end{array}$ & $\begin{array}{c}\text { Difference } \\
(\mathrm{kW})\end{array}$ \\
\hline HWFET & 7.79 & 25.09 & 99 & 73.91 \\
\hline UDDS & 3.78 & 32.07 & 99 & 66.93 \\
\hline US06 & 12.75 & 73.13 & 99 & 25.87 \\
\hline Track & 54.82 & 168.73 & 99 & -69.73 \\
\hline
\end{tabular}

Table 4.5. Sport Coupe Power Requirements.

\begin{tabular}{|c|c|c|c|c|}
\cline { 2 - 5 } \multicolumn{1}{c|}{} & $\begin{array}{c}\text { Average } \\
\text { Power }(\mathrm{kW})\end{array}$ & $\begin{array}{c}\text { Maximum } \\
\text { Power }(\mathrm{kW})\end{array}$ & $\begin{array}{c}\text { Continuous } \\
\text { Power }(\mathrm{kW})\end{array}$ & $\begin{array}{c}\text { Difference } \\
(\mathrm{kW})\end{array}$ \\
\hline HWFET & 9.6 & 28.05 & 162 & 133.95 \\
\hline UDDS & 4.36 & 35.68 & 162 & 126.32 \\
\hline US06 & 15.43 & 81.4 & 162 & 80.6 \\
\hline Track & 63.29 & 193.57 & 162 & -31.57 \\
\hline
\end{tabular}


Table 4.6. Sport Sedan Power Requirements.

\begin{tabular}{|c|c|c|c|c|}
\cline { 2 - 5 } \multicolumn{1}{c|}{} & $\begin{array}{c}\text { Average } \\
\text { Power }(\mathrm{kW})\end{array}$ & $\begin{array}{c}\text { Maximum } \\
\text { Power }(\mathrm{kW})\end{array}$ & $\begin{array}{c}\text { Continuous } \\
\text { Power }(\mathrm{kW})\end{array}$ & $\begin{array}{c}\text { Difference } \\
(\mathrm{kW})\end{array}$ \\
\hline HWFET & 10.66 & 32.74 & 190 & 157.26 \\
\hline UDDS & 5.01 & 41.74 & 190 & 148.26 \\
\hline US06 & 17.28 & 95.22 & 190 & 94.78 \\
\hline Track & 72.5 & 222.73 & 190 & -32.73 \\
\hline
\end{tabular}

Table 4.7. Exotic Sports Car Power Requirements.

\begin{tabular}{|c|c|c|c|c|}
\cline { 2 - 5 } \multicolumn{1}{c|}{} & $\begin{array}{c}\text { Average } \\
\text { Power }(\mathrm{kW})\end{array}$ & $\begin{array}{c}\text { Maximum } \\
\text { Power }(\mathrm{kW})\end{array}$ & $\begin{array}{c}\text { Continuous } \\
\text { Power }(\mathrm{kW})\end{array}$ & $\begin{array}{c}\text { Difference } \\
(\mathrm{kW})\end{array}$ \\
\hline HWFET & 9.88 & 30.31 & 273 & 242.69 \\
\hline UDDS & 4.64 & 38.65 & 273 & 234.35 \\
\hline US06 & 16.017 & 88.16 & 273 & 184.84 \\
\hline Track & 67.19 & 206.32 & 273 & 66.68 \\
\hline
\end{tabular}

From these results it can be seen that for all regulatory cycles the ICE is sufficient to make the trace. However, in most cases the ICE is not sufficient to meet the demands posed by the aggressive track trace, as an example the sport compact concept will require a sizeable hybrid system of nearly $70 \mathrm{~kW}$ to even attempt to meet the trace. A second group of results were found indicating average and peak braking power values over each trace. The average is found by taking the average of all of the negative power requirements over the trace, thus providing an average for sizing of the energy storage system. The peak value is found by taking the maximum absolute value of the negative power requirements, and this value is used to help determine the peak power, and therefore current carrying ability of the electric drive and energy storage systems. 
Table 4.8. Sports Compact Car Peak and Average Regeneration Values.

\begin{tabular}{|c|c|c|c|c|}
\cline { 2 - 5 } \multicolumn{1}{c|}{} & $\begin{array}{c}\text { Average Braking } \\
\text { Power }(\mathrm{kW})\end{array}$ & $\begin{array}{c}\text { Max Braking } \\
\text { Power }(\mathrm{kW})\end{array}$ & $\begin{array}{c}\text { Peak Regenerative } \\
\text { Braking Rate }(\mathrm{kW})\end{array}$ & $\begin{array}{c}\text { Difference } \\
(\mathrm{kW})\end{array}$ \\
\hline HWFET & 0.88 & 34.98 & 75 & 40.02 \\
\hline UDDS & 1.73 & 26.12 & 75 & 48.88 \\
\hline US06 & 3.83 & 48.09 & 75 & 26.91 \\
\hline Track & 36 & 661.13 & 75 & -586.13 \\
\hline
\end{tabular}

Table 4.9. Sport Coupe Peak and Average Regeneration Values.

\begin{tabular}{|c|c|c|c|c|}
\cline { 2 - 5 } \multicolumn{1}{c|}{} & $\begin{array}{c}\text { Average Braking } \\
\text { Power }(\mathrm{kW})\end{array}$ & $\begin{array}{c}\text { Max Braking } \\
\text { Power }(\mathrm{kW})\end{array}$ & $\begin{array}{c}\text { Peak Regenerative } \\
\text { Braking Rate }(\mathrm{kW})\end{array}$ & $\begin{array}{c}\text { Difference } \\
(\mathrm{kW})\end{array}$ \\
\hline HWFET & 0.9 & 38.06 & 32 & -6.06 \\
\hline UDDS & 1.87 & 28.61 & 32 & 3.39 \\
\hline US06 & 4.03 & 52.79 & 32 & -20.79 \\
\hline Track & 39.03 & 724.75 & 32 & -692.75 \\
\hline
\end{tabular}

Table 4.10. Sport Sedan Peak and Average Regeneration Values.

\begin{tabular}{|c|c|c|c|c|}
\cline { 2 - 5 } \multicolumn{1}{c|}{} & $\begin{array}{c}\text { Average Braking } \\
\text { Power }(\mathrm{kW})\end{array}$ & $\begin{array}{c}\text { Max Braking } \\
\text { Power }(\mathrm{kW})\end{array}$ & $\begin{array}{c}\text { Peak Regenerative } \\
\text { Braking Rate }(\mathrm{kW})\end{array}$ & $\begin{array}{c}\text { Difference } \\
(\mathrm{kW})\end{array}$ \\
\hline HWFET & 1.1 & 45.06 & 53 & 7.94 \\
\hline UDDS & 2.22 & 33.75 & 53 & 19.25 \\
\hline US06 & 4.85 & 62.2 & 53 & -9.2 \\
\hline Track & 46.32 & 854.73 & 53 & -801.73 \\
\hline
\end{tabular}

Table 4.11. Exotic Sports Car Peak and Average Regeneration Values.

\begin{tabular}{|c|c|c|c|c|}
\cline { 2 - 5 } \multicolumn{1}{c|}{} & $\begin{array}{c}\text { Average Braking } \\
\text { Power }(\mathrm{kW})\end{array}$ & $\begin{array}{c}\text { Max Braking } \\
\text { Power }(\mathrm{kW})\end{array}$ & $\begin{array}{c}\text { Peak Regenerative } \\
\text { Braking Rate }(\mathrm{kW})\end{array}$ & $\begin{array}{c}\text { Difference } \\
(\mathrm{kW})\end{array}$ \\
\hline HWFET & 1.02 & 41.71 & 53 & 11.29 \\
\hline UDDS & 2.06 & 31.25 & 53 & 21.75 \\
\hline US06 & 4.49 & 57.58 & 53 & -4.58 \\
\hline Track & 42.87 & 791.24 & 53 & -738.24 \\
\hline
\end{tabular}

With these values in hand further analysis of the engine design, gearing selection, electrical energy storage sizing and electric traction drive system can proceed. 


\section{Performance and Efficiency Gains Through Vehicle Optimization}

Reductions in losses of the existing vehicle system can result in substantial gains in both performance and efficiency. The road load equation is shown below. $\mathrm{P}_{\mathrm{L}}$ is the power required from a prime mover to drive a vehicle at velocity $\mathrm{v}$ and acceleration $\mathrm{dv} / \mathrm{dt}$.

$$
\mathrm{P}_{\mathrm{L}}=\left(\mathrm{mvdv} / \mathrm{dt}+.5 \rho \mathrm{CdAv}{ }^{3}+\mu \mathrm{mgv}\right) /(\eta . \mathrm{eff})
$$

\section{Equation 5.1 Road Load Equation}

From this equation it can be seen that reductions in the mass, or in the combined $\mathrm{Cd}$ and A terms of the aerodynamic losses can lead to reductions in the power lost over a driving cycle. Also, improvements in the overall efficiency through reductions in system losses can lead to fuel efficiency improvements.

\subsection{Effect of Aerodynamics}

Aerodynamic drag has a substantial effect on vehicle performance and efficiency. The term of the road load equation relating aerodynamic drag to the power required to overcome it by the vehicle is shown below.

Power Required To Overcome Aerodynamic Drag at The Wheels $=.5 \rho \mathrm{CdAv}^{3}$

\section{Equation 5.2}

It can easily be seen that a reduction in the drag coefficient $(\mathrm{Cd})$ or the frontal area $(\mathrm{A})$ can allow for increased terminal velocity and performance for a given fixed power at the wheels and increased fuel efficiency by requiring less energy to be consumed while completing a given cycle. This also can allow for engine downsizing and an inherent increase in fuel efficiency. The largest limitations to reducing drag are vehicle packaging, and maintaining vehicle stability at higher speeds. 


\subsection{Effect of Vehicle Mass}

The numerous advantages of a lighter vehicle include enhanced acceleration performance, improved cornering and braking, as well as increased fuel efficiency, either through the downsizing of the engine or through less overall energy being required to drive the vehicle over a given cycle. In an attempt to realistically model the proposed vehicle layouts an estimation of the hybrid system's weight and a weight reduction step have been taken into account. The terms of the road load equation containing mass are shown below.

Power Required to Overcome Mass Related Losses $=\mu \mathrm{mgv}+\mathrm{mdv} / \mathrm{dt}$

\section{Equation 5.3}

The first term in this equation is the power required to overcome rolling resistance, and the second term is the power required to accelerate the vehicle mass, the inertial requirement.

\subsection{Effect of Accessory Losses}

A final area of improvement of a conventional vehicle in terms of both fuel efficiency and performance is through the reduction of accessory losses and internal losses. Internal losses in the valvetrain, engine inertial losses, and frictional losses in the engine, transmission and driveline contribute to reduced efficiency. Other accessories that require power to operate include air injection devices, and high-pressure injection pumps. Power steering pumps, airconditioning compressors and alternators are all belt-driven devices that rob energy from the output of the engine. The largest drawback to these devices is that they consume the most power at the point the engine is least able to deal with the demand efficiently; typically at very low speed, such as when parking or idling in traffic. By converting these devices to electrically powered devices an efficiency gain may be found. Also, the engine alternator operates in this same manner, optimized to operate over a wide range of engine speeds. By using solid state

DC/DC converters, the high voltage battery pack of a hybrid may be used to help charge the 
low voltage $(12 \mathrm{~V})$ system, at much higher overall efficiency than an engine driven alternator. A further advance in this area is the introduction of $42 \mathrm{~V}$ automotive electrical systems. The benefits of the $42 \mathrm{~V}$ systems are widespread. They allow the use of smaller and lighter components to deliver an equivalent power output by reducing the current load. They also allow for more aggressive use of electrical components like the ones mentioned above. Also, the use of starter-alternator-flywheel systems becomes viable with the use of the higher voltage system. This system allows for a substantial reduction in fuel consumption by eliminating engine idling when the vehicle is stopped. 


\section{Engine Configuration and Design}

As was mentioned in section 1.2, practically all of the energy used by a hybrid comes the on-board fuel - hence the efficiency of the fuel conversion device (the engine) is of the greatest importance in HEV design. This section reviews available engine technologies and design for the purposes of simulation.

\subsection{Introduction}

Current engine designs incorporate a great number of technologies to meet the requirements of their chosen role. The strictest limitations on engine design come from the regulation of both exhaust emissions and the fuel efficiency standards set in the Corporate Average Fuel Economy (CAFE) standards. The ways that automakers meet these requirements are often very complex, involving exhaust aftertreatment, exhaust gas recirculation (EGR), and other internal methods to reduce the regulated emissions of hydrocarbons (HC), carbon monoxide (CO), particulate matter (PM) and oxides of nitrogen (NOx). The regimes of spark ignited engine operation that are most problematic for emissions compliance are cold start, primarily a $\mathrm{HC}$ and $\mathrm{CO}$ problem, high power hot operation when NOx becomes the primary pollutant, and at wide-open-throttle (WOT) when $\mathrm{HC}, \mathrm{CO}$, and even PM can be a problem. When the engine operates stoichiometrically then 3-way catalysis does an excellent job of reducing these emissions. In primarily lean-burn type operation, both in gasoline direct injection engines (GDI) and diesel engines, NOx is the problem. When constructing an engine to meet the needs of the CAFE standards other measures are taken. In the case of higher performance engines the trend to 4 -valve per cylinder, high-output engines is obvious. These engines meet CAFE standards by either downsizing the engine and regaining the power through boosting, or by taking advantage of gearing to place the engines' operation in a more 
efficient regime. Engines are most efficient at high load and mid-speed ranges, where in SI engines the wider throttle opening can reduce throttling losses, and other losses in diesels are minimized. Figure 6.1. shows an engine efficiency map, indicating fractional engine efficiencies with contours $(0.3=30 \%$ efficiency $)$. A point to note is that the contours at the top of the map are artifacts of the software used to create the map, and are used to close the contours shown.

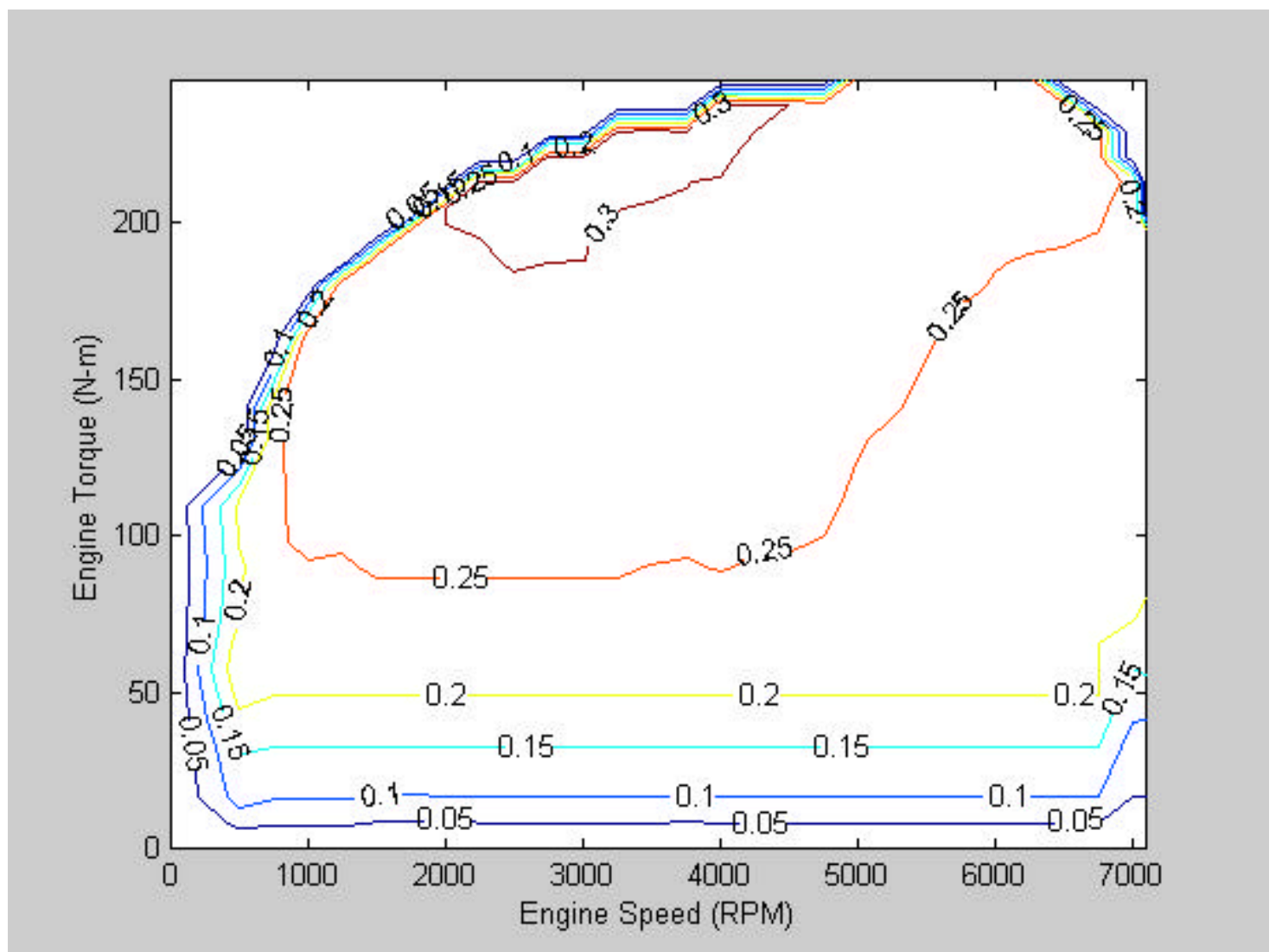

Figure 6.1. Efficiency Plot, 162kW 4-Cylinder Engine. Contours Indicate Fractional Engine Efficiencies relative to Torque and Engine Speed.

\subsection{Engine Performance Requirements}

In engine design the only immediately regulated constraints are emissions and fuel economy, but as each parameter of an engine's design is fixed it may limit or dictate others. There are limits on compression ratio, rotating inertia, engine speed, and air-fuel ratio for 
emissions concerns. The cylinder surface area to volume ratio also effects total thermal efficiency of the engine as well as the engine's power density. There is an upper limit to volumetric efficiency, either due to the maximum flow of air available in naturally-aspirated engines, or structurally in boosted engines.

\subsection{Basic Engine Layout}

Engine layout is often dictated by concerns separate from the engine itself. Packaging and space concerns often dictate engine physical size and layout, whether a compact V-type engine, a flat, H-type layout to place the engine lower in the vehicle to improve handling, or an inline configuration for balance and smoothness. After a choice is made for the maximum physical space of the engine then actual internal design can be undertaken. Issues of application, durability, and in the modern manufacturing industry, modularity are then examined, and then modeling and design work can be initiated. There is a myriad of issues surrounding an engine design, but after some areas are specified then others become fixed.

Figure 6.2. illustrates the interconnectivity of many of the parameters that must be specified in engine design. Figure 6.2. will be referenced again, in later sections and in the final choice of parameters for the engine designs undertaken for this work. The following sections will address other advanced technology choices for use in current and future engine applications to justify the engine designs chosen. 


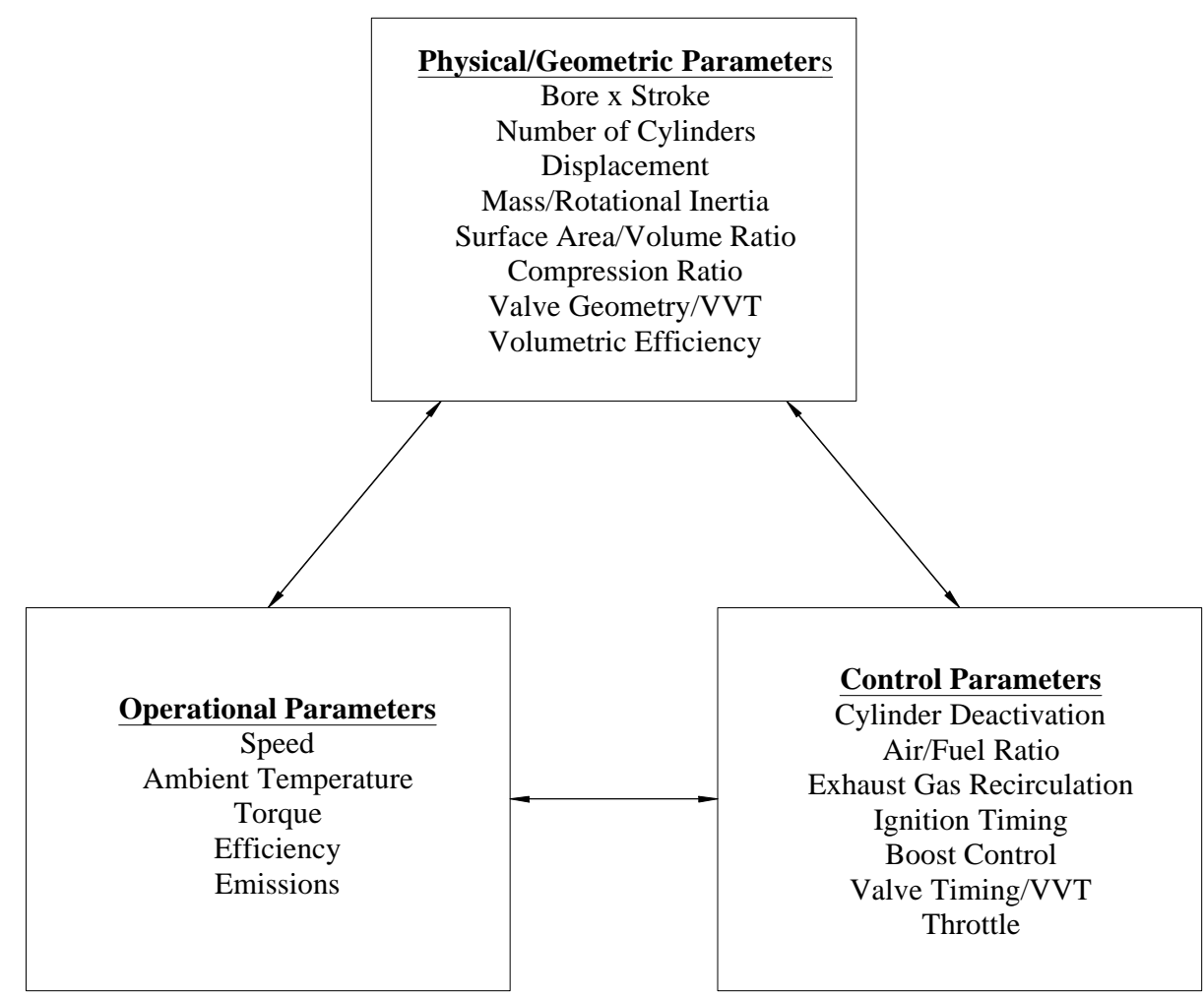

Figure 6.2. Engine Design Flowchart, As Various Parameters are Fixed Other Become

\section{More Defined}

\subsection{Variable Intake Manifold}

Variable intake manifold systems allow for optimization of engine tuning at more than one engine operating speed, which is of interest to all SI engines with their more transient engine operation. Through resonance supercharging effects the volumetric efficiency of the engine can be increased at these engine-operating points, typically a very high and a very low engine speed. Equation 6.1 is used to determine the resonant frequencies at which supercharging effects occur in a multicylinder engine. A schematic is shown in Figure 6.3. 


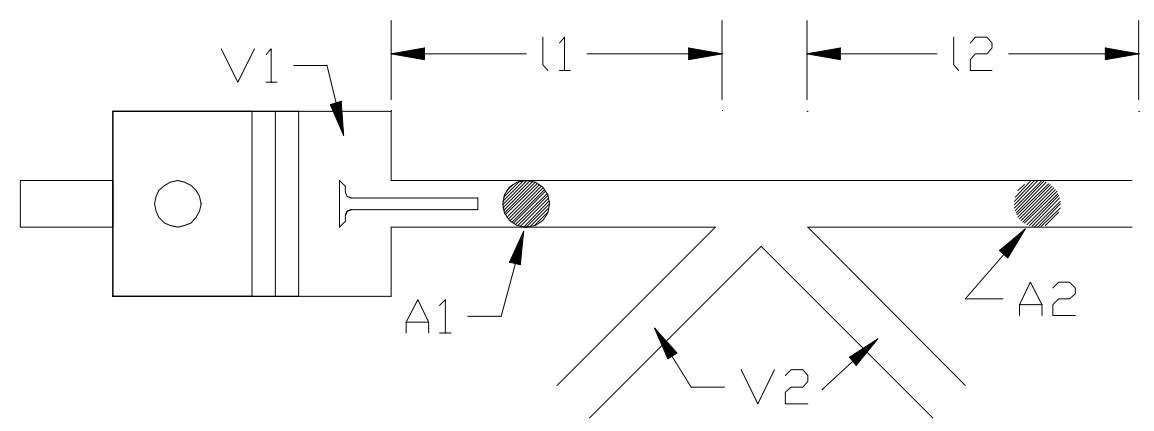

Figure 6.3. Multicylinder Engine Intake Design

$$
\mathrm{f} \mp=a / 2 \pi\left\{(\alpha \beta+\alpha+1) \mp\left[(\alpha \beta+\alpha+1)^{2}-4 \alpha \beta\right]^{1 / 2}\right\} /\left(2 \alpha \beta \mathrm{L}_{1} \mathrm{C}_{1}\right)
$$

Equation 6.1

Where $a$ is the speed of sound $(\mathrm{m} / \mathrm{s}), \alpha=\mathrm{L}_{2} / \mathrm{L}_{1}, \beta=\mathrm{C}_{2} / \mathrm{C}_{1}, \mathrm{C}_{1}=\mathrm{V}_{1}, \mathrm{C}_{2}=\mathrm{V}_{2}, \mathrm{~L}_{1}=$ $(1 / A)_{2}$, and $V_{\text {eff }}=V_{1}$. This is a reasonably accurate predictive model, and uses the following assumptions: flow in the manifold is one dimensional and no axial heat transfer occurs; states in the engine cylinders and manifold are uniform in space; boundary conditions are steady; coefficients of discharge, heat transfer, pipe friction, and bend losses for steady flow are valid for unsteady flow; and the working gas can be modeled as an ideal gas.

The benefits of this design from an efficiency standpoint are limited to the ability to downsize the engine due to increased output. Designs for a fully variable intake system have been undertaken, but currently none are in use on a production engine (Heywood, 1988).

\subsection{Variable Valve Control}

Variable valve control has been and continues to be a popular means to effect many engine operating characteristics. Variable Valve Timing (VVT) is intended to favorably effect the thermal and fluid processes within the cylinder by changing the relationship between flows and swept volume. The result is to reduce pumping losses and to improve intake charge 
properties in SI, homogenous charge engines. Also in the improvement of breathing and other charge fluid processes an increase in the speed range of the engine is found (Asmus, 2000).

More specifically, the optimum valve lift and cam phasing fall generally in the following engine speed regimes:

- At idle, combustion stability, lower throttling losses, and lower idle speed fluctuation are the primary concerns, which are addressed by minimizing valve overlap with low lift and early intake valve closing

- At low engine speed increased low speed torque is desired, which is achieved with early intake valve closing and high lift; this prevents the back flow of the intake charge from the cylinder to the manifold

- At high engine speed the performance object is greater peak power, which is reached by late intake valve closing and high lift, the effect of this is to utilize the inertia of the high speed intake charge to after-charge the cylinder even after the piston has reached bottom dead center.

Variable cam phasing can be an economic answer for varying valve timing, and is used in several current production engines. With these objectives identified some of the various variable valve control schemes will be examined in further detail (Atkinson and Yacoub, 1998).

\subsubsection{Early Intake Valve Closing}

Early intake valve closing (EIVC) can provide many benefits, including higher efficiency, reduced emissions and increased part load performance. Higher efficiency through EIVC is obtained through several effects aimed at reducing pumping losses: 
- Early closing of the intake valve reduces the effective compression ratio while keeping the geometric expansion ratio constant, known as overexpansion or Atkinson cycling,

- EIVC results in lower compression temperature, and thus lower peak cylinder gas temperature. This lower in-cylinder temperature results in higher knock resistance and lower NOx emissions

- Enhanced knock resistance permits higher degrees of spark advancement to achieve higher thermal efficiency.

However, it should be noted that EIVC also has its drawbacks:

- At idle the intake valve is open for a sufficiently short time as to have a negative effect on combustion stability due to charge rarification and the adverse effects on flame propagation

- As engine speed increases the pumping loss benefits of this arrangement decline due to throttling at the intake valve

- In the case of fixed EIVC specific power is lower compared to a base engine, due to lower trapped charge mass for the same volume, to some extent these effects can be overcome with pressure boosting, or Miller cycling (Atkinson and Yacoub, 1998; Asmus, 2000).

\subsubsection{Late Exhaust Valve Closing}

Late exhaust valve closing (LEVC) can achieve many of the benefits found with EIVC. The same benefits of overexpansion can be found, however peak in cylinder gas temperatures are expected to be higher for an LEVC configuration compared to an EIVC setup. A further benefit of LEVC is the implementation of internal EGR. LEVC has different combustion stability issues compared to EIVC, namely ignition limits and timing limits related to onset of knock (Atkinson and Yacoub, 1998; Asmus, 2000). 


\subsubsection{Separate Profile Systems}

These systems utilize wholly separate cam profiles depending on the engines operation. Traditionally this has been a profile that is optimized for efficiency at low speed, and a separate profile that is optimized for high-output at high engine speed. There are several of these systems in use currently in the market, including systems by Honda, Toyota, BMW and Porsche (VTEC, VVTL-i, VANOS, VarioCam). Other combinations have been used, notably a profile that is efficient at low speed, and another that is also tuned for efficiency at high speed (Honda Insight, Toyota Prius). The drawbacks to these systems are added complexity, and added friction at higher speeds due to moving parts. Durability has also been a question, but the VTEC system has shown excellent reliability (Otobe et al., 2000; Shikada et al., 2000; Flierl and Kluting, 2001; Porsche, 2001).

\subsubsection{Full Authority Systems, Camless Valve Systems}

A higher degree of valve control flexibility drives interest in camless valve actuation. The benefits that can be realized from this type of operation are those of traditional VVT plus enabling and simplifying other techniques such as cylinder deactivation and variable apparent compression ratio, among others. Pumping loss reductions and other fluid based efficiency gains can be realized with the wide range of intake and exhaust valve timing. The most fundamental problems with these systems are complexity and power demand, as early versions of these systems can consume as much as $20 \mathrm{~kW}$ in regular operation. A further problem is control of valve speeds, especially of the seating events to prevent premature valve seat wear. At this time there are no commercial applications of electromagnetic/electronic valve timing systems (Pischinger et al., 2000; Navistar, 2000). 


\subsection{Cylinder Deactivation}

Cylinder deactivation is primarily a fuel efficiency enhancing technique that can offer substantial benefit. Most cylinder deactivation schemes fall into one of two categories, bank deactivation or skip-fire strategies. Engine operation on half the cylinders during idle and light load and power demands can yield significant fuel economy improvements, both from the smaller apparent displacement of the engine and the reduction of throttling losses by working the active portion in a more efficient manner. Vehicles most likely to see dramatic improvements in economy are light duty trucks and other vehicles with larger displacement engines. Beyond the obvious integration hurdles that must be overcome in this application there are other concerns. In automatic transmission equipped vehicles the efficiency gain from the deactivated cylinders may be offset by losses incurred in the transmission, as a result of inability to lock the torque converter. Another concern is emissions issues due to one side of the engine becoming cold, in effect adding a new set of "cold-start" emissions whenever the bank is re-activated. In skip-fire operation the combustion event in some cylinders is skipped to reduce the apparent displacement of the engine. Many of the same mechanical implementation concerns that are present in bank deactivation are present in skip-fire schemes as well. One benefit of this application when compared to bank strategies is that individual cylinders are deactivated one at a time, keeping all cylinders warm. Some of the limitations in this application are higher control complexity, and increased vibration and harshness problems due to higher pulsating power inputs (Asmus, 2000; Heywood, 1988; Atkinson and Yacoub, 1998). 


\subsection{Saab Variable Compression}

The Saab SVC is a new, innovative design, with the upper section of the engine physically moving to vary the $\mathrm{CR}$. This alters the volume of the combustion chamber with the piston at top dead center. To achieve this, the monohead is pivoted at the crankcase via a hydraulic actuator moving through a maximum of $4^{\circ}$. The CR can be varied between $8: 1$ and 14:1 automatically. To increase the CR, the slope of the monohead is reduced. The volume of the combustion chamber will then decrease and the CR will increase. Saab's variable compression mono-block design is the only design that changes the mechanical compression ratio of the engine continuously during operation. The Saab SVC (Saab Variable Compression) engine is constructed using an upper section containing the cylinder head with integrated cylinders and a lower section consisting of the engine block, crankcase, and pistons. The compression ratio of the engine is varied by adjusting the slope of the upper section relative to the lower section, allowing compression ratios to be varied between $8: 1$ and 14:1. Combined with a supercharger this allows highly efficient un-boosted operation at the higher $\mathrm{CR}$ and high power operation with the supercharger active and the CR lower to prevent detonation. The Saab SVC is not currently in production, and as such questions of complexity, control, and reliability are unanswered (Automotive Engineering, SAE, 2000).

\subsection{Boosting}

The most apparent benefit of pressure boosting, either by supercharging or turbocharging is the increase in power density for the engine. From this a fuel economy benefit can be realized if the increase in power density leads to engine downsizing and the vehicles' expected operating regime is carefully examined. If techniques to control knock, such as enrichment, retarded timing, and compression ratio reductions are carefully applied the 
net gain in efficiency for a boosted engine can be sizeable. There are tradeoffs in durability, cost, and internal engine stress limits as well. Other possible gains can be realized by using VVT in combination with boosting (Miller cycling), where the effect of increasing the apparent expansion ration is amplified by boosting the intake charge. Turbocharging is the most efficient way to pressure boost the engine by recovering energy that otherwise would have been lost through the exhaust. However turbocharging leads to acceleration "lag" due to the rotational inertia of the turbocharger. Supercharging eliminates the lag issues, but is more inefficient as mechanical power is drawn from the engine to drive the compressor.

\subsection{Gasoline Direct Injection}

Gasoline Direct Injection (GDI) technologies are currently in production and are available in several mass markets. The majority of these applications employ lean burn stratified combustion for superior fuel efficiency at light load and stoichiometric homogenous charge combustion at high load. Significant fuel efficiency gains can be reached with this technology, although somewhat dependent on the application and drive cycle. The primary drawback with this type system is the inability to utilize traditional three-way catalysis in lean burn operation and the accompanying increase in NOx emissions over stoichiometric operation with three-way catalysis. A second application of these technologies is toward early injection homogenous charge GDI with the intent of reducing cold start emissions, increased power density and a small fuel economy benefit, primarily from aggressive fuel management strategies. A benefit of this method is that it does not face the lean NOx emissions challenges faced by stratified charge GDI applications. 


\subsection{Diesel}

Recent advances in the area of low displacement high-speed diesel engines have made them viable, and even preferable in passenger cars in some markets, as seen by the $30 \%$ average market penetration in Europe. When compared to SI engines, CI engines offer many advantages in terms of fuel economy and performance, but have many obstacles to overcome in the American market. Foremost from a regulatory standpoint are emissions issues, principally NOx. While aftertreatment, fuels, and engine controls research are making strides towards overcoming these problems, currently available options for diesel emissions treatment and reduction are limited at best. Consumer acceptability in the US is also somewhat restricting market penetration by the newest generation of diesel engines. With this said, high speed, direct-injection, turbocharged and intercooled diesels are an increasingly attractive option for use in light duty passenger vehicles, and advances in driveability and controls are making them more attractive to consumers. Modern CIDI engines are approaching the power densities of SI engines, however tuning for highly transient driving schedules imposes further emissions challenges. 


\section{Transmission}

All modern automobiles, whether conventional or hybrid, utilize a transmission of some type to effect the torque transmitted to the wheels during operation. Most current vehicles use some form of multi-speed transmission, although designs for infinite ratio transmissions exist and are used in some applications. The transmission is one of two mediums through which the driver can interact with the drivetrain of the automobile, the other being the accelerator pedal. As such the selection of a suitable transmission for a vehicle is crucial. In most modern vehicles the automatic transmission is the most common, except in economy or performance cars. This trend can be attributed to the ease of use, and congestion in urban areas. A second transmission option for easy use and automatic-like appearance is the continuously variable transmission (CVT) that offers continuous operation without shifting. The final type of transmission is the traditional manual transmission. In the design and marketing of a high-performance type vehicle the option of a manual transmission is of high priority for enthusiast use, both in the added flexibility it gives the driver, and in a measure of "street-credibility"; that the car is not a true sports vehicle unless a manual transmission is offered. Over time the number of ratios in transmissions has increased, from 3 and 4 speed transmissions in the past up to 5, 6, and even 7 speed transmissions today. The logic in this is that more ratios allow greater flexibility and the ability to operate the engine in a more efficient regime. This is also a driving force behind CVT research, as they have effectively infinite ratios.

\subsection{Manual Transmissions}

Manual transmissions are the oldest and least complicated design of power transmission available. Manual transmissions require a higher degree of driver skill and input 
for proper control and operation, including the use of a clutch for shifting and launching the vehicle. Automotive manual transmissions use a linear combination of a clutch and a series of directly geared combinations to allow different output speeds for the same input speed. Typical light duty automotive manual transmissions are synchronized. In a synchronized manual transmission a synchronizer is coupled to each gear that allows the operator to disengage the clutch and select whatever gear is necessary. The selection of a different gear engages the synchronizer, which matches the engine input speed to the transmission output speed before the gears are engaged. Unsynchronized manual transmissions are more durable than synchronized transmissions, but are generally used in heavy-duty applications and are more difficult to operate. Manual transmissions are highly efficient due to their direct mechanical coupling; manual transmission efficiencies can reach the 92-99\% range (Kluger, 1999).

\subsection{Automatic Transmissions}

Automatic transmissions are complex devices allowing for the seamless transmission of power, with little driver interaction. The driver requires only one input to the drivetrain, the accelerator pedal position. Automatic transmissions are popular for this reason in that little additional skill is needed to launch and operate the vehicle. Currently available production automatic transmissions use torque converters, clutches, and planetary gear sets for the selection of different output ratios. The engine is connected to a torque converter that acts as the clutch in some conditions and more as a direct connection in others. A torque converter is a hydraulic coupling that will slip under light load and engage under progressively higher load. The torque converter also provides a speed reduction during low speed operation. At higher vehicle speeds the torque converter is locked to achieve a direct drive connection. The output of the torque converter is connected to a hydraulic pump that provides the pressure needed to 
engage different clutches in the transmission. Different gear ratios are created through the use of planetary gearsets. By engaging and disengaging different gearsets multiple gear ratios are possible.

Traditional automatic transmissions are equipped with only one control input, from the accelerator pedal position. This along with the internal hydraulic control in the transmission is all that is needed for operation. Modern automatic transmissions are equipped with more complex electronic feedback controls. Shifting is controlled by such variables as engine speed, temperature, and throttle position. Newer control systems integrate the engine and the transmission control so that both are governed simultaneously for purposes of improved shift control, traction control, and others. The primary drawback of the automatic transmission from an efficiency standpoint is that the torque converter is a highly inefficient device, with

maximum non-locked efficiencies in the $75 \%$ range, and efficiencies in parts of the operating envelope as low as $50 \%$ are not uncommon. A further drawback in automatic transmissions for use in a sports type vehicle is the removal of one level of driver control and input (Anderson, 2000).

\subsection{Continuously Variable Transmissions}

One of the most researched areas in automotive transmissions in the last several years is the continuously variable transmission (CVT). A CVT allows power transmission over a set operating range with infinitely variable gear ratios within this range. A CVT is constructed using two variable diameter pulleys with a belt connecting the two. By locating one stationary sheave and a mobile sheave on each shaft the pulleys can change size relative to each other, allowing for the change in ratios. In most automotive applications a hydraulic actuator controls movement of the sheaves. The belt is constructed of flexible metal. The benefits of the CVT design are the ability to operate the engine in its most efficient manner, as well as 
providing automatic transmission type operation to the driver. Efficiency of the CVT itself is limited, however. CVT efficiency is directly related to the tension in the belt. CVT torque carrying capacity increases with increased tension in the belt, but efficiency lowers with higher belt tension. The sliding of the belt across the faces of the sheaves creates frictional losses within the system. In addition losses associated with the high hydraulic pressures needed to actuate the sheaves may be encountered (Anderson, 2000).

\subsection{Automatically Shifted Manual Transmissions}

A recent innovation is the automatically shifted manual transmission. The benefit of this type of transmission is that the inherent high efficiency of the manual is retained. These transmissions have normally been synchronized transmissions with the addition of automatic control of the clutch and gear selection. Electronic control is also utilized to decide when to shift. The automatic shifting is usually performed through the use of electro-hydraulic solenoids. A high-pressure pump supplies pressure to the solenoids to perform the shift and a hydraulic ram is used to engage and disengage the clutch. Other versions use unsynchronized transmissions with electronic control monitoring engine speed and output speed. When a gear change is requested the controller opens the clutch, matches the engine speed through the engine controller to the output speed, shifts the transmission, and then closes the clutch. In current production gearboxes the change can occur in less than 250msec (Ferrari, 1999) and in racing gearboxes these gear changes can be accomplished much faster. With shifts occurring this quickly, automatically shifted manual transmissions shift much faster than a human driver.

\subsection{Manually Shifted Automatic Transmissions}

Manually shifted automatic transmissions have been offered in many production vehicles in recent years. These transmissions use a variation of the control of the transmission. 
The driver is allowed to select either fully automatic of manual shifting modes. In the automatic mode the transmission functions identically to an automatic transmission. While in manual shift mode the transmission allows the driver complete authority over gear changes, provided the change will not damage the driveline. This type of operation is also normally calibrated to provide faster, firmer shifts. The biggest requirement, and most common shortcoming, in this type of transmission is that the shifts must be accomplished fast enough to give the driver a sense of fluidity with minimal jerk, and must perform as the driver intends.

\subsection{Planetary Transmissions}

Planetary gearsets are useful in that the combination of gears provides for a two degreeof-freedom system. A planetary gearset is comprised of a sun gear in the center, a ring gear, and planetary gear that contact both the ring and the sun gears. The carrier on which the planetary gears rotate controls the motion of the planetary gears. Inputs to the geartrain are the ring gear, sun gear, and the planet carrier. By setting the motion of any two of these components the third is fixed in relation to the other two. One planetary geartrain creates a fixed ratio between input and output. Changing the number of teeth on the ring and sun gears can alter this ratio. When combining more than one planetary geartrain at one time the control of movement of different elements can create a wide range of operation in terms of speeds, torque transfer, and rotation, allowing the transmission to operate in a manner similar to a continuously variable transmission (Tóth-Nagy, 2000). 


\section{Drive Configuration}

\subsection{Front Wheel Drive}

Front wheel drive (FWD) was used in its first modern type of application in the BMC Mini in 1959, and was first used in the US by Oldsmobile in 1966 (Mini, 1999; Automuseum 2001). Since that time it has become nearly universal in modern automobiles, with nearly $88 \%$ of new cars sold in North America in 1999 having the front wheel drive configuration. The primary benefit of the front wheel drive layout is the benefit of packaging. By removing the intrusion of the longitudinally mounted engine, transmission and driveshaft tunnel from the passenger compartment and placing it all in front of the driver a smaller overall vehicle can be constructed without compromising passenger comfort. Another potential benefit of this layout is that with the drive wheels also providing the steering force the primary handling trait is understeer, something desirable to most drivers. A further benefit of FWD is the severeweather ability of the vehicle. From the standpoint of hybridization a FWD configuration is not entirely desirable as packaging concerns for the hybrid systems become a driving issue; simply put, there is insufficient space to efficiently integrate a hybrid system in a FWD package (Wards Auto, 2000).

\subsection{Rear Wheel Drive}

Previously the exclusive drivetrain configuration, then falling out of favor after the gas crisis in the 1970's, rear-wheel drive is enjoying a renaissance as buyers, who see rear wheel drive vehicles as more stylish and purpose built, are increasing the market for this configuration. Rear wheel drive is known for providing a more fluid and more challenging, driving experience and recent advances in traction control and active handling have eliminated some of the traditional foul-weather concerns. In terms of sports cars, rear wheel drive is 
almost essential for street credibility and is associated with a more upscale vehicle. Hybridization is less challenging with a rear wheel drive vehicle, in that components can be arranged sequentially in the longitudinal layout, allowing use of all the underbody space for component packaging.

\subsection{All Wheel Drive}

All wheel drive (AWD) can be applied to both the longitudinal and transverse drivetrain layouts, with either a transfer case or a viscous coupling providing the torque split capability. AWD's strength lies in the stability and controllability it provides a vehicle in demanding road conditions, such as snow, rain, and on other loose surfaces. Hybridization of an AWD vehicle is potentially the easiest of the presented options, by integrating the hybrid system on one axle, and the conventional drive on the second axle, a design patented as the “through-the-road”, or TTR, hybrid system by DaimlerChrysler (DaimlerChrysler, 2000). Implementation of traction and stability control systems in TTR systems is a bit of a challenge in that governing the output of the two separate drive units or controlling ABS is much more difficult. Alternatively the hybrid system can be integrated as in either the FWD or RWD configurations, provided that the hybrid motive force is split through the same AWD power transmission device as a conventional vehicle. 


\section{Electric Drive and Energy Storage}

$\mathrm{HEVs}$ require some form of energy storage, typically in the form of some mechanical or electro-chemical battery. The primary purpose of these systems is the storage of regenerative braking energy. Desirable HEV battery attributes include a low self-discharge rate, high charge acceptance to maximize regenerative braking utilization, and long cycle life. No current battery technology has demonstrated an economically acceptable combination of power, weight, efficiency, and life cycle. A summary of the specifications of some of these devices is shown in Table 9.1. (Battery Technology, 2000; Michigan Technical University, 2000; OTT, 2000).

Table 9.1. Various Energy Storage Type Comparison

\begin{tabular}{|c|c|c|c|c|c|c|c|}
\hline Battery Type & $\begin{array}{c}\text { Energy } \\
\text { Density } \\
(\mathrm{Wh} / \mathrm{kg})\end{array}$ & $\begin{array}{c}\text { Power } \\
\text { Density } \\
(\mathrm{W} / \mathrm{kg})\end{array}$ & $\begin{array}{c}\text { Cycle } \\
\text { Life } \\
80 \% \text { DOD }\end{array}$ & $\begin{array}{c}\text { Product } \\
\text { Maturity }\end{array}$ & $\begin{array}{c}\text { Current } \\
\text { Cost } \\
\$ / \mathrm{kWh}\end{array}$ & $\begin{array}{c}\text { Future } \\
\text { Cost }\end{array}$ & $\begin{array}{c}\text { Environmental } \\
\text { Impact }\end{array}$ \\
\hline Advanced $\mathrm{PbA}$ & 35 & 412 & 500 & Production & 150 & 100 & Low w/Recycling \\
\hline NiMH & 80 & 220 & 600 & Production & 1000 & 200 & Low \\
\hline Lithium Ion & 100 & NA & 1200 & Prototype & NA & NA & Low \\
\hline Flywheel & 50 & 10000 & $1,000,000+$ & Prototype & NA & NA & Low \\
\hline Ultracapacitor & 12 & 2000 & $500,000+$ & Production & 34000 & NA & Low \\
\hline
\end{tabular}

\subsection{Electric Drive Systems}

Electric traction drive systems have evolved substantially in recent years, and now have become a viable option for automotive use. A primary technical advantage with electric drive systems is the inherent ability to recapture energy that would otherwise be lost in braking through regeneration. An electric powertrain can convert stored energy into motive work, and it can also reverse direction and convert vehicle motion (kinetic energy) back into energy stores through regenerative braking. The significance of regeneration becomes apparent when 
one considers that approximately 60 percent of the total energy spent in urban driving goes to overcoming the effects of inertia, and theoretically, up to half of this energy can be reclaimed on deceleration. Other technical advantages center on the mechanical simplicity electromechanical powertrain. In comparison to the internal combustion engine, an electric motor is a relatively simple and far more efficient machine. Moving parts consist primarily of the armature (DC motors) or rotor (AC motors) and bearings, and motoring efficiency is typically on the order of $70 \%$ to $85 \%$. In addition, electric motor torque characteristics are much more suited to the torque demand curve of a vehicle. A vehicle needs high torque at low speeds for acceleration, then demands less torque as cruising speed is approached. An electric motor develops maximum torque at low speed, then torque declines with speed, in contrast, an ICE develops very little torque at low speed, and must accelerate through most of its speed range before it can deliver maximum torque.

The mechanical simplicity of the electrical powertrain is somewhat offset by increased complexity on an electronic level. Electrical power is delivered to the wall outlet in the form of alternating current, and must be converted into direct current in order to charge the onboard electrical storage. In the case of DC motors, electricity from the battery must then be "chopped" into small bursts of variable duty cycle in order to control the speed and torque of the motor. With AC motors, the direct current from the battery must undergo complex power condition in order to deliver alternating current and provide control over motoring output. In recent years, however, electronic control technology has improved and costs and size have declined. With increased demand, the technology will continue to improve, and economies of scale will come into play.

The most popular of these choices for use in HEVs is the permanent magnet configuration, owing to its excellent output characteristics and high power density. While 
other systems have benefits in simplicity and durability, the permanent magnet type motor is the primary choice for use in this design (Riley, 2000).

\subsection{Batteries}

Electrochemical batteries are the most commonly used devices in hybrid vehicles to date, and are currently used in the two HEVs in mass production, the Toyota Prius and the Honda Insight. There are several types of batteries available for use in HEVs and the characteristics of some more promising types are detailed below.

\subsubsection{Nickel Metal Hydride Batteries}

Nickel metal hydride (NiMH) batteries are currently the most popular batteries for use in hybrid vehicle applications, and are currently used in both the Toyota Prius and the Honda Insight. The adoption of NiMH technologies for HEV applications has been a challenge due to the desire to provide the same performance at a much lower cost-per-unit energy when compared to other battery technologies. One of the primary causes of these limitations is the relative youth of NiMH technology, which was developed in the 1980's. The primary benefit of $\mathrm{NiMH}$ batteries is their relatively high specific power and energy characteristics when compared to other batteries, and the components are recyclable. The main challenges to NiMH technology are high cost, high self-discharge rates, the high temperature they create during charging, and the need to control hydrogen loss and their low cell efficiency.

\subsubsection{Lead Acid Batteries}

Lead-acid batteries are the forerunner technology, and are currently used in commercially available electric vehicles (EVs). The basis for selection is low cost, high reliability, and an established recycling infrastructure. However, problems including low 
energy density, poor cold temperature performance, and low cycle life remain an impediment. High power, bi-polar lead-acid batteries are being specifically developed for HEV applications.

\subsubsection{Lithium Ion Batteries}

Lithium batteries have the potential for achieving higher specific energy than lead acid and nickel metal hydride technologies. Lithium-based batteries also are strong candidates for HEV applications because of good power densities, good thermal characteristics, high cycle life, and high abuse tolerance. A further potential benefit is that lithium batteries can be produced with very light weight. The major drawback to these batteries is that they are still highly experimental for use in automotive applications, with first-run production not anticipated until 2005 or later (OTT, 2000).

\subsection{Ultracapacitors}

Ultracapacitors retain electrical energy by storing and separating unlike electrical charges. To use the energy stored a load is applied across the terminals of the ultracapacitor and it discharges. Ultracapacitors have evolved greatly over the past several years, and are only now beginning to become a viable energy storage option for use in an automotive type application. Ultracapacitors act like very high power, low energy batteries. Ultracapacitors are highly efficient energy storage devices, and have very high specific power compared to batteries. Ultracapacitors have virtually unlimited life - these devices have been tested to 500,000 cycles and experienced a less than $25 \%$ reduction in charge storage capacity. Ultracapacitors are, in theory, ideal devices for use in HEVs. The very high power density, light weight, virtually limitless life and almost instantaneous response make them perfect candidates to match the peak power requirements of an automotive application. The largest limitations to these devices are their reliability in an automotive environment, and safety issues 
regarding the potentially large amounts of energy that could be released in the event of accidental contact with the terminals (Maxwell Technologies, 1999).

\subsection{Flywheels}

Flywheels store energy mechanically in a high-speed rotating device. To store energy, the flywheel converts electrical energy to kinetic energy in the flywheel. To release the stored energy the flywheel is connected to a generator that converts the mechanical energy to electrical energy for use. Flywheels as energy storage devices are an old idea that has been renewed by advances in materials and by the need for a high efficiency device to store energy in an HEV application. Advances in composite material science have led to most of the current flywheel research, by allowing high-speed flywheels with relatively low mass and volume requirements. Flywheel batteries are very efficient energy storage devices, and have very high specific power compared to batteries. Flywheel batteries also have virtually unlimited life and are not effected by any number of deep discharge cycles, as long as mechanical failure of the rotor never occurs. Flywheels are currently used in a limited number of HEV applications, primarily in hybrid buses and in stationary power applications. The limitations to flywheel batteries are fairly extensive, however. The cost of manufacture of the high strength composite rotors is prohibitively expensive, and finally the safety concerns over the possible failure of a significantly high rotating mass at very high speeds has prevented this technology from being thoroughly exploited (Koeneman and McAdams, 1998).

\subsection{Fuel Cells}

Fuel cells are an area of great interest in the automotive community today. The complete automotive fuel cell power system incorporates a fuel cell stack, fuel cell auxiliaries such as air and water supplies, cooling and power control, fuel supply storage and reforming if 
necessary, and drivetrain in the form of an electric motor, controller and gear set. By far the most common type of fuel cell is the proton exchange membrane type. A fuel cell utilizes fuel and air directly to produce electricity, which is then stored in a suitable electrical energy storage device or immediately used by the vehicle. The reaction is analogous to an electrochemical battery, except the oxidant and reductant are continuously provided to the cell. Fuel cells use a refillable fuel supply to produce their energy.

A proton exchange membrane type fuel cell operates on the following principles:

- Hydrogen molecules give up electrons at the anode, forming hydrogen ions, a process facilitated by the use of a platinum catalyst

- Electrons travel to the cathode through a circuit, producing electrical work at the motor

- Hydrogen ions flow through the proton exchange membrane to the cathode, where they combine with oxygen molecules and electrons to form water.

This operation allows the use of hydrogen's natural tendency to form water through oxidation, producing electricity and useful work. The other benefit of this process is that no pollution is produced, and the only byproducts of the reaction are water and heat. The process reactions are shown below.

$$
\begin{gathered}
\text { Anode }: 2 \mathrm{H}_{2} \rightarrow 4 \mathrm{H}^{+}+4 e^{-} \\
\text {Cathode }: 4 e^{-}+4 \mathrm{H}^{+}+\mathrm{O}_{2} \rightarrow 2 \mathrm{H}_{2} \mathrm{O} \\
\text { Overall }: 2 \mathrm{H}_{2}+\mathrm{O}_{2} \rightarrow 2 \mathrm{H}_{2} \mathrm{O}
\end{gathered}
$$

The advantages of a fuel cell are numerous. The first is the potential for highly efficient operation. Fuel cells lose very little energy to friction because of the few moving parts. Also, little fuel energy is lost because of the relatively low reaction temperatures, unlike 
the high heat loss inherent to an internal combustion engine. A further benefit of these characteristics is very low emissions, which are a result of low temperature reaction and fuel selection when a reformer is used with hydrocarbon type fuels. In a reformer type fuel cell byproducts may include $\mathrm{CO}$ and $\mathrm{CO}_{2}$, as well as hydrocarbon emissions from the fuel system. These emissions are usually very low, especially in the case of $\mathrm{CO}$ and $\mathrm{CO}_{2}$, which poison the fuel cell reaction. In the case of a hydrogen-fueled cell, water is the only exhaust product. In order for fuels other than hydrogen to be utilized by fuel cells, they must be processed or reformed to provide a hydrogen-rich gas mixture. Catalysts are used to facilitate the chemical reactions. The two primary types of reformers being developed for transportation are steam reformers and partial oxidation reformers. Steam reformers have higher efficiency but partial oxidation reformers are simpler. Because current fuel cells require pure hydrogen to run effectively, impurities (primarily carbon monoxide) in the reformer product gas stream must be removed. This can be achieved with water-gas shift reactors, preferential oxidation reactors, or hydrogen separation membranes (DOE, 1999). The drawbacks of a fuel cell are sizable, given the experimental nature of the device.

To make fuel cells profitable for large scale production will require several developments. At this time fuel cells are large and heavy devices. Consequently, the specific power of fuel cells is less than half that of conventional petroleum fueled engines. The cost of manufacturing fuel cells is prohibitively high. Fuel cells are produced in low numbers and use exotic materials. The fuel distribution network for hydrogen is very limited. Other types of fuel cells use petroleum-based fuels as well as alcohol or ammonia, but hydrogen is the ideal fuel. Hydrogen is difficult to store due to its small atomic size, and must either be stored as a liquid at cryogenic temperature, or as a gas at very high pressures for use. The proton exchange membrane must be kept hydrated for the reaction to proceed, but if the membrane 
becomes "flooded" then the efficiency drops. Fuel cells may be pressurized in order to increase power density, but then a compressor, with its accompanying inefficiencies must be used. To maintain efficiency the fuel cell must be sized appropriately. A final limitation of most currently existing fuel cells is their lack of efficiency as higher specific power demands are met. In order to maintain the high efficiency of the fuel cell a larger cell must be used (DOE, 1999; Ballard, 2000).

\subsubsection{Direct Hydrogen Fuel Cells}

Fuel cells operate best on pure hydrogen, both from an efficiency standpoint because of the lack of a reforming system and from an operational standpoint in that the reaction does not "poison" and reduce the effectiveness of the stack. Storing hydrogen on board a fuel cell vehicle greatly simplifies the propulsion system design by not requiring on-board fuel processing. It also results in a more energy efficient system. Because hydrogen is normally a gas, a relatively large volume is required to contain enough energy to provide the same driving range as today's automobiles. Currently, two methods of storing hydrogen on board a vehicle are receiving the most attention, compressed gas in storage tanks at high pressure or liquid hydrogen in insulated storage tanks at low temperature and pressure. Other methods based on metal hydrides, solid adsorbents, and glass micro-spheres have potential advantages but are not as well developed. Hydrogen storage systems can be engineered to be as safe as the fuel systems in current automobiles (DOE, 1999; Ballard, 2000).

\subsubsection{Reformer Type Fuel Cells}

In order for fuels other than hydrogen to be utilized by fuel cells, they must be processed or reformed to provide a hydrogen-rich gas mixture. Catalysts are used to facilitate the chemical reactions. The two primary types of reformers being developed for transportation 
are steam reformers and partial oxidation reformers. Steam reformers have higher efficiency but partial oxidation reformers are simpler. Because current fuel cells require pure hydrogen to run effectively, impurities (primarily carbon monoxide) in the reformer product gas stream must be removed. This can be achieved with water-gas shift reactors, preferential oxidation reactors, or hydrogen separation membranes. Low-cost components are necessary for the system to be competitive Low-cost, high-volume manufacturing methods need to be developed Fuel processor technology need to be improved to meet vehicle cost, start-up, and transient response requirements (Gottesfeld et al., 1999).

\subsection{Combination Energy Storage Systems: Batteries and Ultracapacitors}

As hybrid technologies evolve the need for more advanced energy storage options becomes apparent. Of the technologies presented above, each has its own apparent substantial drawback. To overcome some of these disadvantages a "hybrid" energy storage pack/device would be desirable. An investigation of one such configuration proposed utilizing batteries and ultracapacitors in this type application is presented below.

The design of a combination battery and ultracapacitor stack for onboard energy storage in a hybrid vehicle is presented. The primary reason for choosing these two specific types of devices is to exploit the complementary strong points of each device. A battery pack has the advantage of high energy density, but is limited in the duration and intensity of regeneration and assist periods. Conversely a ultracapacitor stack has the advantage of very high power density compared to a comparably sized battery pack, allowing for aggressive regeneration and assist schedules, up to the limits or the electric traction device if other components are sized properly, such as connectors and wiring. A proposed design, component selection and control strategy for the electric traction drive system and energy storage system is outlined in a later section. 


\section{Hybrid Configuration and Component Selection}

\subsection{Hybrid Configuration}

After analysis of the proposed vehicles application, continuous and peak power requirements and with respect to the strengths and weaknesses of the various hybrid configurations a charge-sustaining parallel hybrid design was chosen. The overall layout of all designs was selected as a post-transmission parallel due to increases in overall system efficiency by eliminating losses in the transmission and also to simplify the integration of the hybrid system in a production type vehicle. The benefits of this configuration include the ability to significantly downsize the engine while relying on an aggressive hybrid strategy to meet the peak power requirements over an aggressive driving cycle. A design based on these requirements is also able to meet consumer desires for a vehicle with more than adequate dynamic performance. The selection and sizing of specific components is outlined in the following sections.

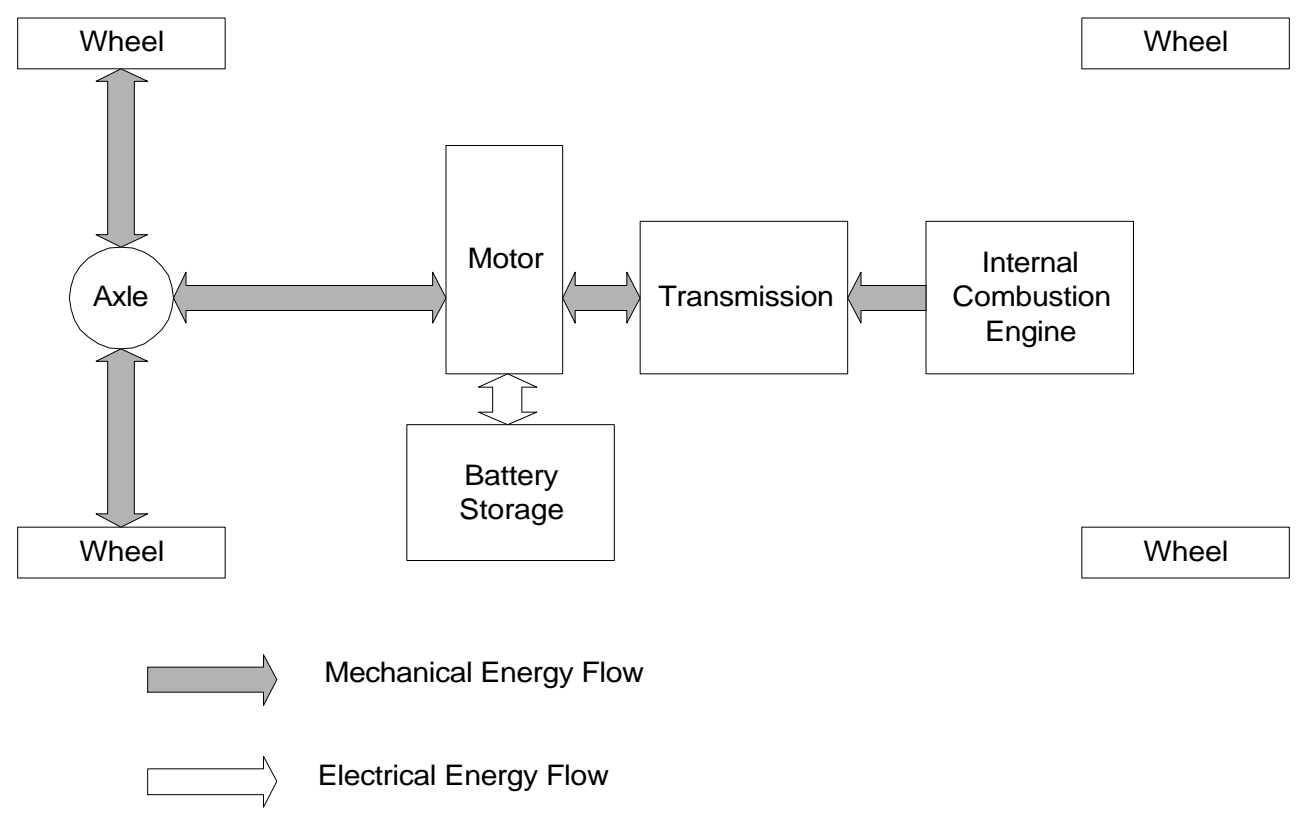

Figure 10.1. Post Transmission Parallel Layout Diagram 


\subsection{Component Selection}

After extensive modeling and simulation, components for use in the driveline can specified. An effort to either design components that are realistic in their simulated operation, or to employ existing off-the-shelf technologies was made in the selection of components. Tables summarizing the components used in each concept are shown below.

Table 10.1. Sport Compact Component Summary

\begin{tabular}{|l|l|l|}
\hline \multirow{3}{*}{ Engine } & Type & $\mathrm{L}-3 \mathrm{w} / \mathrm{VVT}$ \\
\cline { 2 - 3 } & Max Power/Speed & $99 \mathrm{~kW} / 6500 \mathrm{rpm}$ \\
\cline { 2 - 3 } & Max Torque/Speed & $152 \mathrm{Nm} / 5800 \mathrm{rpm}$ \\
\hline \multirow{3}{*}{ Mransmission } & Type & $6-$-speed manual \\
\cline { 2 - 3 } & Ratios & $3.34,2.15,1.55,1.20,0.93,0.83$ \\
\hline \multirow{3}{*}{ Electrical Storage } & Type & Brushless DC 400V \\
\cline { 2 - 3 } & Max Power/Speed & $75 \mathrm{~kW} / 8000 \mathrm{rpm}$ \\
\cline { 2 - 3 } & Max Torque/Speed & $240 \mathrm{Nm} / 0-3000 \mathrm{rpm}$ \\
\cline { 2 - 3 } & Type & Battery/Ultracapacitor \\
\cline { 2 - 3 } & Capacity & $4.5 \mathrm{kWh}$ \\
\hline
\end{tabular}

Table 10.2. Sport Coupe Component Summary

\begin{tabular}{|l|l|l|}
\hline \multirow{3}{*}{ Engine } & Type & $\mathrm{L}-4 \mathrm{w} / \mathrm{VVT}$ \\
\cline { 2 - 3 } & Max Power/Speed & $162 \mathrm{~kW} / 6500 \mathrm{rpm}$ \\
\cline { 2 - 3 } & Max Torque/Speed & $248 \mathrm{Nm} / 5800 \mathrm{rpm}$ \\
\hline \multirow{3}{*}{ Mransmission } & Type & 6-speed manual \\
\cline { 2 - 3 } & Ratios & $3.46,2.03,1.38,1.06,0.82,0.67$ \\
\hline \multirow{3}{*}{ Electrical Storage } & Type & Brushless DC 250V \\
\cline { 2 - 3 } & Max Power/Speed & $32 \mathrm{~kW} / 8000 \mathrm{rpm}$ \\
\cline { 2 - 3 } & Max Torque/Speed & $156 \mathrm{Nm} / 0-2000 \mathrm{rpm}$ \\
\cline { 2 - 3 } & Type & Battery/Ultracapacitor \\
\hline
\end{tabular}


Table 10.3. Sport Sedan Component Summary

\begin{tabular}{|l|l|l|}
\hline \multirow{3}{*}{ Engine } & Type & L-6/V-6/H-6 w/VVT \\
\cline { 2 - 3 } & Max Power/Speed & $190 \mathrm{~kW} / 6500 \mathrm{rpm}$ \\
\cline { 2 - 3 } & Max Torque/Speed & $291 \mathrm{Nm} / 5800 \mathrm{rpm}$ \\
\hline \multirow{3}{*}{ Mransmission } & Type & $6-$ speed manual \\
\cline { 2 - 3 } & Ratios & $3.73,2.20,1.43,1.05,0.87,0.76$ \\
\hline \multirow{3}{*}{ Electrical Storage } & Type & Brushless DC \\
\cline { 2 - 3 } & Max Power/Speed & $53 \mathrm{~kW} / 8000 \mathrm{rpm}$ \\
\cline { 2 - 3 } & Max Torque/Speed & $240 \mathrm{Nm} / 0-2500 \mathrm{rpm}$ \\
\cline { 2 - 3 } & Type & Battery/Ultracapacitor \\
\cline { 2 - 3 } & Capacity & $4.5 \mathrm{kWh}$ \\
\hline
\end{tabular}

Table 10.4. Exotic Sports Car Component Summary

\begin{tabular}{|l|l|l|}
\hline \multirow{3}{*}{ Engine } & Type & $\mathrm{V}-8 \mathrm{w} / \mathrm{VVT}$ \\
\cline { 2 - 3 } & Max Power/Speed & $272 \mathrm{~kW} / 7000 \mathrm{rpm}$ \\
\cline { 2 - 3 } & Max Torque/Speed & $392 \mathrm{Nm} / 6100 \mathrm{rpm}$ \\
\hline \multirow{3}{*}{ Mransmission } & Type & 6-speed manual \\
\cline { 2 - 3 } & Ratios & $3.05,1.96,1.39,1.06,0.86,0.70$ \\
\hline \multirow{3}{*}{ Electrical Storage } & Type & Brushless DC \\
\cline { 2 - 3 } & Max Power/Speed & $32 \mathrm{~kW} / 8000 \mathrm{rpm}$ \\
\cline { 2 - 3 } & Max Torque/Speed & $156 \mathrm{Nm} / 0-2000 \mathrm{rpm}$ \\
\cline { 2 - 3 } & Type & Battery/Ultracapacitor \\
\hline
\end{tabular}

\subsubsection{Engine Selection}

Prior to starting on the actual engine design exercise, simulations were performed in AccelSim to determine the maximum continuous power requirement. In this type of application this power requirement is for that of top speed sustained cruise. These continuous power requirements were found, and the values are shown in Table 4.2. After a peak power output for the engines was found the design of the engine began. After fixing some specifications for the engine the engine design flowchart (Figure 6.2.) was utilized to address other issues. Spark-ignited engines were chosen because of their potential for high-specific outputs, and for their ability to meet existing and future emissions requirements through three- 
way catalysis, something that diesels are currently unable to accomplish. A minimum specific power output of $74.5 \mathrm{~kW} / 1(100 \mathrm{hp} / \mathrm{l})$ was specified, and maximum piston speeds and brake mean effective pressures (BMEP) were taken near that of the industry average. Engine specifications from 1999 model year vehicles available in the United States were entered into a database and separated into naturally aspirated, naturally aspirated with variable valve timing, boosted (turbo- and supercharging), and diesel engines. The database was then further separated by number of cylinders and displacement. Information for this database was taken from Ward's Engine and Vehicle Technology Update, which provided engine performance and specifications for engines available in North America in 2000. This database contains information on engine geometry, including displacement, number and dimensions of cylinders, number of valves per cylinder, intake design, compression ratio, and valvetrain configuration. The database also includes performance figures; maximum brake power and maximum torque, redline, and speeds at maximum power and torque. This information was used to calculate engine parameters like piston speed, BMEP, and specific power. Plots taken from this data are shown below, with lines indicating general trends in the category.

With a power requirement and a specific power specified the displacement is easily found, by division. As it is an emerging technology with many benefits for engines all engines were modeled on the assumption of variable valve timing. After these assumptions were made trends were found in VVT-equipped engines. Average maximum piston speeds were found to be near $18 \mathrm{~m} / \mathrm{s}$, with a maximum production piston speed of $24.7 \mathrm{~m} / \mathrm{s}$ found. Table 10.5 . shows range values for piston speeds. 
Table 10.5. Piston Speed Range Values

\begin{tabular}{|c|c|}
\cline { 2 - 2 } \multicolumn{1}{c|}{} & Piston Speed $(\mathrm{m} / \mathrm{s})$ \\
\hline Average & 18.4 \\
\hline Maximum & 24.7 \\
\hline Minimum & 14.3 \\
\hline Used in Simulation & 21 \\
\hline
\end{tabular}

A plot of maximum piston speed vs. specific power is shown in Figure 10.2.

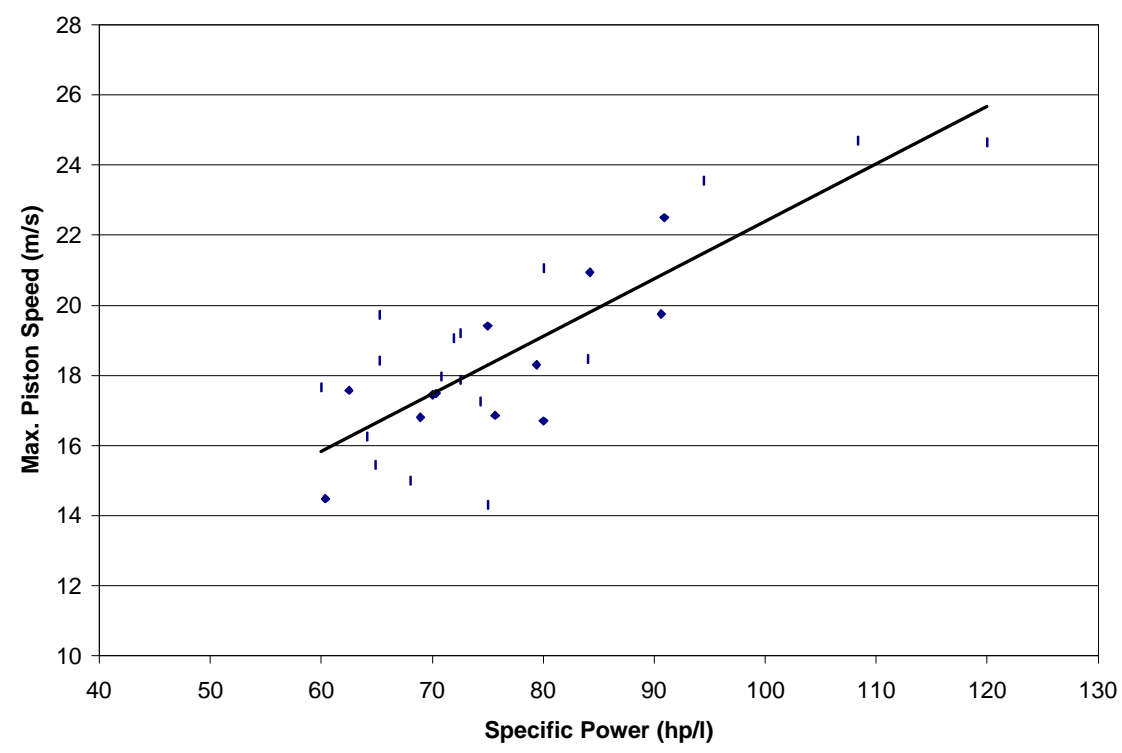

Figure 10.2. Maximum Piston Speed vs. Specific Power

From the trends found in Figure 10.2. a value of maximum piston speed of approximately $21 \mathrm{~m} / \mathrm{s}$ was found for an engine producing $100 \mathrm{hp} / \mathrm{l}$. With a displacement and a maximum piston speed fixed values for bore and stroke can be found. A plot of bore/stroke ratio vs. specific power is shown in Figure 10.3. A trendline was inserted in Figure 10.3, and a value calculated to find a representative bore-stroke ratio for the required specific power. 


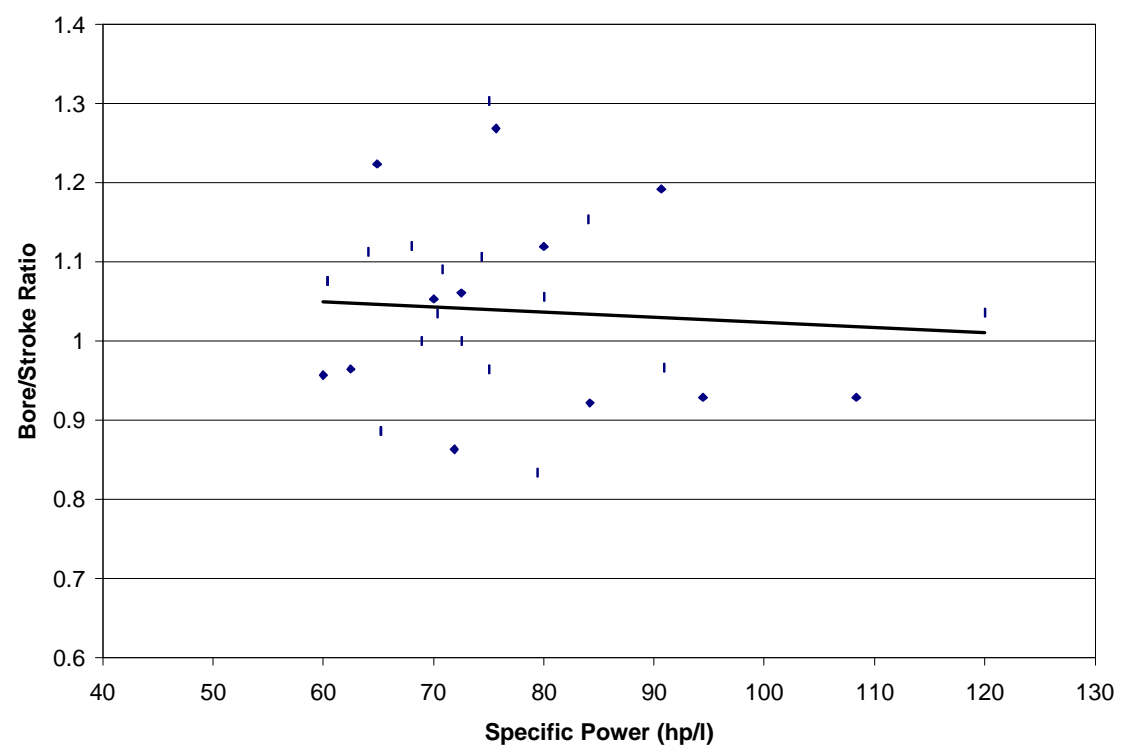

Figure 10.3. Bore/Stroke Ratio vs. Specific Power

Table 10.6. shows average, maximum, minimum, calculated and used values for borestroke ratio.

\section{Table 10.6. Bore/Stroke Ratio Range Values}

\begin{tabular}{|c|c|}
\cline { 2 - 2 } \multicolumn{1}{c|}{} & Bore/Stroke Ratios \\
\hline Average & 1.03 \\
\hline Maximum & 1.30 \\
\hline Minimum & 0.833 \\
\hline Used in Simulation & 1 \\
\hline
\end{tabular}

A bore-stroke ratio approaching 1 was found to be optimal for this application. With an approximate displacement fixed, and a bore-stroke ratio found, the number of cylinders can be found, and then displacement, bore, and stroke can be adjusted. Also with a maximum piston speed set and bore and stroke found approximately, then a maximum engine speed, or "redline" can be established. Production trends indicate that VVT-equipped engines make peak power at approximately $92 \%$ of maximum engine speed. Using values from production engines a reasonable BMEP range for this type of engine is found. Figure 10.4. illustrates BMEP vs. specific power. 


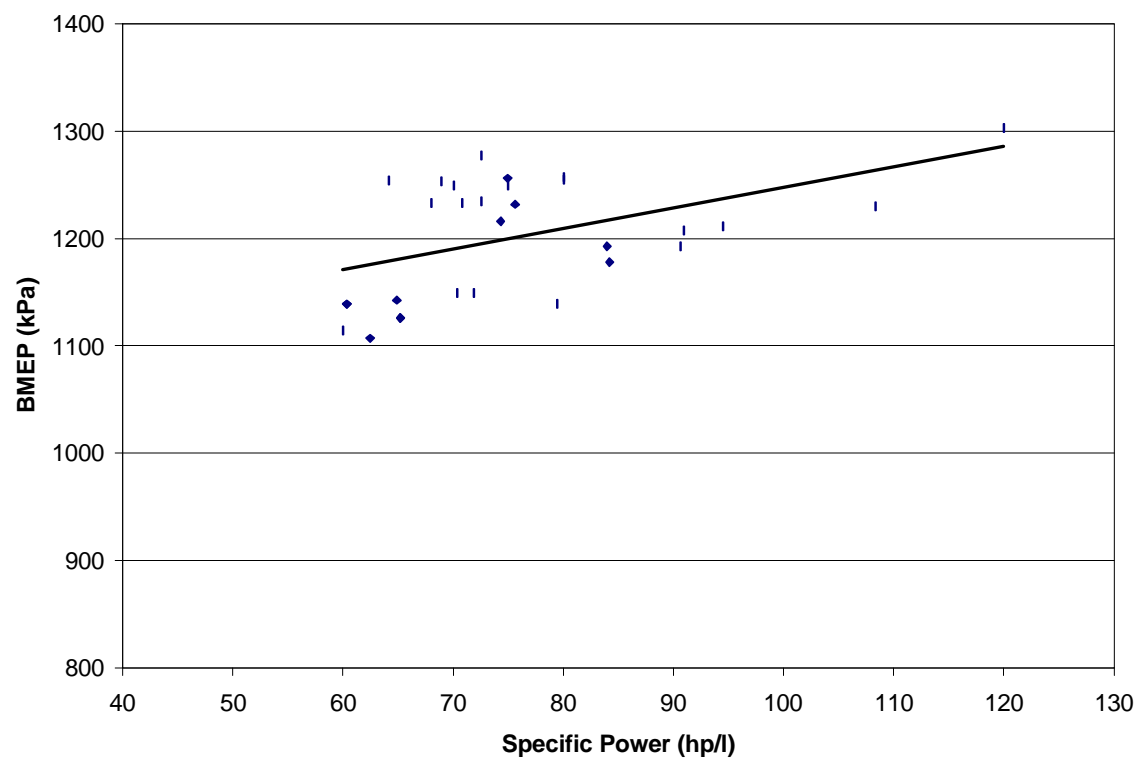

Figure 10.4. BMEP vs. Specific Power

With an approximate maximum BMEP range established parameters for the engine could again be re-evaluated to meet all of the above requirements. Table 10.7. contains range values for BMEP.

Table 10.7. BMEP Range Values

\begin{tabular}{|c|c|}
\cline { 2 - 2 } \multicolumn{1}{c|}{} & BMEP $(\mathrm{kPa})$ \\
\hline Average & 1201 \\
\hline Maximum & 1303 \\
\hline Minimum & 1107 \\
\hline Used in Simulation & 1247 \\
\hline
\end{tabular}

Finally compression ratio vs. specific power was compared. Figure 10.5. illustrates compression ratio vs. specific power. Table 10.8. shows range values for compression ratio. 


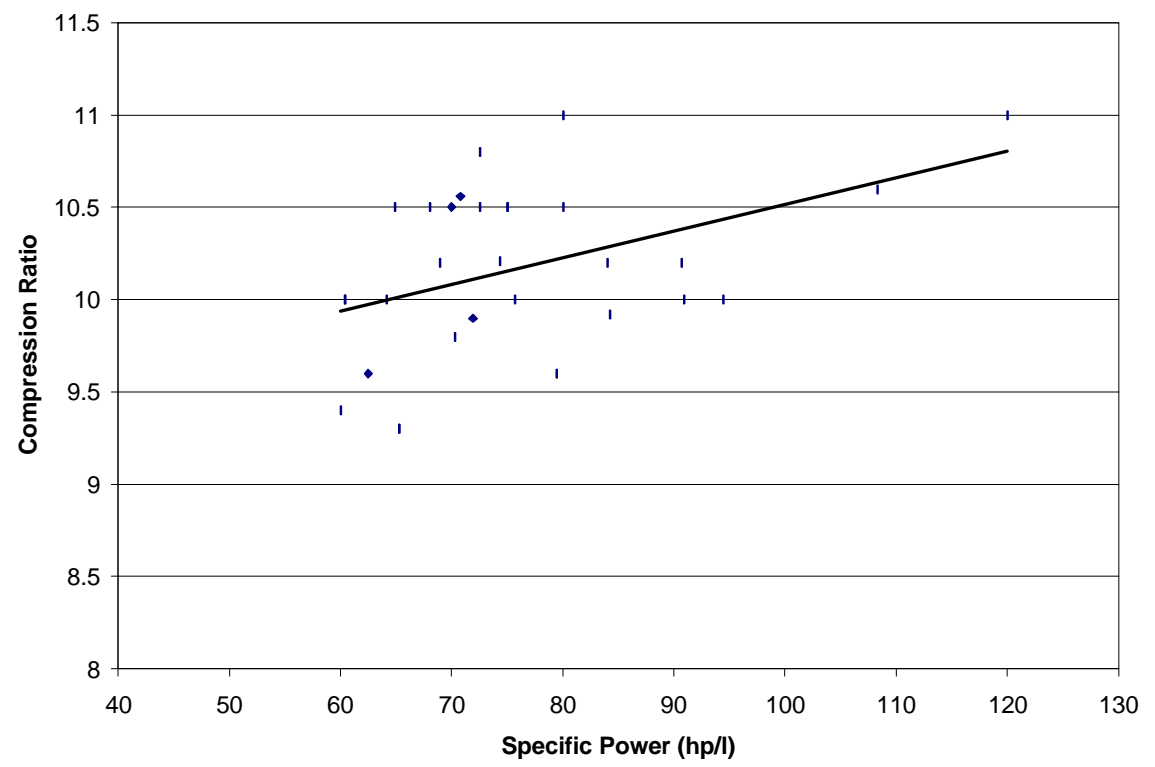

Figure 10.5. Compression Ratio vs. Specific Power

Table 10.8. Compression Ratio Range Values

\begin{tabular}{|c|c|}
\hline & Compression Ratio \\
\hline Average & 10.2 \\
\hline Maximum & 11 \\
\hline Minimum & 9.3 \\
\hline Used in Simulation & 10.5 \\
\hline
\end{tabular}

From this a compression ratio is established. After re-examining the proposed specifications a group of engines for each application is specified. Table 10.9. shows the various specifications found for the group of engines.

Table 10.9. Proposed Engine Specifications

\begin{tabular}{|l|c|c|c|c|c|c|c|}
\cline { 2 - 8 } \multicolumn{1}{c|}{} & Design 1 & Design 2 & Design 3 & Design 4 & Design 5 & Design 6 & Design 7 \\
\hline Displacement (1) & 4.28 & 3.65 & 3.21 & 2.55 & 2.17 & 2.17 & 1.60 \\
\hline Number of Cylinders & 8 & 8 & 6 & 6 & 4 & 4 & 3 \\
\hline Bore x Stroke $(\mathrm{mm})$ & $88 \times 88$ & $83 \times 83$ & $88 \times 88$ & $81.5 \times 81.5$ & $88 \times 89.3$ & $88.4 \times 88.4$ & $88 \times 88$ \\
\hline Max Piston Speed $(\mathrm{m} / \mathrm{s})$ & 21 & 21 & 21 & 21 & 21 & 21 & 21 \\
\hline Peak RPM & 7100 & 7500 & 7100 & 7700 & 7000 & 7100 & 7100 \\
\hline Compression Ratio & $10.5: 1$ & $10.5: 1$ & $10.5: 1$ & $10.5: 1$ & $10.5: 1$ & $10.5: 1$ & $10.5: 1$ \\
\hline BMEP $(\mathrm{kPa})$ & 1155.2 & 1278 & 1077.3 & 1243 & 1376.7 & 1355.8 & 1117.3 \\
\hline
\end{tabular}


To further narrow the selections the surface area/volume ratio for each proposed configuration was examined. Surface area/volume ratio has impact on many areas of engine performance, including efficiency and emissions. Figure 10.6. plots surface area/volume ratio vs. specific power. With this final parameter the group of proposed layouts can be further narrowed.

Emissions concerns can be addressed in throttled, spark-ignited, homogenous charge engines through the use of currently available three-way catalyst technology. Engines on the market currently employ a variety of technologies, including EGR, air injection, and closecoupled catalysts to meet and exceed legislated exhaust emissions requirements.

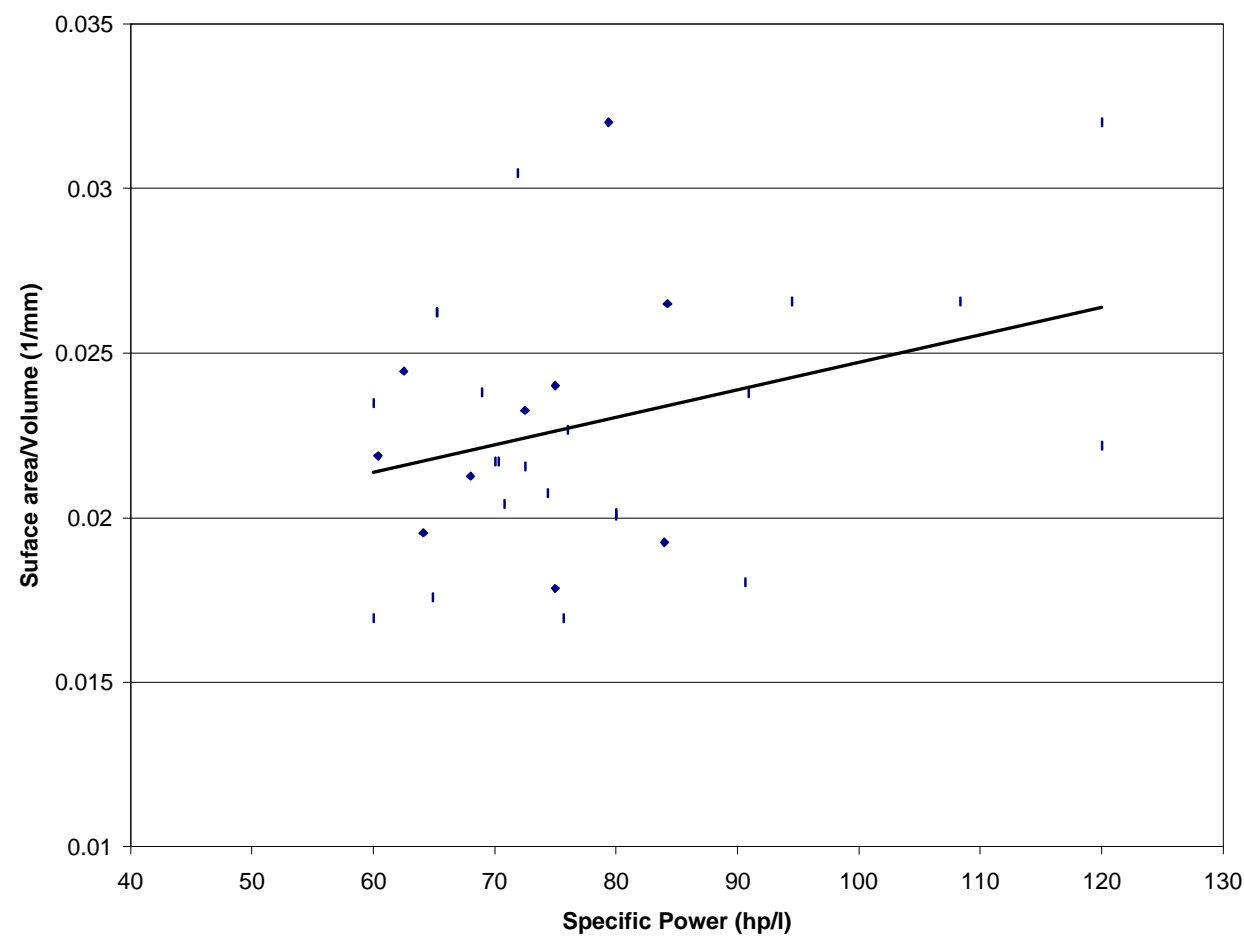

Figure 10.6. Surface Area-Volume Ratio vs. Specific Power 


\subsubsection{Transmission Selection}

Transmission selection in this application is of particular import to the market viability of the vehicle. Currently in the North American auto market over $80 \%$ of vehicles sold are equipped with automatic transmissions (Wards Auto, 2000). However, automatics suffer from inefficiencies relative to manual transmissions, and in a sporting vehicle remove one dimension of driver input. A possible compromise solution to this is either through the use of an automatically shifted manual with automatic and manual modes, or a "manumatic" approach to a manually shifted automatic, provided it was responsive and provided the desired level of driver control. In the modeling performed vehicles were modeled with 6-speed manual transmissions. Ratios were synthesized for use in this model, and the specific ratios used in each application are shown below. Transmission efficiencies were chosen based upon research performed at Southwest Research Institute, which indicates that transmission efficiencies in every gear in a manual transmission are typically higher than $94 \%$, with efficiencies in direct drive gears 3-5\% higher than those for non-direct drive gears (Kluger, 1999). Engine speed vs. vehicle speed plots and efficiency values used are also shown below.

Table 10.10. Transmission Ratios

\begin{tabular}{|c|c|c|c|c|c|c|c|}
\hline & 1st & 2nd & 3rd & 4th & 5th & $6^{\text {th }}$ & Final Drive \\
\hline Sport Compact Car & 3.34 & 2.15 & 1.55 & 1.2 & 0.93 & 0.83 & 4.27 \\
\hline Sport Coupe & 3.46 & 2.03 & 1.38 & 1.06 & 0.82 & 0.67 & 3.56 \\
\hline Sport Sedan & 3.73 & 2.2 & 1.43 & 1.05 & 0.87 & 0.76 & 3.56 \\
\hline Exotic Sports Car & 3.05 & 1.96 & 1.39 & 1.06 & 0.86 & 0.7 & 4.10 \\
\hline
\end{tabular}




\section{Table 10.11. Gear Efficiency Table}

\begin{tabular}{|c|c|}
\hline Gear & Efficiencies \\
\hline First & 0.96 \\
\hline Second & 0.96 \\
\hline Third & 0.96 \\
\hline Fourth & 0.98 \\
\hline Fifth & 0.955 \\
\hline Sixth & 0.95 \\
\hline
\end{tabular}




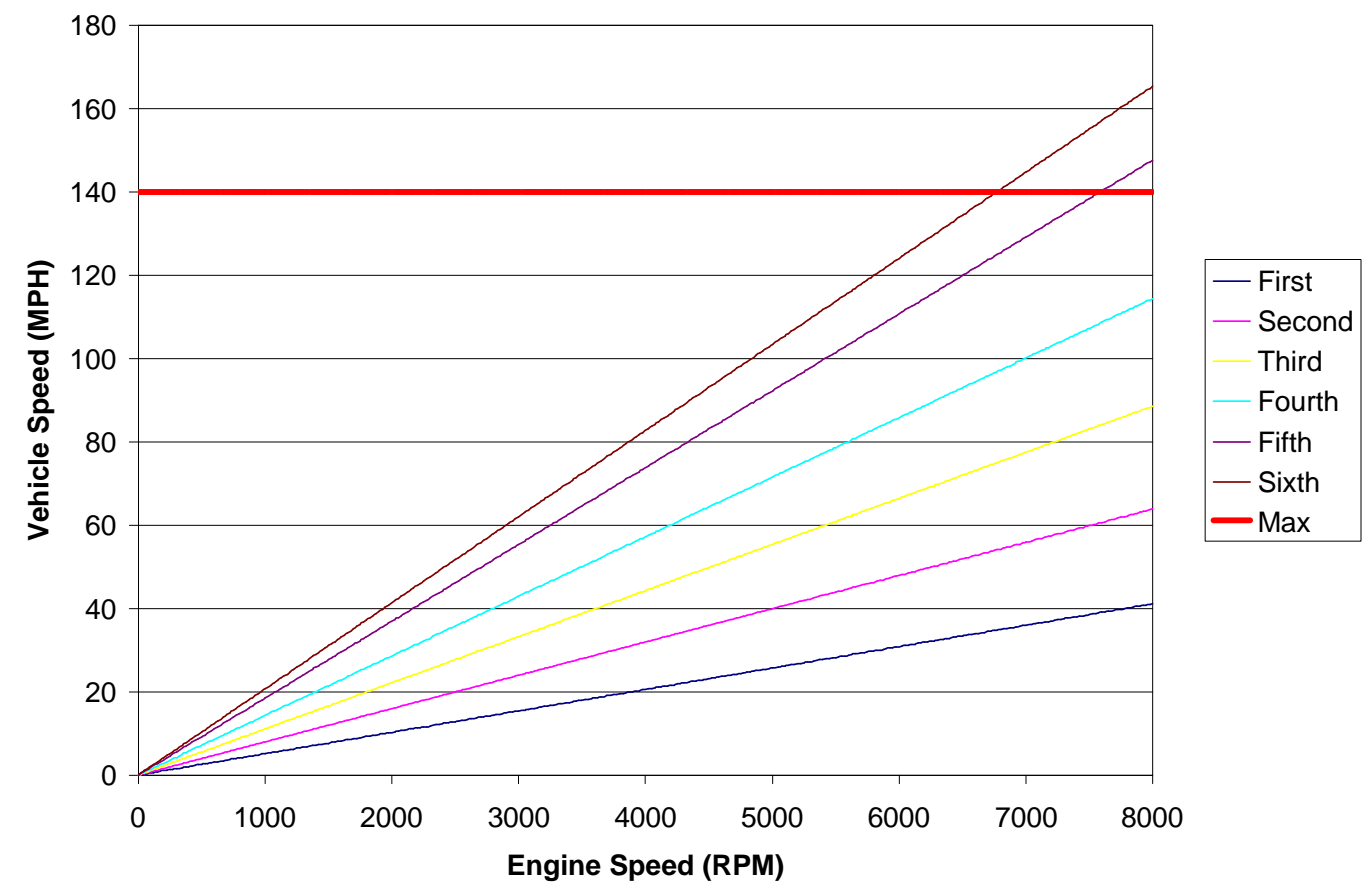

Figure 10.7. Sport Compact Car Engine Speed vs. Vehicle Speed

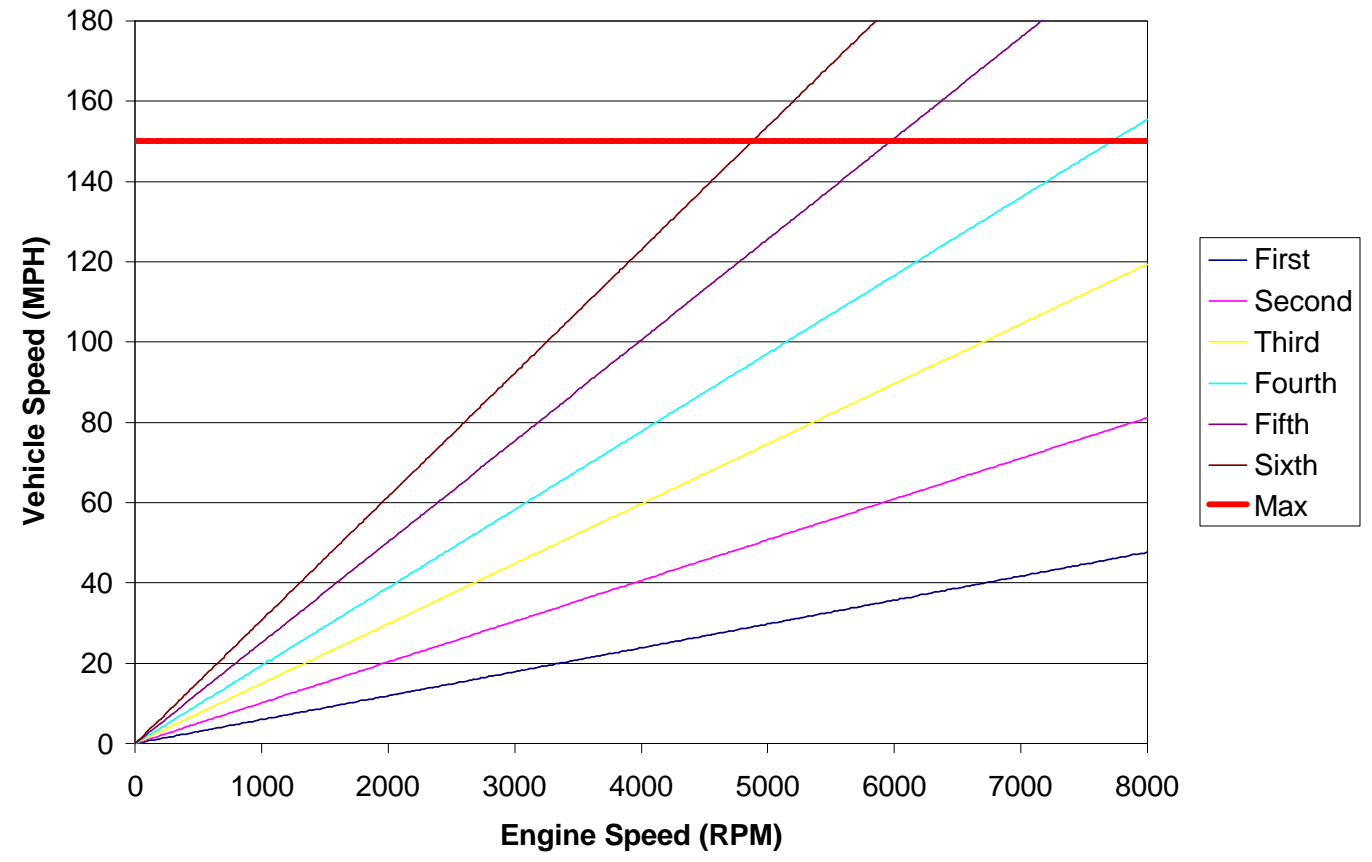

Figure 10.8. Sport Coupe Engine Speed vs. Vehicle Speed 


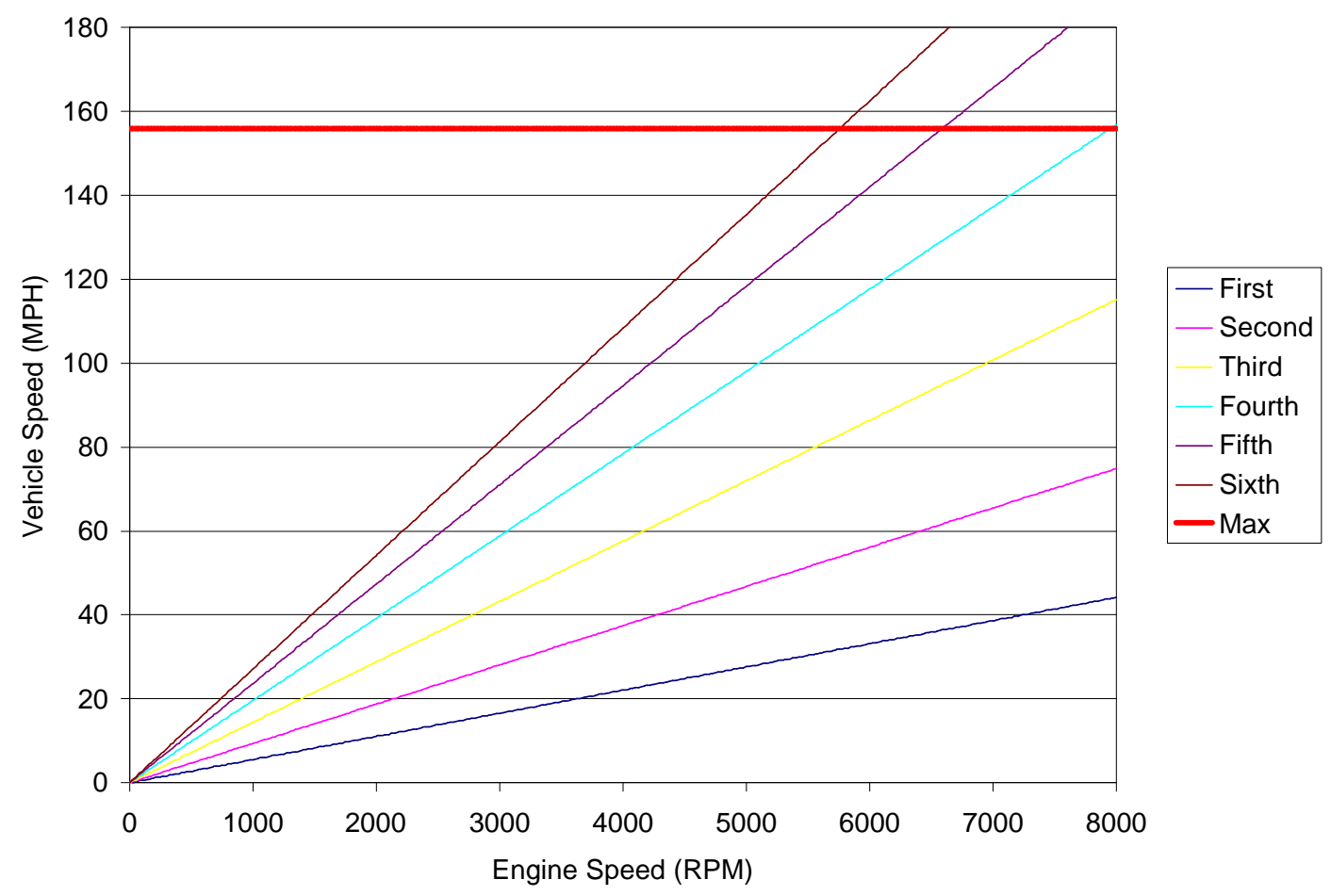

Figure 10.9. Sport Sedan Engine Speed vs. Vehicle Speed

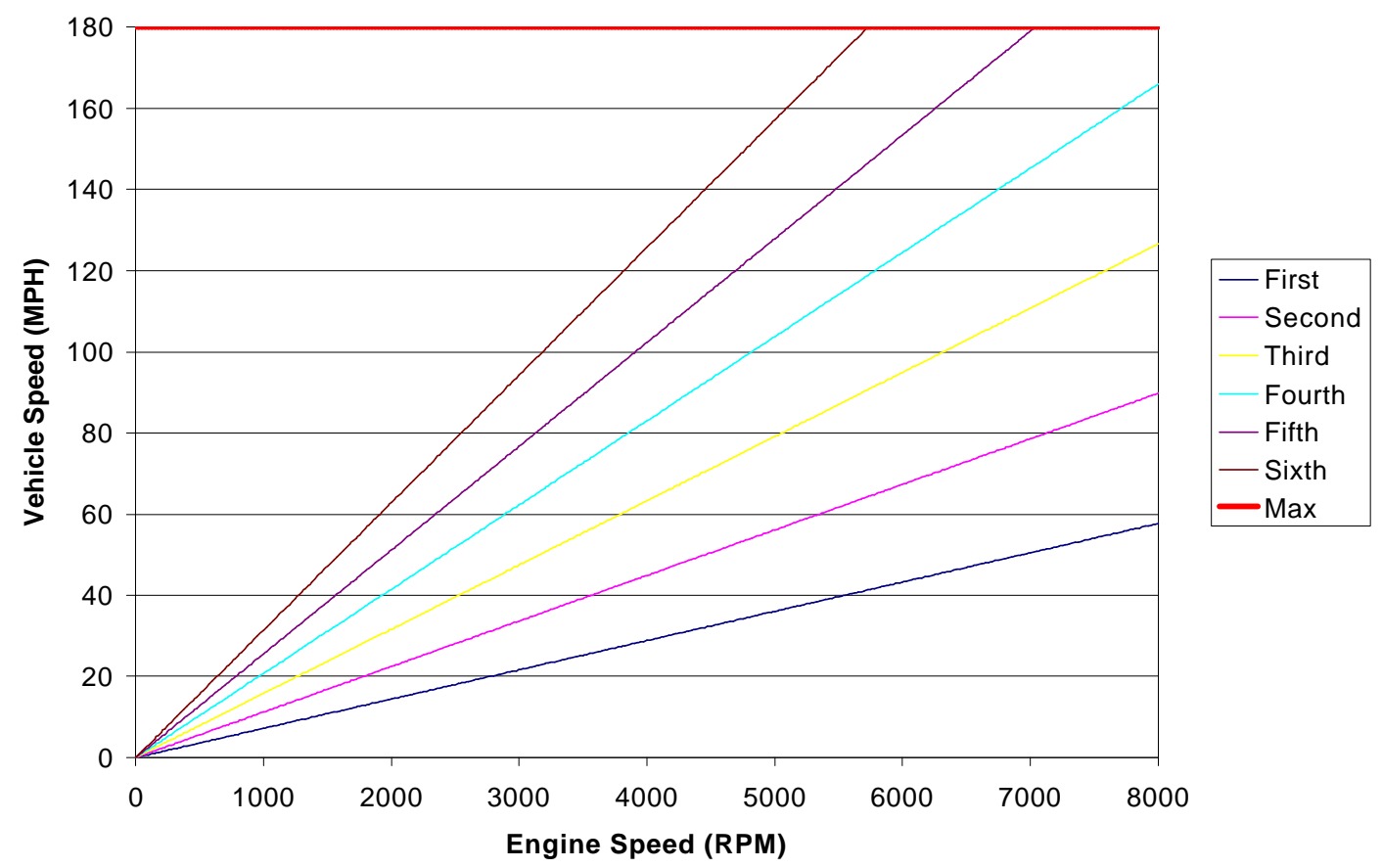

Figure 10.10. Exotic Sports Car Engine Speed vs. Vehicle Speed 


\subsubsection{Electric Traction Drive Selection}

The electric traction drive in this application is sized to provide the desired acceleration performance, and to absorb regenerative braking. After modeling was performed in AccelSim and HVSim the size of the electric drive was specified for each class of vehicle modeled. Electric drive characteristics are based on the Unique Mobility SR218 series of motors, which were chosen for their light weight, high specific power, high reliability, and the ability to scale production to meet a full-scale production output. Output curves, and modeled drive specifications are shown below.

Table 10.12. Motor Drive Specifications

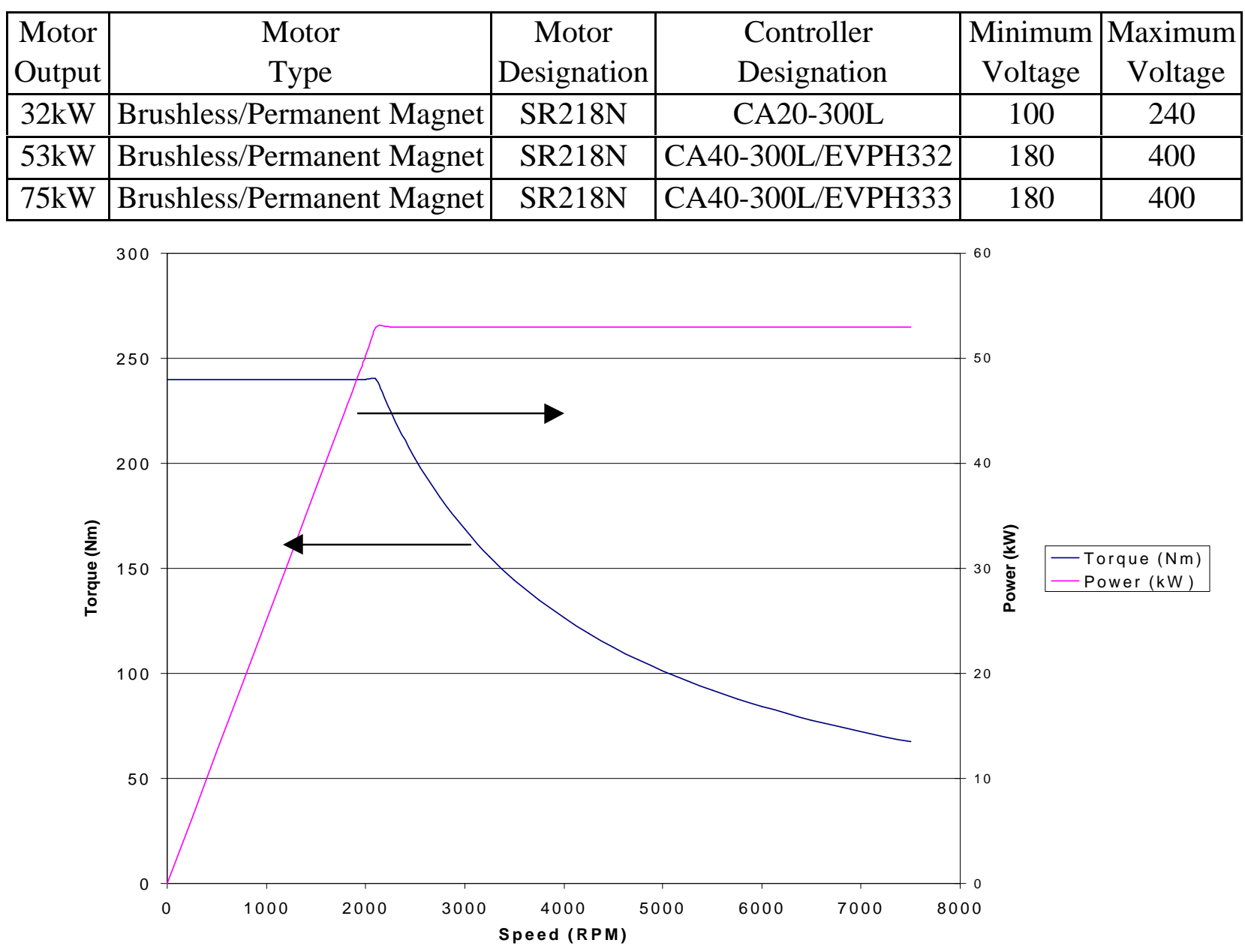

Figure 10.11. Unique Mobility 53kW Motor Output Curves 


\subsubsection{Electric Energy Storage Selection}

A combination battery/ultracapacitor electrical energy storage system has been selected for use in this application. The battery modeled is a Hawker type lead-acid ( $\mathrm{PbA})$ battery, chosen for low internal resistance, high power density, and then sized to optimize weight. The ultracapacitors chosen are production Maxwell Technologies PowerCache units (Maxwell Technologies, 2000; Hawker Energy Products, 2001). Specifications for these units are shown below. Control of the combination pack is outlined in a later section.

Table 10.13. Maxwell Technologies 2.7V Ultracapacitor Specifications

\begin{tabular}{|c|c|}
\hline Capacitance $(\mathrm{F})$ & 2500 \\
\hline Series Resistance $(\mathrm{m} \Omega)$ & 1 \\
\hline Voltage $(\mathrm{V})$ & 2.7 \\
\hline Rated Current $(\mathrm{A})$ & 400 \\
\hline Dimensions $(\mathrm{mm})$ & $161 \times 61.5 \times 61.5$ \\
\hline Weight $(\mathrm{g})$ & 725 \\
\hline Energy Storage $(\mathrm{J})$ & 8400 \\
\hline
\end{tabular}

Table 10.14. Hawker Energy 12V Lead Acid Battery Specifications

\begin{tabular}{|c|c|}
\hline Capacity $(\mathrm{Ah})$ & 13 \\
\hline Series Resistance $(\mathrm{m} \Omega)$ & 8.5 \\
\hline Voltage $(\mathrm{V})$ & 12 \\
\hline Short Circuit Current $(\mathrm{A})$ & 1400 \\
\hline Dimensions $(\mathrm{mm})$ & $176 \times 83.4 \times 130$ \\
\hline Weight $(\mathrm{g})$ & 4900 \\
\hline Energy Storage $(\mathrm{J})$ & 561600 \\
\hline
\end{tabular}

The final size of each pack was determined by sizing the ultracapacitors to optimally meet the regeneration load of each vehicle, and then sizing the battery pack to match the voltage requirement of the system. A tradeoff in battery storage and internal resistance was made in exchange for reduced size and weight of the pack. As a result theoretical pack weights are lower than those used earlier. 
Table 10.15. Ultracapacitor Stack Properties

\begin{tabular}{|c|c|c|c|c|}
\cline { 2 - 5 } \multicolumn{1}{c|}{} & $\begin{array}{c}\text { Ultracap Stack } \\
\text { Mass (kg) }\end{array}$ & $\begin{array}{c}\text { Nominal Ultracap } \\
\text { Stack Voltage (V) }\end{array}$ & $\begin{array}{c}\text { Peak Ultracap } \\
\text { Stack Voltage (V) }\end{array}$ & $\begin{array}{c}\text { Ultracap Energy } \\
\text { Storage (kWh) }\end{array}$ \\
\hline Sport Compact Car & 124.56 & 340 & 400 & 0.19 \\
\hline Sport Coupe & 74.88 & 210 & 240 & 0.11 \\
\hline Sport Sedan & 124.56 & 340 & 400 & 0.19 \\
\hline Exotic Sports Car & 74.88 & 210 & 240 & 0.11 \\
\hline
\end{tabular}

Table 10.16. Battery Stack Properties

\begin{tabular}{|c|c|c|c|c|}
\cline { 2 - 5 } \multicolumn{1}{c|}{} & $\begin{array}{c}\text { Battery Stack } \\
\text { Mass (kg) }\end{array}$ & $\begin{array}{c}\text { Nominal Battery } \\
\text { Stack Voltage (V) }\end{array}$ & $\begin{array}{c}\text { Peak Battery } \\
\text { Stack Voltage (V) }\end{array}$ & $\begin{array}{c}\text { Battery Energy } \\
\text { Storage (kWh) }\end{array}$ \\
\hline Sport Compact Car & 138.8 & 340 & 400 & 4.42 \\
\hline Sport Coupe & 85.75 & 210 & 240 & 2.73 \\
\hline Sport Sedan & 138.8 & 340 & 400 & 4.42 \\
\hline Exotic Sports Car & 85.75 & 210 & 240 & 2.73 \\
\hline
\end{tabular}

Table 10.17. Total Energy Storage Stack Properties

\begin{tabular}{|c|c|c|c|c|}
\cline { 2 - 5 } \multicolumn{1}{c|}{} & $\begin{array}{c}\text { Total Stack } \\
\text { Mass }(\mathrm{kg})\end{array}$ & $\begin{array}{c}\text { Nominal Stack } \\
\text { Stack Voltage }(\mathrm{V})\end{array}$ & $\begin{array}{c}\text { Peak Stack } \\
\text { Stack Voltage }(\mathrm{V})\end{array}$ & $\begin{array}{c}\text { Total Energy } \\
\text { Storage }(\mathrm{kWh})\end{array}$ \\
\hline Sport Compact Car & 263.36 & 340 & 400 & 4.61 \\
\hline Sport Coupe & 160.63 & 210 & 240 & 2.84 \\
\hline Sport Sedan & 263.36 & 340 & 400 & 4.61 \\
\hline Exotic Sports Car & 160.63 & 210 & 240 & 2.84 \\
\hline
\end{tabular}

Volume calculations for each stack were also performed to estimate the space required in a vehicle for the stacks.

Table 10.18. Electrical Storage Volume Requirements

\begin{tabular}{|c|c|c|c|}
\cline { 2 - 4 } \multicolumn{1}{c|}{} & $\begin{array}{c}\text { Ultracap Stack } \\
\text { Volume (1) }\end{array}$ & $\begin{array}{c}\text { Battery Stack Volume } \\
\text { Volume (1) }\end{array}$ & $\begin{array}{c}\text { Total Volume } \\
(\mathrm{l})\end{array}$ \\
\hline Sport Compact Car & 105.3 & 54.6 & 159.9 \\
\hline Sport Coupe & 63.4 & 32.8 & 96.2 \\
\hline Sport Sedan & 105.3 & 54.6 & 159.9 \\
\hline Exotic Sports Car & 63.4 & 32.8 & 96.2 \\
\hline
\end{tabular}




\section{Control}

The implementation and optimization of a control strategy for all driving purposes is perhaps the most important part of hybrid vehicle system designs. It has been shown in previous designs that an non-optimized control strategy, when used in a hybrid, can actually return lower fuel efficiencies than a conventional vehicle. Strategies for each element's control are outlined below, and then a general control strategy is presented for the demands of highperformance driving. The post-transmission parallel configuration allows for several modes of operation, including:

- $\quad$ ZEV Operation, with limited range

- Conventional Vehicle Operation, with range limited by onboard fuel storage

- $\quad$ Parallel hybrid operation with multiple sub-modes

The control system is intended to operate the system at a high efficiency, while preserving the ability for high dynamic performance. Further detail of the overall control strategy is provided below.

\subsection{Engine Control}

Actual engine control can occur in this application in much the same way that conventional vehicles are controlled today. The elements of a feedback oxygen sensor, digitally controlled fuel injection, EGR, and spark timing are almost universally used in SI engines today, and the VVT systems proposed for use in these engines mimic those already in production. In this application an engine output request value would be sent from the hybrid ECU and then interpreted into an electronic throttle signal for the engine at the engine ECU. Feedback signals of engine speed and actual throttle position can then be returned to the system. While only manual transmissions were modeled in this design, the control of an 
automatic transmission would only be marginally more difficult in the hybrid design proposed due to the post-transmission hybrid design.

\subsection{Electrical Drive Control and Combination Energy Storage Pack Control}

The Unique Mobility electric traction motor drives that were selected as applicable for this design are all microprocessor controlled, and have torque-based control algorithms. The benefit of this is that a torque request signal from the accelerator pedal can be used to control both the engine and the motor through a central processor. In the proposed control network a drive or regeneration request signal is sent from the hybrid ECU to the motor ECU, which then controls the inverter operation. Feedback regarding motor temperature, motor speed, voltage and current are sent from the inverter to the motor ECU and then to the hybrid ECU to protect the device. Motoring and regeneration torque values are found based on Accelerator Position (APS) and Brake Position (BPS) signals, which are then converted at the hybrid ECU to percent-torque values for use by the motor ECU. Motor regeneration events would be slaved to the ABS/stability control systems and to the hydraulic braking system, with the intent that panic stops or the event of lockup would disable the regeneration system in favor of the conventional hydraulic system.

The control of the combination energy storage pack is extremely important to both the efficiency and safety of the hybrid drive system. Flow diagrams illustrating the proposed control logic are shown below. As can be seen, it is proposed for simplicity in this early model and for reliability in a production type application that the switching of the energy storage units be performed based on percent APS and percent BPS basis. A second benefit of this approach is that panic braking events, and $\mathrm{ABS} /$ traction control strategies can be implemented with minimal changes from current technology as they would be based entirely in the hydraulic operating range of the brakes. 


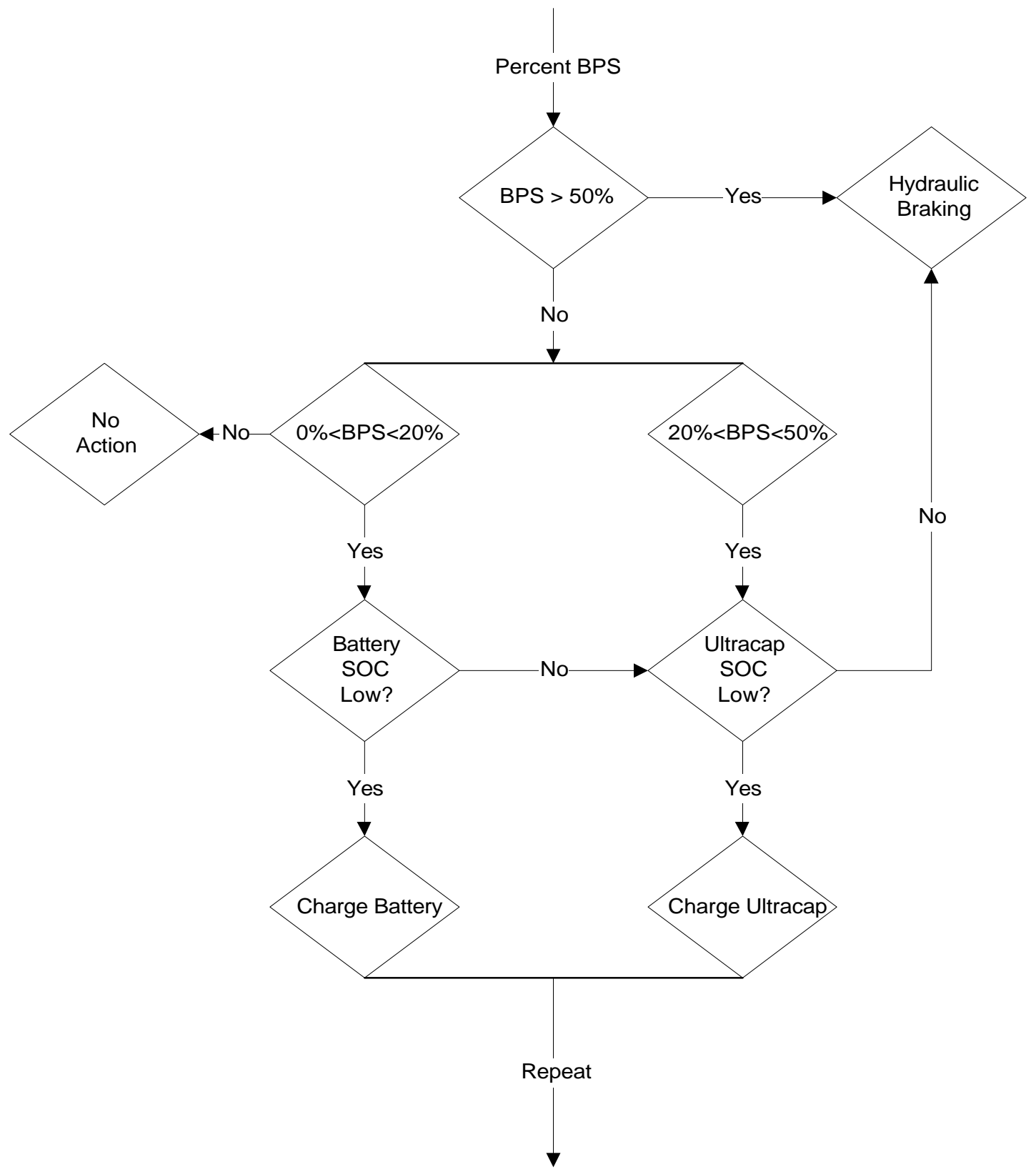

Figure 11.1. Regeneration Control Flow Diagram 


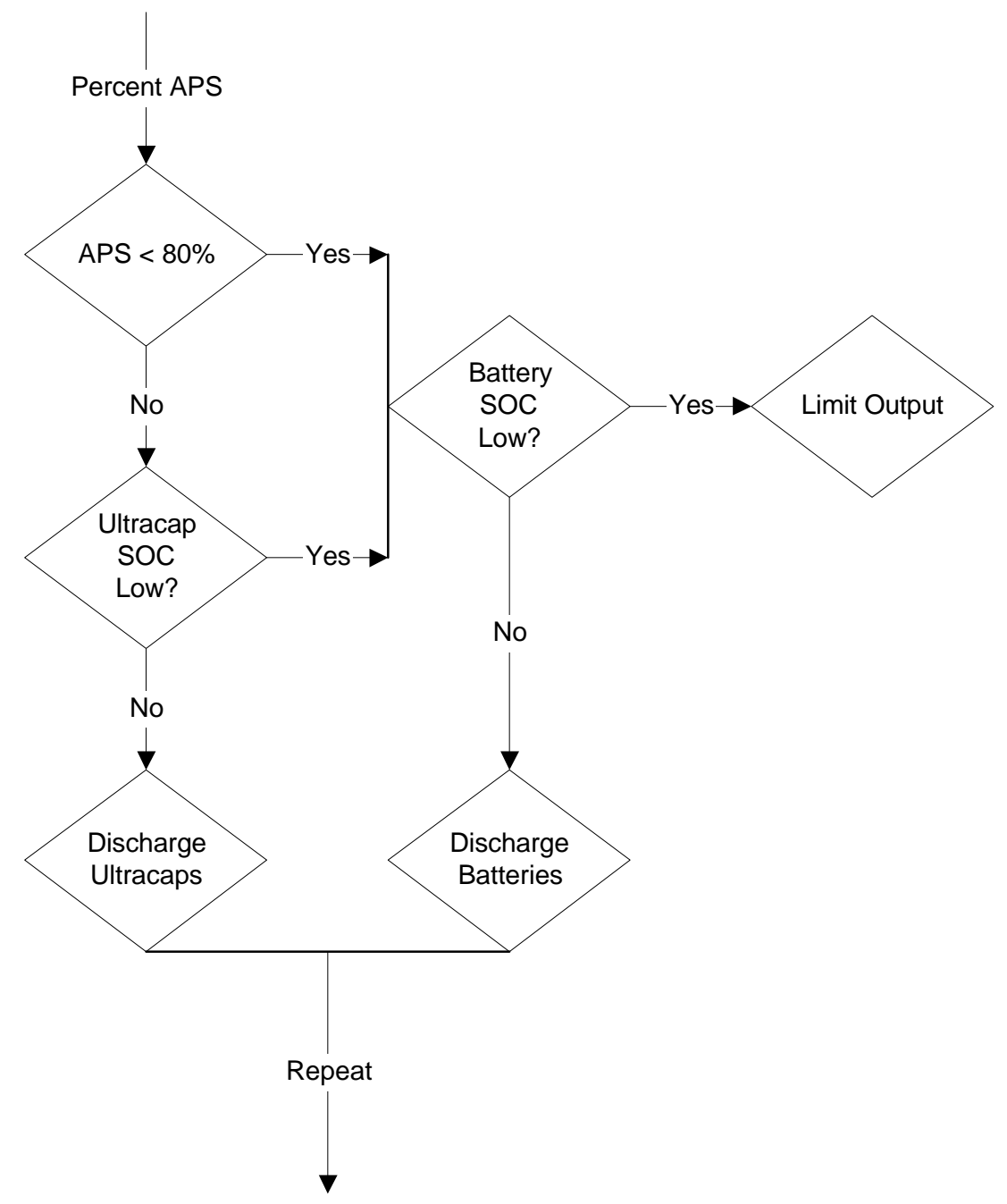

Figure 11.2. Motoring Control Flow Diagram

\subsection{Brake System/Traction Control System}

The braking system is configured to handle several duties within the overall vehicle control strategy. The first duty of the brake ECU is to coordinate the regenerative braking effort with that of the conventional hydraulic braking system. A system similar to this is in use currently in the Toyota Prius. A second responsibility of the brake ECU is to monitor and 
control all of the duties of conventional ABS and traction control, including monitoring wheelspin and yaw sensors. Also, in practice a signal can then be sent from the brake ECU to the hybrid ECU to reduce output from the motor and the engine. Finally, the brake pedal signal sent to the hybrid ECU prioritizes regeneration vs. hydraulic braking based on many parameters including braking effort, battery SoC, and ABS/traction control signals.

\subsection{Total System Control}

After individual component control strategies are decided upon, the implementation and optimization of the overall hybrid control strategy, and thus the design of the hybrid ECU can be undertaken. The operating priority of the hybrid ECU is such that the controllability and safety of the vehicle and its operation are of first priority, with efficiency and performance second. The overall ECU network is shown below.

The driver inputs are APS, BPS, and transmission position. These inputs can be summarized as

- $\quad$ APS from 0 to $100 \%$

- $\quad$ BPS from 0 to $100 \%$

- $\quad$ Transmission Selection - Neutral, Reverse, or Forward Gear.

The transmission position switch serves two purposes, first if the transmission is in neutral the drive may be set to zero-torque to prevent unintended acceleration events, and secondly, if the transmission is in reverse the motor would be set to zero-torque owing to the post-transmission position of the motor.

The BPS switch would be used to dictate the amount of regeneration and as a result which portion of the energy storage system receives the regenerated energy. The proposed control strategy for the braking side is: 
- If BPS exceeds $50 \%$ pedal travel a panic-stop type situation will be assumed, and all braking will be handled by the hydraulic system with ABS

- $\quad 0 \%$ BPS will indicate a zero regeneration situation (i.e. the vehicle can coast freely without regeneration)

- $0 \%<\mathrm{BPS} \leqslant 20 \%$ - Batteries have priority in regeneration, low current requirement

- $20 \%<\mathrm{BPS} \leqslant 50 \%$ - Ultracapacitors have priority in regeneration, high current requirement

- If wheelspin or other of the traction/stability/ABS control flags is indicated the regeneration is disabled and the hydraulic system becomes active.

The regeneration torque is scaled from zero to its full value in this first $50 \%$ of pedal travel. Thus at $50 \%$ of pedal travel the peak regeneration value is attained. 


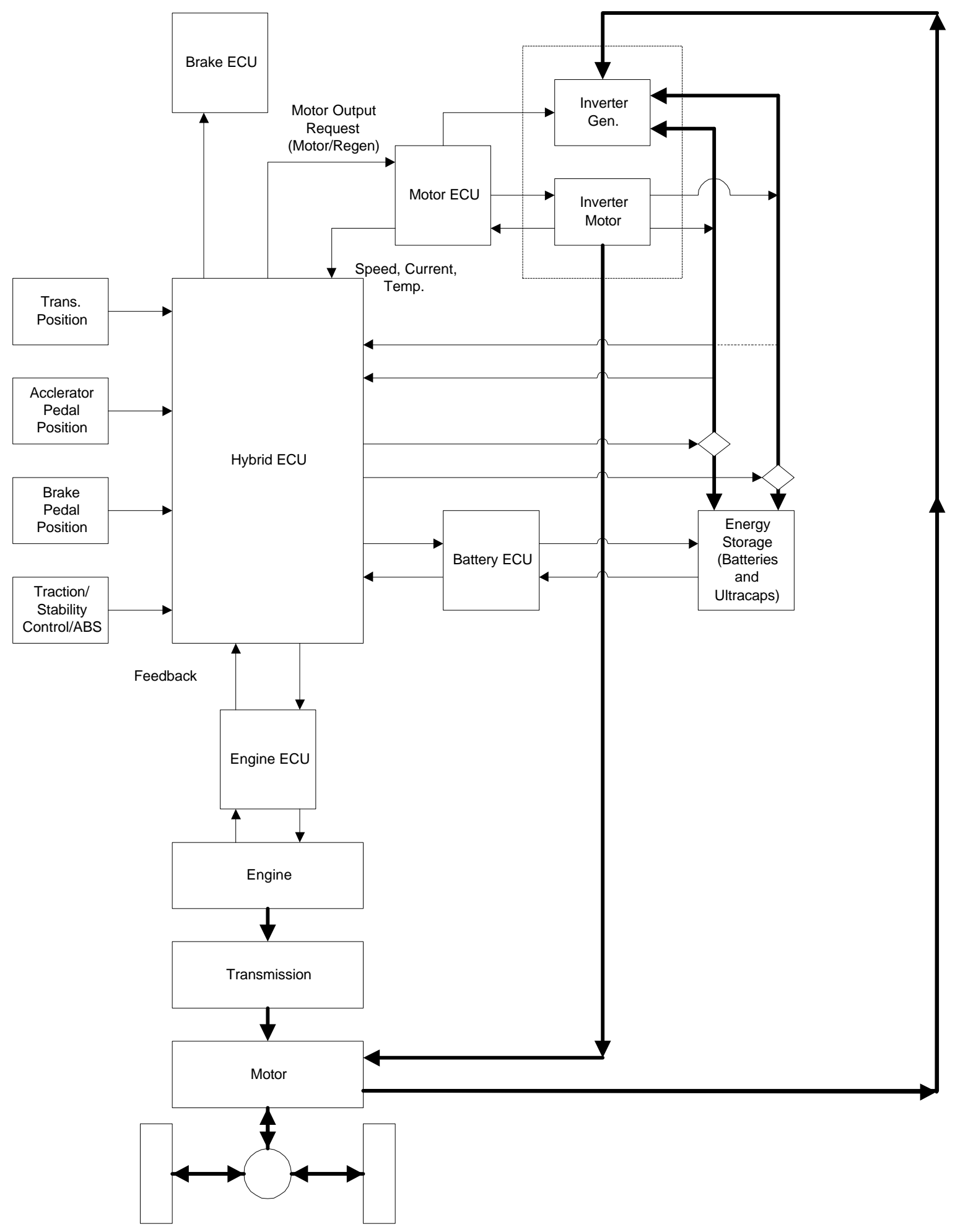

Figure 11.3. ECU Layout Diagram 
The APS switch would be used to dictate the amount of torque provided by the engine and the motor combined. This allows a great deal of flexibility in the control and operation of the drive system. Some of the hard conditions of the system are:

- If APS exceeds $80 \%$ the ultracapacitors will be prioritized to discharge first, as a high power demand condition has been indicated

- If APS is less than $80 \%$ and the battery SoC is acceptable then the batteries are prioritized to discharge first. Again, in this condition it should be noted that the torque split of motor vs. engine is dictated in the overall control strategy

- If overall energy storage $\mathrm{SoC}$ is low then power output of the electric drive will be limited resulting in lowered performance, but preventing damage to the storage devices or the motor itself

- Finally, the ABS/traction/stability control systems will have override capability over the drive system, similar to current systems.

The control system dictates component operation based on the vehicle speed, APS, SoC, and inputs from the ABS system. Once a mode of operation has been selected the hybrid ECU then uses a map to determine the torque split of the engine and motor based on APS. Regeneration is also set to deactivate at vehicle speeds less than $10 \mathrm{mph}$.

A representative torque map is shown below (Conley, 2001). 


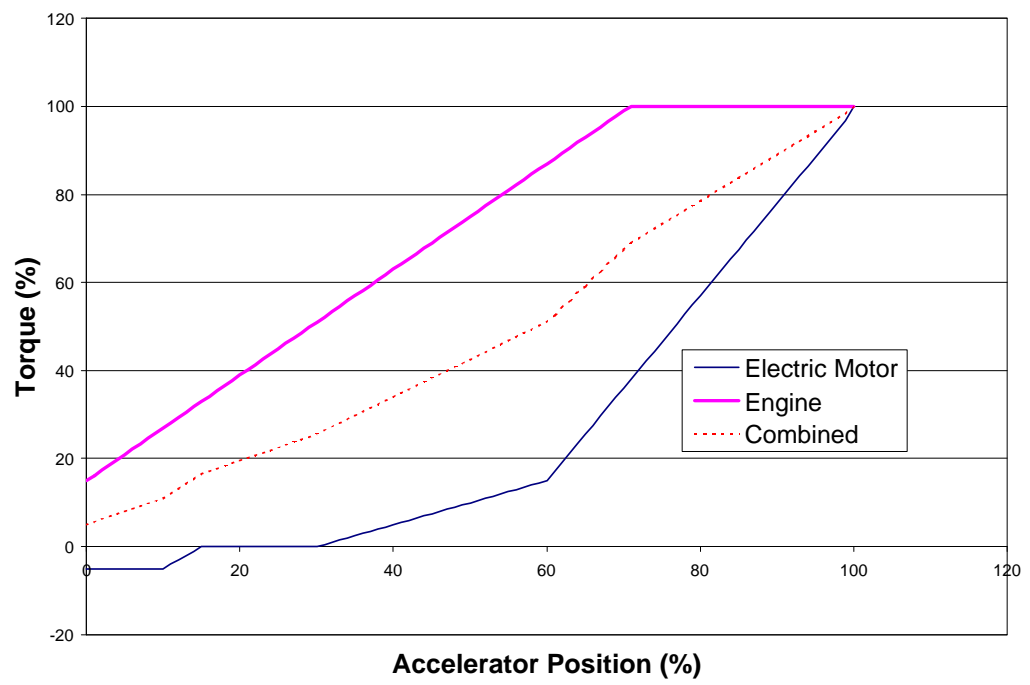

Figure 11.4. APS vs. Torque - Charge Depleting Map 


\section{Performance and Efficiency Modeling}

\subsection{Performance Modeling Using AccelSim}

With components specified for all of the proposed vehicles a final estimation of dynamic performance can be made for each case. Tables listing the predicted performance for each type of vehicle are shown below. The "actual" column is an average of actual vehicles performance values, and is used as the performance baseline. The modeled conventional vehicle performance is based on the modeled engine that is also used in the hybrid case, at maximum power, which in all cases is less than that of the actual vehicle.

Table 12.1. Sport Compact Car Final Performance Estimates

\begin{tabular}{|c|c|c|c|}
\cline { 2 - 4 } \multicolumn{1}{c|}{} & Actual & Modeled Conventional & Modeled Hybrid \\
\hline 0-60mph $(\mathrm{sec})$ & 6.2 & 8.73 & 5.63 \\
\hline 1/4mi ET $(\mathrm{sec})$ & 14.8 & 16.66 & 14.20 \\
\hline 1/4mi TS $(\mathrm{mph})$ & 95.1 & 78.23 & 99.02 \\
\hline Top Speed $(\mathrm{mph})$ & 138 & 140.1 & 140.11 \\
\hline
\end{tabular}

Table 12.2. Sport Coupe Final Performance Estimates

\begin{tabular}{|c|c|c|c|}
\cline { 2 - 4 } \multicolumn{1}{c|}{} & Actual & Modeled Conventional & Modeled Hybrid \\
\hline 0-60mph $(\mathrm{sec})$ & 5.8 & 6.4 & 5.38 \\
\hline 1/4mi ET $(\mathrm{sec})$ & 14.3 & 14.82 & 13.73 \\
\hline 1/4mi TS $(\mathrm{mph})$ & 98.9 & 94.52 & 104.17 \\
\hline Top Speed $(\mathrm{mph})$ & 150 & 147.1 & 147.15 \\
\hline
\end{tabular}

Table 12.3. Sport Sedan Final Performance Estimates

\begin{tabular}{|c|c|c|c|}
\cline { 2 - 4 } \multicolumn{1}{c|}{} & Actual & Modeled Conventional & Modeled Hybrid \\
\hline 0-60mph $(\mathrm{sec})$ & 5.3 & 6.31 & 5.01 \\
\hline 1/4mi ET $(\mathrm{sec})$ & 13.8 & 14.89 & 13.46 \\
\hline 1/4mi TS $(\mathrm{mph})$ & 103 & 93.9 & 106.56 \\
\hline Top Speed $(\mathrm{mph})$ & 156 & 155.69 & 155.69 \\
\hline
\end{tabular}


Table 12.4. Exotic Sports Car Final Performance Estimates

\begin{tabular}{|c|c|c|c|}
\cline { 2 - 4 } \multicolumn{1}{c|}{} & Actual & Modeled Conventional & Modeled Hybrid \\
\hline 0-60mph $(\mathrm{sec})$ & 4.6 & 4.45 & 3.98 \\
\hline 1/4mi ET $(\mathrm{sec})$ & 13 & 12.93 & 12.25 \\
\hline 1/4mi TS $(\mathrm{mph})$ & 111 & 111.25 & 117.27 \\
\hline Top Speed $(\mathrm{mph})$ & 180 & 180.76 & 180.77 \\
\hline
\end{tabular}

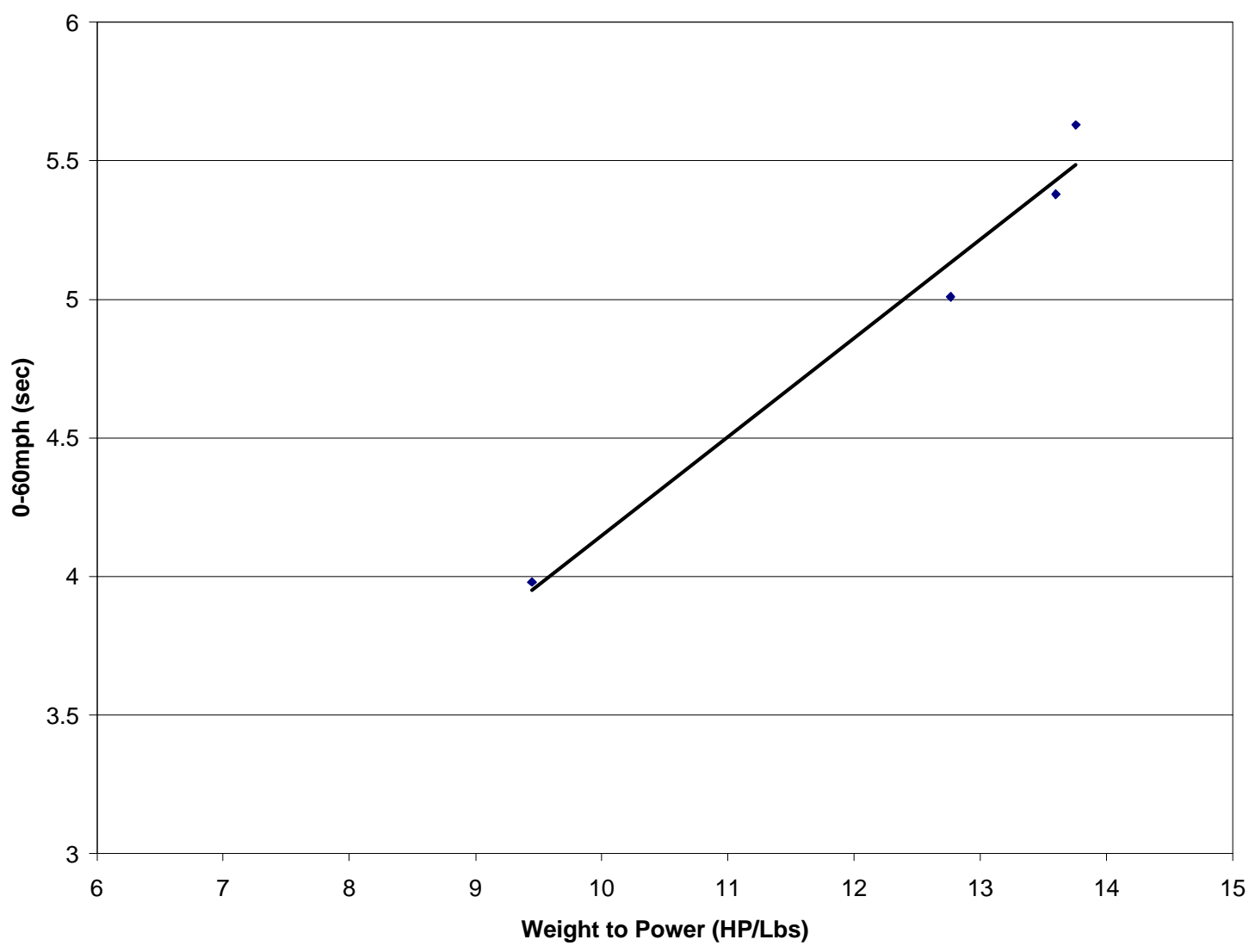

Figure 12.1. Effect of Weight to Power Ratio on Acceleration Performance

From the performance modeling, it is indicated that all of the proposed hybrid systems designs meet or exceed the performance baselines. The effect of weight to power ratio is shown above, and provides a useful indicator for total hybrid power requirements. It should also be noted that in the case of the exotic sports car the conventional powertrain is sufficient to meet all of the proposed performance baselines. However, a lightly hybridized system has 
been modeled in this latter case to indicate the further performance potential of the system and to allow for efficiency gains in normal driving.

\subsection{Efficiency Modeling Using HVSim}

After realizing that all of the proposed designs met the required performance baselines efficiency modeling and optimization was performed in HVSim. Tables showing uncorrected fuel economy results on the UDDS, the HWFET and US06 traces are shown below. Also shown below are results of the track trace, in either pass or fail, and to what degree the trace was met or failed. Table 12.1. shows the effect of the degree of hybridization on fuel efficiency.

Table 12.5. Sport Compact Car Final Fuel Efficiency Estimates (mpg)

\begin{tabular}{|c|c|c|c|c|}
\hline & Actual & Modeled Conventional & Modeled Hybrid & Fuel Economy Gain (\%) \\
\hline FTP & 25 & 19.37 & 32.39 & 67.1 \\
\hline HWFET & 33 & 26.87 & 37.65 & 40.0 \\
\hline US06 & $\sim$ & 24.87 & 34.54 & 38.9 \\
\hline Track Trace & $\sim$ & Failed & 18.95 & $\sim$ \\
\hline
\end{tabular}

Table 12.6. Sport Coupe Final Fuel Efficiency Estimates (mpg)

\begin{tabular}{|c|c|c|c|c|}
\hline & Actual & Modeled Conventional & Modeled Hybrid & Fuel Economy Gain (\%) \\
\hline FTP & 19 & 16.33 & 23.57 & 44.3 \\
\hline HWFET & 27 & 25.50 & 31.40 & 23.1 \\
\hline US06 & $\sim$ & 23.07 & 31.24 & 35.3 \\
\hline Track Trace & $\sim$ & Failed & 17.39 & $\sim$ \\
\hline
\end{tabular}

Table 12.7. Sport Sedan Final Fuel Efficiency Estimates (mpg)

\begin{tabular}{|c|c|c|c|c|}
\hline & Actual & Modeled Conventional & Modeled Hybrid & Fuel Economy Gain (\%) \\
\hline FTP & 15 & 13.92 & 20.42 & 46.7 \\
\hline HWFET & 22 & 18.91 & 27.05 & 43.0 \\
\hline US06 & $\sim$ & 16.43 & 24.21 & 47.4 \\
\hline Track Trace & $\sim$ & Failed & 12.64 & \\
\hline
\end{tabular}


Table 12.8. Exotic Sports Car Final Fuel Efficiency Estimates (mpg)

\begin{tabular}{|c|c|c|c|c|}
\hline & Actual & Modeled Conventional & Modeled Hybrid & Fuel Economy Gain (\%) \\
\hline FTP & 14 & 12.87 & 14.31 & 11.2 \\
\hline HWFET & 20 & 16.11 & 19.00 & 17.9 \\
\hline US06 & $\sim$ & 15.82 & 15.96 & $\sim 0$ \\
\hline Track Trace & $\sim$ & 13.39 & 12.49 & -6.8 \\
\hline
\end{tabular}

Figure 12.2. Fuel Economy Improvement vs. Degree of Hybridization

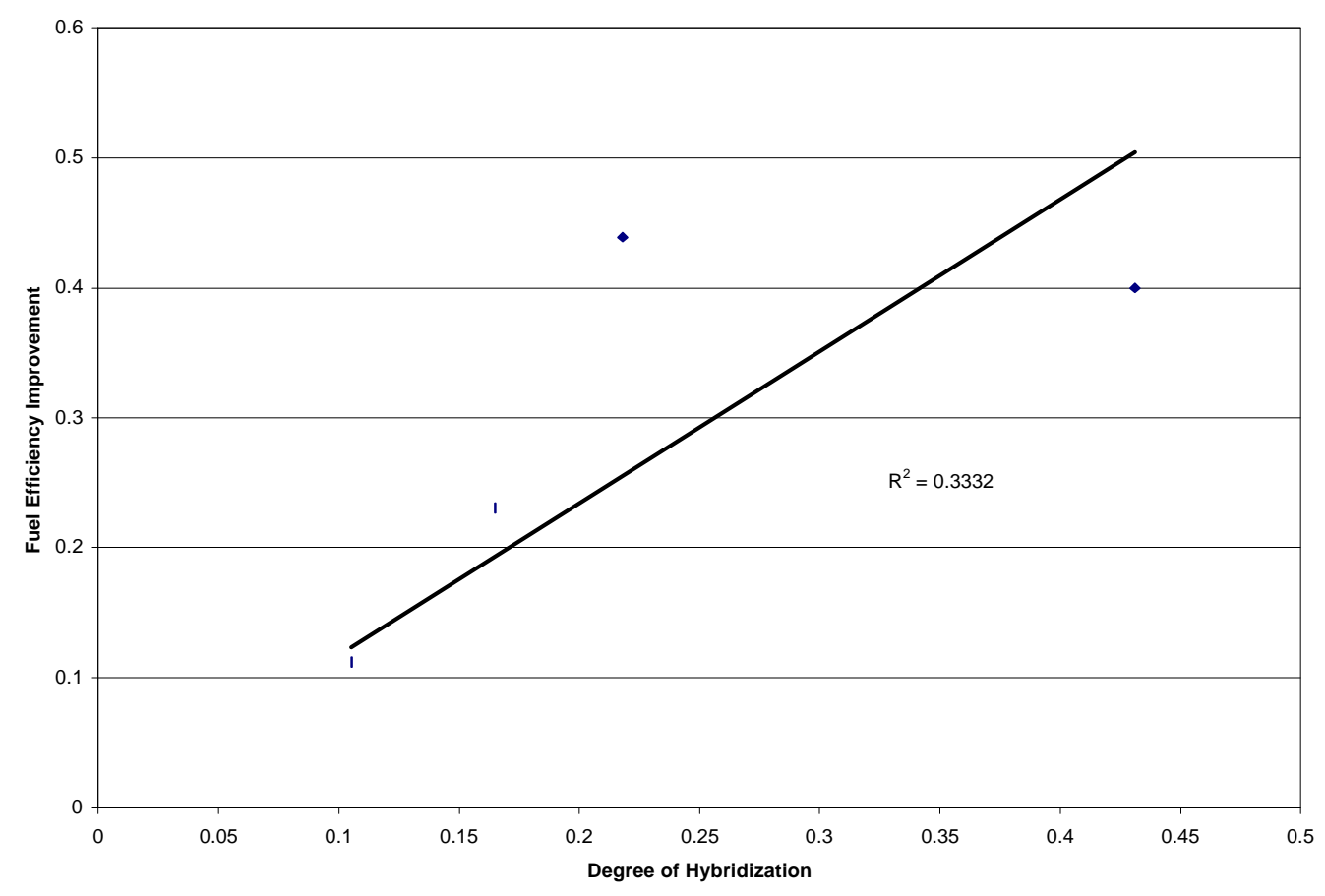




\section{Summary and Conclusions}

\subsection{Summary}

Overall powertrain designs for four different vehicle types have been designed, modeled and simulated. Table 13.1. summarizes the results of the dynamic and efficiency simulations, as well as the components selected for each. 
Table 13.1. Final Vehicle Specifications and Performance

\begin{tabular}{|c|c|c|c|c|}
\hline & Sport Compact Car & Sport Coupe & Sport Sedan & Exotic Sports Car \\
\hline Engine & $1.6 \mathrm{~L} \mathrm{~L}-3 \mathrm{w} / \mathrm{VVT}$ & $2.2 \mathrm{~L} \mathrm{~L}-4 \mathrm{w} / \mathrm{VVT}$ & 2.6L L-6/V-6/H-6 w/VVT & 3.6L V-8 w/VVT \\
\hline $\begin{array}{l}\text { Power @ } \\
\text { Speed }\end{array}$ & 99 kW@6500 rpm & $\begin{array}{c}162 \mathrm{~kW} @ 6500 \\
\mathrm{rpm}\end{array}$ & 190 kW@6500 rpm & $\begin{array}{c}272 \mathrm{~kW} @ 7000 \\
\mathrm{rpm}\end{array}$ \\
\hline $\begin{array}{c}\text { Torque @ } \\
\text { Speed } \\
\end{array}$ & $\begin{array}{c}152 \mathrm{Nm} @ 5800 \\
\mathrm{rpm}\end{array}$ & $\begin{array}{c}248 \mathrm{Nm} @ 5800 \\
\mathrm{rpm}\end{array}$ & 291 Nm@5800 rpm & $\begin{array}{c}392 \text { Nm@6100 } \\
\text { rpm }\end{array}$ \\
\hline Trans. & 6-speed manual & 6-speed manual & 6-speed manual & 6-speed manual \\
\hline $\begin{array}{l}\text { Gear } \\
\text { Ratios }\end{array}$ & $\begin{array}{l}3.34,2.15,1.55, \\
1.20,0.93,0.83\end{array}$ & $\begin{array}{l}3.46,2.03,1.38, \\
1.06,0.82,0.67\end{array}$ & $\begin{array}{c}3.73,2.20,1.43,1.05, \\
0.87,0.76\end{array}$ & $\begin{array}{l}.05,1.96,1.39, \\
1.06,0.86,0.70\end{array}$ \\
\hline Motor & $\begin{array}{c}\text { Unique Mobility } \\
\text { SR-218N }\end{array}$ & $\begin{array}{c}\text { Unique Mobility } \\
\text { SR-218N }\end{array}$ & $\begin{array}{c}\text { Unique Mobility } \\
\text { SR-218N }\end{array}$ & $\begin{array}{c}\text { Unique Mobility } \\
\text { SR-218N }\end{array}$ \\
\hline $\begin{array}{l}\text { Power / } \\
\text { Speed }\end{array}$ & $75 \mathrm{~kW} / 8000 \mathrm{rpm}$ & $32 \mathrm{~kW} / 8000 \mathrm{rpm}$ & $53 \mathrm{~kW} / 8000 \mathrm{rpm}$ & $32 \mathrm{~kW} / 8000 \mathrm{rpm}$ \\
\hline $\begin{array}{l}\text { Torque / } \\
\text { Speed }\end{array}$ & $\begin{array}{c}240 \mathrm{Nm} / 0-3000 \\
\mathrm{rpm}\end{array}$ & $\begin{array}{c}156 \mathrm{Nm} / 0-2000 \\
\mathrm{rpm}\end{array}$ & $240 \mathrm{Nm} / 0-2500 \mathrm{rpm}$ & $\begin{array}{c}156 \mathrm{Nm} / 0-2000 \\
\mathrm{rpm}\end{array}$ \\
\hline $\begin{array}{c}\text { Final } \\
\text { Drive }\end{array}$ & 4.27 & 3.56 & 3.56 & 4.1 \\
\hline $\begin{array}{l}\text { Ultracap } \\
\text { Model }\end{array}$ & $\begin{array}{l}\text { Maxwell } \\
\text { Technologies 2.7V }\end{array}$ & $\begin{array}{c}\text { Maxwell } \\
\text { Technologies } \\
2.7 \mathrm{~V}\end{array}$ & $\begin{array}{l}\text { Maxwell } \\
\text { Technologies 2.7V }\end{array}$ & $\begin{array}{c}\text { Maxwell } \\
\text { Technologies 2.7V }\end{array}$ \\
\hline $\begin{array}{l}\text { Battery } \\
\text { Model }\end{array}$ & $\begin{array}{c}\text { Hawker Energy } \\
\text { G13EP }\end{array}$ & $\begin{array}{c}\text { Hawker Energy } \\
\text { G13EP } \\
\end{array}$ & $\begin{array}{c}\text { Hawker Energy } \\
\text { G13EP }\end{array}$ & $\begin{array}{c}\text { Hawker Energy } \\
\text { G13EP }\end{array}$ \\
\hline $\begin{array}{c}0-60 \mathrm{mph} \\
(\mathrm{sec})\end{array}$ & 5.63 & 5.38 & 5.01 & 3.98 \\
\hline $\begin{array}{c}\text { 1/4mi ET } \\
(\mathrm{sec})\end{array}$ & 14.20 & 13.73 & 13.46 & 12.25 \\
\hline $\begin{array}{c}\begin{array}{c}1 / 4 \mathrm{mi} \mathrm{TS} \\
(\mathrm{mph})\end{array} \\
\end{array}$ & 99.02 & 104.20 & 106.56 & 117.30 \\
\hline $\begin{array}{c}\text { Top Speed } \\
(\mathrm{mph})\end{array}$ & 140.11 & 147.20 & 155.69 & 180.80 \\
\hline $\begin{array}{c}\text { FTP City } \\
\text { (mpg) }\end{array}$ & 32.39 & 23.57 & 20.42 & 14.31 \\
\hline $\begin{array}{l}\text { HWFET } \\
\text { (mpg) }\end{array}$ & 37.65 & 31.40 & 27.05 & 19.00 \\
\hline $\begin{array}{l}\text { US06 } \\
\text { (mpg) }\end{array}$ & 34.54 & 31.24 & 24.21 & 15.96 \\
\hline $\begin{array}{l}\text { Track } \\
\text { Trace } \\
(\mathrm{mpg})\end{array}$ & 18.95 & 17.39 & 12.64 & 12.49 \\
\hline
\end{tabular}




\subsection{Conclusions}

The purpose of this work was the design, modeling, and analysis of several different high-performance light-duty hybrid electric vehicle powertrains. Different design configurations were studied for each case of interest and the most promising and feasible designs were selected for further simulation. Control strategies for each separate configuration were developed and modeled to simulate the performance and fuel economy of the proposed vehicle.

The simulated performance and fuel economy results of each design were compared to baseline values for conventional vehicles of the same type. Fuel economy and trace meeting simulations were performed for the FTP City cycle, the HWFET highway cycle, and the US06 cycle. Further trace matching simulations were performed for a high-power demand track trace. Performance estimates were modeled for 0-60, 1/4mi, and top speed.

The results show the potential for maintaining, or even improving vehicle dynamic performance through hybridization, while allowing in most cases for an improvement in fuel efficiency. The exception in this study is the case of the exotic sports car, with a high dynamic performance requirement. A possible explanation for this result is that the sizing of the IC engine to meet a very aggressive top speed cruise requirement leads to oversizing of the engine for use in typical driving, even to the point where hybridization from a dynamic standpoint is unnecessary. Perhaps a lighter requirement for sustained cruise, with equivalent peak speeds could results in a more favorable fuel efficiency result.

Table 13.1 indicates the high potential for an aggressively hybridized powertrain design. Most of the proposed designs meet or exceed their performance benchmarks, while providing improved fuel economy. 


\section{References}

1. Anderson, John; Design and Modeling a Torque and Speed Control Transmission (TSCT), MSME Thesis, West Virginia University, 2000

2. http://www.caranddriver.com, objective performance testing database, (10/2000)

3. An, F.; Stodolsky, F.; Santini, D.; "Hybrid Options for Light-Duty Vehicles", Argonne National Laboratories, SAE 1999-01-2929

4. Ng, H. K.; Anant, V.D.; Santini, D.J.; “The Prospects for Hybrid Electric Vehicles 2005-2020, Results of a Delphi Study”, Argonne National Laboratories, SAE 1999-012942

5. Rennels, K.; Reid, K.; Walin, J.; "High Performance Electric Vehicles”, Purdue School of Engineering and Technology at IUPUI, SAE 1999-01-2908

6. Lamperth, M.U.; Pullen, K.R.; "How Size and Performance of HEV Components are Influenced by Acceleration Patterns", Imperial College of Science, Technology, and Medicine, SAE 1999-01-2909

7. Shikada, T.; Nakamura, Y.; Nakakubo, T.; Kawase, H.; "Development of the High Speed 2ZZ-GE Engine", Toyota Motor Corporation, SAE 2000-01-0671

8. Otobe, Y.; Kawaguchi, H.; Ueshima, H.; "Development of the High Power, Low Emission Engine for the "Honda S2000"”, Honda R\&D Co. LTD., SAE 2000-01-0670

9. Heywood, J.; Chon, D.; "Performance Scaling of SI Engines, Correlation and Historical Analysis of Production Engine Data”, Massachusetts Institute of Technology, SAE 2000-01-0565 
10. Asmus, T.; "A Manufacturer's Perspective on IC Engine Technology at Century's End", Daimler Chrysler, ASME ICE Division Fall Technical Conference, Ann Arbor, MI, $10 / 18 / 1999$

11. Atkinson, C.; Yacoub, Y.; "Modularity in SI Engines: A Review of its Benefits, Implementation, and Limitations", West Virginia University, SAE 982688

12. Kellermeyer, W.; Anderson, J.; Benson, R.; Billard, E.; Burke, S.; Doble, J.; Atkinson, C.; "The Development of a Third Generation Hybrid Electric Vehicle at West Virginia University", West Virginia University, SAE Special Publications, SP-1452, FutureCar 1998

13. Taylor, S.; Anderson, J.; Tóth-Nagy, C.; Burke, S.; Atkinson, C.; "Further Development of a Third Generation Hybrid Electric Vehicle at West Virginia University”, West Virginia University, SAE Special Publications, SP-1521, FutureCar 1999

14. Conley, J.; Taylor, S.; Tóth-Nagy, C.; Smith, J.; Waters, R.; Clay, B.; Atkinson, C.; "The Development of a Fourth Generation Hybrid Electric Vehicle at West Virginia University”, West Virginia University, SAE 2001-01-0682

15. www.toyota.co.jp/ Toyota Track Testing, (10-28-1999)

16. Heywood, J.; Internal Combustion Engine Fundamentals, McGraw-Hill, Inc., 1988

17. Flierl, R.; Klüting, M.; “The Third Generation of Valvetrains - New Fully Variable Valvetrains for Throttle-Free Load Control”, BMW Group, SAE 2000-01-1227

18. http://www.porsche.com/english/911/models/turbo/onthetrack/includes/variocam.htm $(1-13-2001)$

19. Pischinger, M.; Salber, W.; Van Der Staay, F.; Baumgarten, H.; Kemper, H.; "Benefits of the Electromechanical Valvetrain in Vehicle Operation”, FEV Motorentechnik GmbH, SAE 2000-01-1223 
20. http://www.navistar.com/ (11-15-2000)

21. http://www.sae.org/automag/techbriefs_05-00/03.htm Automotive Engineering Magazine (32000)

22. Kluger, M.; Long, D.; “An Overview of Current Automatic, Manual and Continuously Variable Transmission Efficiencies and Their Projected Future Improvements", Southwest Research Institute, SAE 1999-01-1259

23. www.ferrari.com $(3 / 20 / 2001)$

24. Tóth-Nagy, Csaba; Investigation and Simulation of the Planetary Combination Hybrid Electric Vehicle, MSME Thesis, West Virginia University, 2000

25. www.mini.com $(5 / 9 / 2000)$

26. http://www.automuseum.com/Toron'66.htm (3/12/2001)

27. Wards Auto World, "Falling Out of Love with Front Wheel Drive", October 1999, pp. 34-43, Visnic, B.

28. http://www.daimlerchrysler.com/index_e.htm?/news/top/2000/t01026b_e.htm ; Through The Road (TTR) Hybrid Technologies (12/21/2000)

29. http://www.madkatz.com/ mikt/batteryTechnologyComparison.html; Battery Technology Summaries $(12 / 27 / 2000)$

30. http://stuweb.ee.mtu.edu/ pchang/ee280/ee280.html\#BTypes; Battery Technology, Michigan Technological University (12/27/2000)

31. http://www.ott.doe.gov/; Battery Technologies (12/27/2000)

32. http://rqriley.com/ev-tech.html; Robert Q. Riley Enterprises, "Electric and Hybrid Vehicles, An Overview of the Benefits, Challenges and Technologies," 1999

33. http://www.powercache.com ; Maxwell Technologies, PowerCache Ultracapacitors, 2000 34. http://www.hepi.com ; Hawker Energy Products Incorporated, 2001 
35. Koeneman, Paul B.; McAdams, Daniel A.; "Load Leveling Device Selection for Hybrid Electric Vehicles," SAE 981130

36. Martin, A.; Mok, P.; “Automotive Fuel Cells - Clean Power for Tomorrow's Vehicles”, Ballard Automotive, Inc., SAE 1999-01-0320

37. http://www.ott.doe.gov/oaat/fuelcell_tech.html, DOE, Office of Transportation Technologies, "Fuel Cell Technologies," 1999

38. Gottesfeld, S.; Moore, R.; Zelenay, P.; "A Comparison Between Direct-Methanol and Direct-Hydrogen Fuel Cell Vehicles", University of California at Davis, SAE Special Publications, SP-1466, Electric and Hybrid Electric Vehicles and Fuel Cell Technology pp. $55-63$

39. www.wardsauto.com Wards Auto World

40. Conley, J.J.; Research and Design Work, FutureTruck Project, 2000-2001, West Virginia University, Mechanical and Aerospace Engineering Dept.

41. http://www.uqm.com/Technologies/index.html ; Unique Mobility Homepage, Traction Motor Technical Datasheets, 1999-2000 